\author{
Universidade de São Paulo \\ Faculdade de Medicina de Ribeirão Preto \\ Departamento de Neurociências e Ciências do Comportamento \\ Pós-Graduação em Saúde Mental
}

LIVIO RODRIGUES LEAL

\title{
Prevalência de transtornos mentais em idosos e comparação de instrumentos breves para rastreamento de transtorno neurocognitivo na atenção básica
}


LÍVIO RODRIGUES LEAL

Prevalência de transtornos mentais em idosos e comparação de instrumentos breves para rastreamento de transtorno neurocognitivo na atenção básica

Dissertação de Mestrado apresentada ao Programa de Pós-Graduação em Saúde Mental da Faculdade de Medicina de Ribeirão Preto da Universidade de São Paulo para obtenção de título de mestre.

Área de Concentração: Saúde Mental

Orientador: Prof. Dr. Marcos Hortes Nisihara Chagas

Ribeirão Preto - SP 
Autorizo a reprodução e divulgação total ou parcial deste trabalho, por qualquer meio convencional ou eletrônico, para fins de estudo e pesquisa, desde que citada a fonte.

FICHA CATALOGRÁFICA

Serviço de documentação da Faculdade de Medicina de Ribeirão Preto - SP

Leal, Lívio Rodrigues

Prevalência de transtornos mentais em idosos e comparação de instrumentos breves para rastreamento de transtorno neurocognitivo na atenção básica / Lívio Rodrigues Leal. - Ribeirão Preto, 2020.

$119 \mathrm{f}$ : il.

Dissertação (Mestrado) - Faculdade de Medicina de Ribeirão Preto da Universidade de São Paulo. Programa de Pós Graduação em Saúde Mental. Área de concentração: Saúde Mental.

Orientador: Chagas, Marcos Hortes Nisihara

1. Transtorno neurocognitivo. 2. Idoso. 3. Prevalência 4. Rastreio cognitivo 


\section{FOLHA DE APROVAÇÃO}

Nome: Lívio Rodrigues Leal

Título: Prevalência de transtornos mentais em idosos e comparação de instrumentos breves para rastreamento de transtorno neurocognitivo na atenção básica.

Dissertação apresentada à Faculdade de Medicina de Ribeirão Preto da Universidade de São Paulo para obtenção do título de Mestre em Saúde Mental.

Aprovado em:

Banca Examinadora

Prof. Dr. Instituição:

Julgamento: Assinatura:

Prof. Dr. Instituição:

Julgamento: Assinatura:

Prof. Dr. Instituição:

Julgamento: Assinatura: 


\section{DEDICATÓRIA}

A todos meus professores, que me ajudaram no processo de me tornar profissional, pesquisador e pessoa. 


\section{AGRADECIMENTOS}

À toda minha família, em especial aos meus pais, José Libório e Maria de Lourdes, e minhas irmãs, Larissa e Letícia, que mesmo distantes fisicamente, sempre se fizeram presentes através do amor e apoio.

A Francisco, pela companhia, cuidado e por me inspirar a ser uma pessoa melhor.

Ao meu querido orientador, Prof. Dr. Marcos Hortes Nisihara Chagas, por ser inspiração, por toda paciência e acolhimento, pelas suas orientações valiosas e por ser luz e caminho para essa jornada.

Aos idosos participantes, que disponibilizaram tempo e atenção se voluntariando tão generosamente a essa pesquisa, por darem sentido a tudo isso.

Ao grupo ProVive, pela oportunidade de ingressar na pesquisa e pela ajuda na coleta dos dados.

Às colegas de trabalho, Rebeca Mendes e Natália Mota Chagas, pela parceria na coleta e pelo compartilhamento de experiências diárias, o que deixou tudo mais leve e alegre. A Mirella Losapio pela companhia e parceria. Aos colegas médicos assistentes do HCFMRP-USP pelo apoio. A Rosana Shuhama pela prontidão na ajuda e explicações valiosas sobre testes estatísticos.

Aos meus amigos queridos e em especial os de residência, Alyssa Figueiredo, Luana Harada e Renato Silva, que estiveram presentes desde o início da jornada que me trouxe até aqui.

À secretária do PGSM, Ivana, pelo auxílio e presteza nesses anos.

À $\boldsymbol{C A P E S}$, por fomentar e proporcionar estrutura para o desenvolvimento de pesquisa e ciência no nosso país. 


\section{RESUMO}

\section{LEAL, L. R. Prevalência de transtornos mentais em idosos e comparação de instrumentos breves para rastreamento de transtorno neurocognitivo na atenção básica.}

Dissertação (Mestrado) - Faculdade de Medicina, Universidade de São Paulo, Ribeirão Preto, 2020 .

Objetivos: Com o processo de envelhecimento acelerado da população nas últimas décadas é preciso obter informações sobre saúde mental em idosos no Brasil. A prevalência dos transtornos neurocognitivos (TNC), e de outros transtornos mentais em idosos tem aumentado. O uso de instrumentos de triagem como o Montreal Cognitive Assessment (MoCA) em sua versão original e sua versão basic, pode ajudar na identificação e no diagnóstico precoce dos TNC. A atenção primária tem potencial de fornecer informações sobre epidemiologia dos transtornos mentais em idosos pois constitui o contato mais próximo com a comunidade. O objetivo principal do estudo é verificar a frequência de transtornos mentais em idosos e comparar as qualidades psicométricas de dois instrumentos breves para rastreamento de TNC. Métodos: Trata-se, de um levantamento epidemiológico transversal, incluindo indivíduos com mais de 60 anos residentes na área de abrangência de uma unidade de saúde da família que passaram por entrevista diagnóstica e testes de rastreio para TNC. Foram entrevistados 271 idosos, realizados 104 MoCA e 81 MoCA basic. Os diagnósticos psiquiátricos foram feitos de acordo com o DSM-5. Foram determinados a área sob a curva ROC e os valores de sensibilidade/especificidade para os pontos de corte de cada instrumento. Resultados: A amostra era constituída de 57,93\% ( $\mathrm{N}=157)$ mulheres, e 70,47\% (N=191) eram aposentados. A média de idade foi de 70,56 anos (DP: $\pm 7,81$ ) e de escolaridade, de 3,09 anos (DP: $\pm 2,97)$. A prevalência geral de transtornos psiquiátricos foi de 55,35\% $(\mathrm{N}=150)$. Os transtornos mais comuns foram os TNC presentes em 33,58\% ( $\mathrm{N}=91)$ dos idosos, Transtornos de Ansiedade em 14,76 \% ( $\mathrm{N}=40)$, Transtornos do humor em 19,19\% ( $=52)$, Transtornos de sono em 14,76\% (N=40) e Transtornos do uso de substâncias em 11,07\% $(\mathrm{N}=30)$. Dos TNC, 21,77\% (N=59) eram Transtorno Neurocognitivo Leve (TNL) e 11,81\% $(\mathrm{N}=32)$ eram Transtorno Neurocognitivo Maior (TNM). O Transtorno de ansiedade generalizada estava presente em 17,34\% ( $\mathrm{N}=47)$ dos idosos, a fobia específica em 9,59\% $(\mathrm{N}=26)$, um Episódio depressivo atual em 5,9\% ( $\mathrm{N}=16)$. Os demais transtornos somaram $8,49 \%$. O MoCA apresentou uma validade discriminativa excelente para o TNM (área sob a 
curva ROC: 0,932; p<0,001; IC95 \% 0,842-1,000) e regular para o TNL (área sob a curva ROC 0,753; p<0,001; IC95\%: 0,654-0,853). O ponto de corte foi 9 (sensibilidade $83 \%$ /especificidade 95\%) e 16 (sensibilidade $83 \%$ /especificidade $68 \%$ ), respectivamente. O MoCA basic apresentou excelente validade discriminativa para TNM (área sob a curva: 0,910 ( $\mathrm{p}<0,001 ;$ IC95 \% 0,818-1.002) e boa para TNL (área sob a curva ROC: 0,834 ( $\mathrm{p}<0,001$; IC95\%: 0,742 - 0,927). O ponto de corte foi 21 para as duas condições (sensibilidade 100\%/ especificidade $72 \%$ para TNM; sensibilidade $89 \%$ /especificidade $72 \%$ para TNL). Conclusões: Os transtornos mentais apresentaram uma prevalência alta, sobretudo com a inclusão dos TNC, diferentemente de outros estudos prévios. Os instrumentos de rastreamento MoCA e MoCA basic são válidos para triagem de TNC em idosos da comunidade de baixa escolaridade. O presente trabalho fornece informações sobre as características dos instrumentos numa população de baixa escolaridade no Brasil.

Palavras-chave: prevalência, transtorno neurocognitivo, demência, transtorno mental, idoso, rastreamento cognitivo 


\begin{abstract}
LEAL, L. R. Prevalence of psychiatric disorders among elderly and comparison between cognitive impairment screening tools in primary care. Dissertação (Mestrado) - Faculdade de Medicina, Universidade de São Paulo, Ribeirão Preto, 2020.
\end{abstract}

Purposes: With the fast aging of the population in recent decades, it is necessary to obtain information about mental health of the elderly in Brazil. Prevalence of Neurocognitive Disorders (NCD) and other mental disorders in the elderly has increased. Brief cognitive assessment instruments, such as Montreal Cognitive Assessment (MoCA) and its basic version, can help in the identification and early diagnosis of NCD. Primary care has the potential to provide information about the epidemiology of psychiatric disorders in the elderly due to its proximity to the community. The main aims of this study are to verify the frequency of psychiatric disorders in the elderly and to compare the psychometric characteristics of two brief screening instruments for NCD. Methods: This is a cross-sectional study, with 60 years or older community dwelling individuals, within the catchment area of a primary care unit. All individuals underwent diagnostic interviews and screening tests for NCD were applied, yielding 271 elderly interviewed, and $104 \mathrm{MoCA}$ and $81 \mathrm{MoCA}$ basic fulfilled. Psychiatric diagnoses were made according to the DSM-5. The area under the ROC curve and the sensitivity / specificity for the cutoff score of each instrument were determined. Results: The sample consisted of 57.93\% ( $\mathrm{N}=157)$ women, and 70.47\% $(\mathrm{N}=191)$ were retired. Mean age was 70.56 years (SD: \pm 7.81$)$ and schooling was 3.09 years (SD: \pm 2.97$)$. Prevalence for any psychiatric disorder was $55.35 \%(\mathrm{~N}=150)$. The most common disorders were NCD, present in $33.58 \%(\mathrm{~N}=91)$ of the elderly, Anxiety Disorders in $25.46 \%(\mathrm{~N}=69)$, Mood Disorders in $19.19 \%(\mathrm{~N}=52)$, Sleep-wake Disorders in 14.76\% $(\mathrm{N}=40)$ and Substance-Related and Addictive Disorders in $11.07 \%(\mathrm{~N}=30)$. Mild Neurocognitive Disorder and Major Neurocognitive Disorder accounted for $21.77 \%(\mathrm{~N}=59)$ and $11.81 \%(\mathrm{~N}=32)$ of $\mathrm{NCD}$, respectively. Generalized Anxiety Disorder was present in 14,76\% $(\mathrm{N}=40)$ of the elderly, Specific Phobia in $9.59 \%(\mathrm{~N}=26)$, a current Major Depressive episode in 5.9\% $(\mathrm{N}=16)$. The remaining disorders amounted to $8.49 \%$. MoCA demonstrated excellent discriminative validity for Major NCD (area under the ROC curve: 0.932; $\mathrm{p}<0.001$; 95\% CI 0.842-1.000) and regular validity for Mild NCD (area under the ROC curve 0.753 ; $<<0.001$; 95\% CI: 
$0.654-0.853)$. The cutoff point was 9 (83\% sensitivity / 95\% specificity) and $16(83 \%$ sensitivity / 68\% specificity), respectively. MoCA basic showed excellent discriminative validity for Major NCD (area under the curve: 0.910 ( $\mathrm{p}<0.001$; 95\% CI 0.818-1.002) and good for Mild NCD (area under the ROC curve: 0.834 ( $p<0.001$; 95\% CI: 0.742 - 0.927) .The cutoff point was 21 for both conditions (sensitivity 100\% / specificity 72\% for Major NCD; sensitivity $89 \%$ / specificity $72 \%$ for Mild NCD). Conclusions: Mental disorders were highly prevalent in the sample, especially after the inclusion NCD, unlike other previous studies. The MoCA and MoCA basic are valid screening instruments for cognitive assessment of lowschooled elderly people from the community. These results provide information about psychometric characteristics of the instruments for elderly with low schooling in Brazil.

Keywords: prevalence, neurocognitive disorder, dementia, psychiatric disorder, cognitive impairment screening 


\section{LISTA DE QUADROS}

Quadro 1 - Propriedades dos instrumentos para rastreio cognitivo, de acordo com o ano de publicação, os domínios cognitivos avaliados, a pontuação máxima e a existência de validação para população brasileira .32 


\section{LISTA DE FIGURAS}

Figura 1 - Fluxograma referente a avaliação da amostra ao longo do estudo 34

Figura 2 - Fluxograma da composição da amostra nas etapas do estudo 35

Figura 3 - Curva ROC do MoCA tendo-se como referência os grupos sem TNC e TNM ..... 45

Figura 4 - Curva ROC do MoCA tendo-se como referência os grupos sem TNC e com TNL

Figura 5 - Curva ROC do MoCA tendo-se como referência os grupos com TNL e com TNM

Figura 6 - Curva ROC do MoCA tendo-se como referência os grupos sem TNC e com algum TNC (TNL ou TNM) 48

Figura 7 - Curva ROC do MoCA tendo-se como referência o grupo de indivíduos com TNM e um grupo sem TNM (indivíduos com TNL e sem TNC)

Figura 8 - Curva ROC do MoCA basic tendo-se como referência os grupos sem TNC e com TNM 50

Figura 9 - Curva ROC do MoCA basic tendo-se como referência os grupos sem TNC e com TNL

Figura 10 - Curva ROC do MoCA basic tendo-se como referência os grupos com TNL e com TNM 52

Figura 11 - Curva ROC do MoCA basic tendo-se como referência os grupos sem TNC e com algum TNC (TNL ou TNM) 
Figura 12 - Curva ROC do MoCA basic tendo-se como referência o grupo de indivíduos com TNM e um grupo composto por indivíduos sem TNM (com TNL e sem TNC) .. 54

Figura 13 - Gráfico de dispersão dos escores totais no MoCA em relação aos escores totais no MEEM em toda amostra de idosos avaliados 55

Figura 14 - Gráfico de dispersão dos escores totais no MoCA basic em relação aos escores totais no MEEM em toda amostra de idosos avaliados. 56 


\section{LISTA DE TABELAS}

Tabela 1: Composição amostral de cada etapa do estudo expressas em número de indivíduos incluídos e porcentagem, a partir de uma população de idosos atendidos por uma unidade do Programa Saúde da Família do bairro Jardim Guanabara em São Carlos - SP. Ribeirão Preto, 2020 36

Tabela 2: Características sociodemográficas, expressas em número de indivíduos, porcentagem, anos e desvio padrão de uma amostra de 271 idosos atendidos por uma unidade do Programa Saúde da Família do bairro Jardim Guanabara em São Carlos - SP. Ribeirão Preto, 2020

Tabela 3: Prevalência de transtornos mentais por categorias, expressa em número de indivíduos e porcentagem, em uma amostra de 271 idosos atendidos por uma unidade do Programa Saúde da Família do bairro Jardim Guanabara em São Carlos - SP. Ribeirão Preto, 2020

Tabela 4: Prevalência de transtornos mentais específicos, expressa em número de indivíduos e porcentagem, em uma amostra de 271 idosos atendidos por uma unidade do Programa Saúde da Família do bairro Jardim Guanabara em São Carlos - SP. Ribeirão Preto, 2020

Tabela 5: Variáveis sociodemográficas e desempenho nos testes neurocognitivos em toda amostra e em cada grupo dos 271 idosos atendidos por uma unidade do Programa Saúde da Família do bairro Jardim Guanabara em São Carlos - SP. Ribeirão Preto, 2020. 43

Tabela 6: Valores de sensibilidade e especificidade expressa em porcentagem por ponto de corte para a pontuação no MoCA de uma amostra de indivíduos com TNM e sem TNC, submetidos ao teste. Ribeirão Preto, 2020. 45

Tabela 7: Valores de sensibilidade e especificidade expressa em porcentagem por ponto de 
corte para a pontuação no MoCA de uma amostra de indivíduos com TNL e sem TNC, submetidos ao teste. Ribeirão Preto, 2020.

Tabela 8: Valores de sensibilidade e especificidade expressa em porcentagem por ponto de corte para a pontuação no MoCA de uma amostra de indivíduos com TNL e com TNM submetidos ao teste. Ribeirão Preto, 2020. 47

Tabela 9: Valores de sensibilidade e especificidade expressa em porcentagem por ponto de corte para a pontuação no MoCA de uma amostra submetida ao teste para discriminar indivíduos sem TNC de indivíduos com algum TNC (TNM ou TNL). Ribeirão Preto, 2020. 48

Tabela 10: Valores de sensibilidade e especificidade expressa em porcentagem por ponto de corte para a pontuação no MoCA de uma amostra para discriminar indivíduos com TNM e o restante (sem TNC ou com TNL) submetidos ao teste. Ribeirão Preto, 2020.

Tabela 11: Valores de sensibilidade e especificidade expressa em porcentagem por ponto de corte para a pontuação no MoCA basic de uma amostra de indivíduos sem TNC e com TNM. Ribeirão Preto, 2020 50

Tabela 12: Valores de sensibilidade e especificidade expressa em porcentagem por ponto de corte para a pontuação no MoCA basic de uma amostra de indivíduos com TNL e sem TNC. Ribeirão Preto, 2020 51

Tabela 13: .Valores de sensibilidade e especificidade expressa em porcentagem por ponto de corte para a pontuação no MoCA basic de uma amostra de indivíduos com TNL e com TNM submetidos aos testes. Ribeirão Preto, 2020

Tabela 14: Valores de sensibilidade e especificidade expressa em porcentagem por ponto de corte para a pontuação no MoCA basic de uma amostra de indivíduos sem TNC e com algum TNC (TNM ou TNL) submetidos ao teste. Ribeirão Preto, 2020 . .... 53 
Tabela 15: Valores de sensibilidade e especificidade expressa em porcentagem por ponto de corte para a pontuação no MoCA basic de uma amostra para discriminação de indivíduos com TNM e o restante (sem TNC ou com TNL) submetidos ao teste.

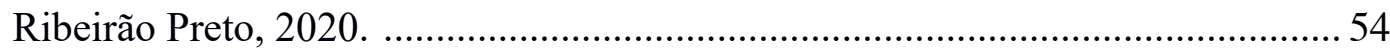




\section{LISTA DE ABREVIAÇÕES E SIGLAS UTILIZADAS}

\begin{tabular}{|c|c|}
\hline ACE- R & Addenbrooke's Cognitive Examination - Revised \\
\hline APA & Associação de Psiquiatria Americana \\
\hline CCL & Comprometimento cognitivo leve \\
\hline CERAD & Consortium to Establish a Registry of Alzheimer's Disease \\
\hline CID & Classificação Internacional das Doenças \\
\hline CIND & Cognitive impairment non-dementia \\
\hline IC & Intervalo de confiança \\
\hline DA & Doença de Alzheimer \\
\hline DSM & Manual de Diagnóstico e Classificação dos Transtornos Mentais \\
\hline $\mathrm{DP}$ & Desvio padrão \\
\hline EDM & Episódio depressivo maior \\
\hline EUA & Estados Unidos da América \\
\hline HIV & Human Immunodeficiency Virus \\
\hline IBGE & Instituto Brasileiro de Geografia e Estatística \\
\hline INSS & Instituto Nacional do Seguro Social \\
\hline $\mathrm{MCI}$ & Mild cognitive impairment \\
\hline MEEM & Mini-exame do Estado Mental \\
\hline MoCA & Montreal Cognitive Assessment \\
\hline OMS & Organizço Mundial da Saúde \\
\hline PSF & Programa Saúde da Família \\
\hline ROC & Receiver Operating Characteristic \\
\hline SIAB & Sistema de Informaçãoda Atenção Básica \\
\hline TAG & Transtorno de ansiedade generalizada \\
\hline TCLE & Termo de Consentimento Livre e Esclarecido \\
\hline TMC & Transtornos mentais comuns \\
\hline TNC & Transtorno neurocognitivo \\
\hline TNM & Transtorno neurocognitivo maior \\
\hline TNL & Transtorno neurocognitivo leve \\
\hline TOC & Transtorno obsessivo-compulsivo \\
\hline
\end{tabular}




\section{SUMÁRIO}

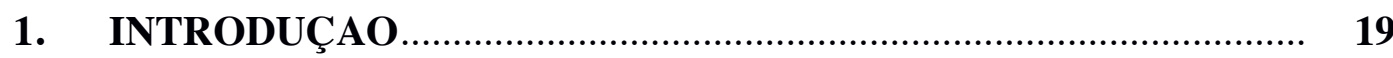

2. REVISÃO DA LITERATURA .......................................................... 21

2.1 Prevalência de transtornos mentais em idosos............................................ 21

2.2 Importância dos estudos de prevalência de transtornos mentais na atenção primária............................................................................. 24

2.3 Instrumentos breves de rastreamento de transtorno neurocognitivo........ 25

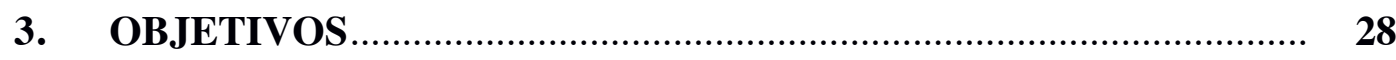

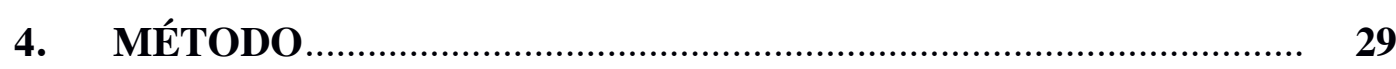

4.1 Contexto e local do estudo .................................................................... 29

4.2 Delineamento do estudo....................................................................... 29

$4.3 \quad$ Participantes................................................................................. 29

4.4 Critérios de exclusão......................................................................... 30

4.5 Instrumentos utilizados para avaliação ................................................... 30

4.5.1 Entrevista clínica pelos critérios do DSM-5 .......................................... 30

4.5.2 Mini-Exame do Estado Mental ............................................................... 31

4.5.3 Montreal Cognitve Assessment ………………………………......... 31

4.5.4 Montreal Cognitive Assessment - Basic................................................ 31

4.6 Procedimentos .............................................................................. 32

4.7 Aspectos éticos.......................................................................... 36

4.8 Análise estatística................................................................................ 37

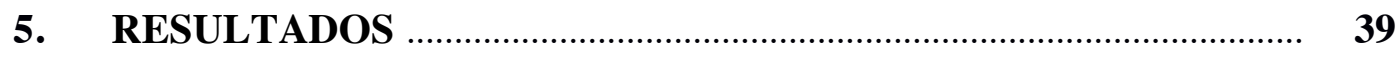

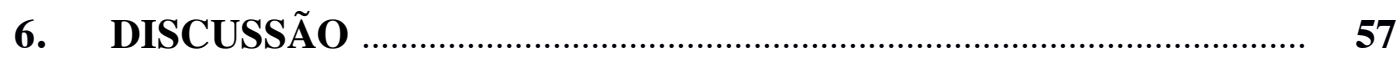

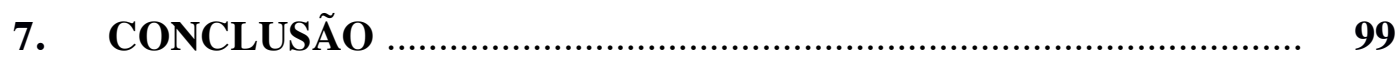

REFERENCIAS .......................................................................... 100

ANEXOS 


\section{INTRODUÇÃO}

A maioria dos países tem vivenciado mudanças significativas em sua estrutura sociodemográfica, deparando-se com uma camada cada vez mais expressiva da população com mais de 60 anos de idade. Os progressos e melhorias conquistados na área da saúde constituem alguns dos fatores que contribuem para essa mudança, inclusive no aumento da expectativa de vida (ANDERSON et al., 1998; ERVATTI; BORGES; JARDIM, 2015).

Dados do último censo do Instituto Brasileiro de Geografia e Estatística (IBGE) mostram que existiam aproximadamente 20 milhões de brasileiros com idade igual ou superior a 60 anos (IBGE, 2010). Comparando com os resultados do Censo de 1980, constatamos que o número de idosos no Brasil triplicou, e a tendência é aumentar ainda mais devendo atingir 41,5 milhões, em 2030, e 73,5 milhões, em 2060. Segundo os dados da Pesquisa Nacional por Amostra de Domicílios Contínuos em 2017 - PNAD Contínuo, a população idosa (60 anos ou mais) representava cerca de $14,6 \%$ da população brasileira (IBGE - 2018).

Essa situação de envelhecimento populacional é consequência, primeiramente, da rápida e contínua queda da fecundidade no país, além de ser influenciada pela queda da mortalidade em todas as idades (ERVATTI; BORGES; JARDIM, 2015). Esse processo leva a uma mudança no perfil das doenças mais prevalentes entre as pessoas, conhecido como transição epidemiológica, com maiores taxas das doenças crônicas e não transmissíveis que são mais frequentes entre os idosos, que requerem acompanhamento médico e tratamento contínuos (BORGES, 2017; ENGROFF et al., 2017; VERAS, 2003; VICTOR et al., 2009).

Essa realidade resulta no aumento nas demandas no âmbito da saúde, maior utilização dos serviços de saúde e custos elevados. Sabe-se que a parcela de idosos que relatam ser portadores de doenças crônicas varia de 62,9\% a 90\%, incluindo doenças mentais (ANDERSON et al., 1998; NAUGHTON; BENNETT; FEELY, 2006; PARAHYBA; VERAS; MELZER, 2005).

Além de mudanças nas características populacionais, o processo de envelhecimento suscita outras questões. Com a idade, ocorrem mudanças nas habilidades cognitivas, comprometendo domínios como atenção, memória, linguagem, habilidades visuoespaciais, funcionamento executivo, entre outros. É sabido que ocorrem alterações estruturais no cérebro com o avançar da idade, sobretudo no córtex pré-frontal, no lobo temporal medial, e na 
substância branca, levando a um verdadeiro espectro de manifestações clínicas (DECARLO et al., 2014; KENSINGER, 2010), que vão desde um declínio cognitivo normal relacionado à idade até as síndromes demenciais ou transtorno neurocognitivo maior (TNM), segundo nomenclatura mais atual da quinta edição do Manual Estatístico e Diagnóstico dos Transtornos Mentais (DSM) (APA, 2013). Apesar da grande relevância das questões de saúde mental relacionadas ao idoso, a escassez de informações no Brasil é ainda preocupante.

Para acompanhar essa mudança demográfica e epidemiológica contínua, são necessárias mais informações sobre as taxas de morbidade em idosos para otimizar os cuidados de saúde mental e fornecer serviços adequados para as pessoas idosas. 


\section{REVISÃO DA LITERATURA}

\subsection{Prevalência dos transtornos mentais em idosos}

Os transtornos mentais são altamente prevalentes na população mundial independente da faixa etária estudada (ANDRADE et al., 2000; KESSLER et al., 2007) e são responsáveis direta ou indiretamente por uma série de prejuízos como aumento no risco do desenvolvimento de outras doenças, hospitalizações mais frequentes e aumento na mortalidade (KESSLER et al., 2009; MOMEN et al., 2020). Essa realidade é pior em alguns países, como o Brasil (RIBEIRO; MELZER-RIBEIRO; CORDEIRO, 2012).

Em 1998, a Organização Mundial de Saúde (OMS) iniciou o Consórcio Internacional em Epidemiologia Psiquiátrica, a fim de realizar estudos para estimar a prevalência dos transtornos mentais na comunidade. Os primeiros resultados foram divulgados em 2000 (ANDRADE et al., 2000) e seguem em execução, atualmente contando com a participação de mais de 30 países (KESSLER et al., 2007). Apesar de ocorrer grande variação entre os diversos países, de forma geral, as prevalências têm sido altas (ANDRADE et al., 2000). Os resultados de 2007 encontraram prevalências variando de 12,0\% a 47,4\% para um ou mais transtornos mentais ao longo da vida (KESSLER et al., 2007).

No Brasil, os estudos epidemiológicos foram realizados com diferentes tipos de amostras populacionais e nas várias regiões do país apontando para altas taxas de prevalência dos transtornos mentais, com índices que variam de índices variaram entre $20 \%$ e $56 \%$ (SANTOS; SIQUEIRA, 2010). Um estudo mais antigo que avaliou três capitais brasileiras relatava prevalências que chegavam a 34\% (ALMEIDA-FILHO et al., 1997). Outro estudo conduzido na cidade de São Paulo, com 1.464 indivíduos acima de 18 anos, mostrou que quase a metade da população tinha pelo menos um diagnóstico psiquiátrico ao longo da vida. As prevalências para qualquer transtorno mental na vida, no ano e no mês foram, respectivamente, de $45,9 \%, 26,8 \%$ e $22,2 \%$. Os mais prevalentes foram: dependência do tabaco, transtornos do humor, transtornos de ansiedade, transtornos somatoformes e abuso/dependência de álcool (ANDRADE et al., 2002). Da mesma forma, pesquisas do estudo epidemiológico de transtornos mentais São Paulo Megacity avaliaram transtornos psiquiátricos em uma amostra probabilística composta por 5.037 adultos maiores de 18 anos 
residentes na região metropolitana de São Paulo e mostraram que a prevalência de pelo menos um transtorno mental ao longo da vida (segundo critérios do DSM-IV) foi de 44,8\%, sendo que $23,2 \%$ dos entrevistados tinham dois ou mais. Os transtornos mais prevalentes foram depressão maior (16,9\%), fobias específicas $(12,4 \%)$ e abuso de álcool $(9,8 \%)$ (VIANA; ANDRADE, 2012).

$\mathrm{Na}$ população idosa, os transtornos mentais também estão entre os mais prevalentes. Segundo dados da OMS, mais de $20 \%$ dos adultos com 60 anos ou mais sofrem de uma doença mental ou neurológica (excluindo as cefaleias) (WORLD HEALTH ORGANIZATION, 2016). Os transtornos depressivos na população idosa estão entre os diagnósticos mais comuns com prevalência entre $10 \%$ e $20 \%$, segundo estudos na comunidade. Os transtornos de ansiedade afetam 3,8\% da população idosa, problemas relacionados ao uso de substâncias psicoativas afetam quase $1 \%$ e cerca de um quarto das mortes por auto-agressão ocorrem em indivíduos com idade igual ou superior a 60 anos (WORLD HEALTH ORGANIZATION, 2016).

Quanto à epidemiologia das demências, uma revisão avaliou estudos em diversas regiões do mundo entre 1994 e 2000 e estimou uma prevalência geral de demência variando de 4,2\% a 7,2\% acima dos 65 anos. Segundo esta revisão, a idade exerceu importante influência sobre os resultados, com taxas médias de prevalência de demência que variaram de 1,17\% na faixa de 65-69 anos, a 54,83\% na faixa acima de 95 anos (LOPES; BOTINO, 2002).

Em 2005, um estudo trouxe dados alarmantes quanto à demência, estimando que existiam cerca de 24,3 milhões de pessoas vivendo com demência e 4,6 milhões de novos casos todos os anos. (PRINCE et al, 2015; WORLD HEALTH ORGANIZATION, 2012). Os dados de um relatório mais atual são ainda mais preocupantes com estimativas de que 46,8 milhões de pessoas sofram deste transtorno, com incidência de 9,9 milhões de novos casos a cada ano (PRINCE et al, 2015). De modo geral, os estudos apontam para maior taxa de crescimento nos países em desenvolvimento como o Brasil. Atualmente, 58\% das pessoas com demência vivem nos países em desenvolvimento e esta proporção deverá aumentar para 68\% até 2050 (FERRI et al., 2005; PRINCE et al, 2015).

Estudos no Brasil também apontam para alta frequência dos transtornos psiquiátricos nos idosos (COELI; VERAS; COUTINHO, 1998; VERAS; COUTINHO, 1991) e para a importância do tema como questão de saúde pública. Dentre os diversos transtornos que afetam idosos no Brasil, o transtorno depressivo é o mais frequente e apresenta prevalência variando entre 4,8\% a 14,6\% entre idosos vivendo na comunidade (LINHARES et al., 2003; 


\section{PARADELA; LOURENÇO; VERAS, 2005).}

No Brasil, os estudos de prevalência de demência encontraram taxas variáveis. Uma revisão recente apontou para taxas de prevalência entre 5,1\% a 17,5\% (BOFF; SEKYIA; BOTTINO, 2015). As diferenças encontradas entre as taxas, possivelmente, estão relacionadas aos diferentes métodos e instrumentos utilizados, além de características próprias de cada região. Deve-se ressaltar também o subdiagnóstico. Um estudo publicado recentemente estimou uma taxa de pelo menos $77 \%$ de pessoas portadoras de demência que não são diagnosticadas (NAKAMURA et al., 2015).

Há escassez sobre dados na população do chamado transtorno neurocognitivo leve (TNL), que é uma categoria diagnóstica recente com objetivo de descrever alterações cognitivas patológicas associadas ao envelhecimento que não configuram no entanto demência e que são distintas daquelas decorrentes do processo de envelhecimento fisiológico (por exemplo diminuição na velocidade de processamento, déficits de atenção, de função executiva, raciocínio abstrato, controle inibitório e flexibilidade cognitiva) (BISCHKOPF; BUSSE; ANGERMEYER, 2002; CLEMENTE; RIBEIRO-FILHO, 2008; FICHMAN et al., 2013).

Esses estágios já receberam diversas denominações e já foram definidos por diversos critérios diagnósticos. Em 1950, foi descrito o esquecimento senil benigno por Kral (1958), posteriormente surgiu o termo comprometimento de memória associada à idade. Posteriormente, surgiram termos como comprometimento cognitivo leve (CCL), comprometimento cognitivo sem demência e por último o TNL. Estes estados são defendidos como possíveis estágios pré-clínicos de demência com maior probabilidade de conversão para algum tipo de demência (STEINER et al., 2017), ou em alguns casos de reversão para a normalidade (GAUTHIER et al., 2006; PETERSEN, 2004).

O termo comprometimento cognitivo leve, do inglês, mild cognitive impairment (MCI) foi defendido como uma entidade clínica por (PETERSEN et al., 1999). Incialmente restrito a queixas de memória, o termo foi ampliado para incluir queixas sobre prejuízo em outros domínios cognitivos, mantendo a necessidade de que a queixa de declínio cognitivo seja objetiva, medida por testes neuropsicológicos, mas que a funcionalidade esteja preservada e o diagnóstico de demência excluído. (FORLENZA et al., 2013; PETERSEN et al., 2014; STEINER et al., 2017). Este conceito estaria englobado na categoria diagnóstica mais atual trazida pela Associação Americana de Psiquiatria com o TNL (APA, 2013).

O comprometimento cognitivo sem demência, no inglês cognitive impairment nondementia (CIND), baseia-se no prejuízo cognitivo com preservação de funcionalidade. Este 
termo englobaria o a ideia de um declínio cognitivo assim como os conceitos de MCI e TNL, no entanto não é necessária a presença de queixa, seja pelo indivíduo ou por um informante. O declínio cognitivo é identificado a partir da avaliação clínica ou através de testes neuropsicológicos, com desempenho aquém do esperado para idade e escolaridade. A funcionalidade deve estar preservada. O declínio cognitivo pode ser decorrente de diversas causas (GRAHAM et al., 1997; UNVERZAGT et al., 2001).

Uma meta-análise recente, que incluiu 35 estudos observacionais com idosos da comunidade, relatou que a prevalência de MCI em diversos países variou de 0,5\% a 41,8\%. e a prevalência estimada foi de 17,3\% (IC 95\%, 13,8-2,8), mas com uma heterogeneidade significativa entre as estimativas $\left(\mathrm{I}^{2}=99,6 \%\right)$ (PESSOA et al., 2019).

Infelizmente, quando se procuram dados específicos para a prevalência dos transtornos mentais na população idosa, observa-se que muitos estudos excluem os idosos ou os incluem como uma categoria única (por exemplo: indivíduos acima de 65 anos). Além disso, estes estudos não investigam categorias diagnósticas mais específicas, como os transtornos neurocognitivos (TNC), visto que não existe disponível instrumento ou entrevista estruturada que investigue simultaneamente $\mathrm{TNC}$ e outros transtornos psiquiátricos como depressão e transtornos de ansiedade. Deste modo, tornam-se necessários estudos que avaliem a prevalência de todos os transtornos mentais, a fim de subsidiar o planejamento da atenção à saúde dessa faixa etária de forma eficaz e otimizada.

2.2 Importância dos estudos de prevalência de transtornos mentais na atenção primária

Os últimos relatórios da OMS sobre saúde mental propuseram que o eixo de atendimento nesta área seja direcionado para centros de atenção primária, com o propósito de atuar em maior parte da população (ANDRADE et al, 2000; KOHN et al, 2004). Segundo o Programa Nacional da Atenção Básica, a atenção primária é o mais importante componente do sistema de saúde pois tem papel central na organização da saúde, sem restrições e acessíveis a todos de forma integrada e continuada. É o primeiro nível de contato dos indivíduos, da família e da comunidade com o sistema nacional de saúde. No Brasil, o Programa Saúde da Família (PSF) tem papel ímpar na atenção básica (BRASIL, 2012).

O PSF teve sua implantação iniciada em 1994, e foi colocado como uma alternativa 
para a organização de sistemas de saúde, segundo os princípios do Sistema Único de Saúde (SUS). A Política Nacional de Atenção Básica tem na Saúde da Família sua estratégia prioritária para expansão e consolidação da atenção básica. Sendo assim, considerando que no Brasil a atenção básica é organizada de acordo com o PSF, o cuidado com os transtornos mentais indubitavelmente requer a inclusão deste programa como ferramenta para a detecção e atuação na saúde mental. Este sistema trabalha para a intervenção precoce, prevenção e educação em saúde, utilizando-se de uma abordagem multidisciplinar e integrada à comunidade (BRASIL, 2012).

A utilização do PSF como ferramenta de intervenção e rastreamento dos transtornos mentais é apresentada não apenas como necessária pela organização do sistema de saúde no Brasil, mas também como viável e desejável. Através da busca ativa de casos, o PSF tem potencial para melhor atuação sobre problemas como os transtornos mentais. Para que isso seja possível é essencial que as equipes de PSF estejam atentas aos aspectos de saúde mental da população atendida (GONÇALVES; KAPCZINSKI, 2008).

Considerando o envelhecimento populacional e, consequentemente, o aumento da prevalência dos TNC, a equipe do PSF deve ser capaz de detectar estes transtornos para possibilitar intervenção precoce e avaliação de fatores de risco. Desta forma, instrumentos de rastreamento de fácil aplicação devem ser considerados nesta população, levando em consideração suas peculiaridades.

\subsection{Instrumentos breves de rastreamento de transtorno neurocognitivo}

Conforme mencionado anteriormente, a prevalência de demência é alta na população idosa. Desta forma, faz-se necessário o rápido diagnóstico e início do tratamento, principalmente em estágios mais precoces quando ainda existem possibilidades de intervenções para prevenir ou retardar as consequências da doença.

Os profissionais da atenção primária estão numa posição única para detectar o declínio cognitivo ao longo do tempo, uma vez que acompanham de forma contínua os seus pacientes. No entanto, muitas vezes o diagnóstico não ocorre. Há, portanto, uma grande necessidade de ferramentas de rastreamento simples, válidas e breves para os profissionais de saúde, facilitando a detecção e o tratamento adequado e precoce (MITCHELL et al, 2015). 
Existem diversos instrumentos, principalmente escalas de avaliação para diversos aspectos relacionados aos sintomas das demências. Algumas delas focam na avaliação da funcionalidade, outras no comportamento e algumas ainda na qualidade de vida, mas as principais são as que avaliam as funções cognitivas, e existem diversas disponíveis (SHEEHAM, 2012).

Dentre os testes de rastreamento mais utilizados, encontra-se o Mini Exame do Estado Mental (MEEM). Inicialmente, o MEEM foi desenvolvido por Folstein et al. (1975) para diferenciar pacientes com alteração cognitiva com ou sem um quadro psiquiátrico e sujeitos saudáveis. Neste estudo, os resultados obtidos na aplicação do MEEM mostraram que o escore médio em pacientes com demência era de 9,7; com depressão com prejuízo cognitivo de 19; com depressão sem prejuízo cognitivo de 25,1 e em indivíduos normais de 27,6. Neste estudo, foram observados escores mais baixos no grupo de pacientes com demência em comparação com os demais e o MEEM passou a ser utilizado como instrumento de rastreio (FOLSTEIN; FOLSTEIN; MCHUGH, 1975).

Atualmente, o MEEM é utilizado extensivamente e fornece informações sobre orientação temporal e espacial, memória de curto prazo (memória imediata), atenção, evocação, cálculo, linguagem, habilidades visuoespaciais e a capacidade de seguir comandos verbais (CHAVES, 2008). Diversos estudos foram realizados no Brasil para determinar a nota de corte do MEEM para discriminar idosos com e sem demência (ALMEIDA, 1998; NITRINI et al., 2005; LOURENÇO; VERAS, 2006), apontando para diferentes escores, de acordo com a escolaridade. Por exemplo, Almeida et al (1998) indicaram como escore 19 para indivíduos analfabetos e 23 para indivíduos alfabetizados. Em outro estudo, Lourenço e Veras (2006) apontaram para o ponto de corte de 18 para indivíduos analfabetos e de 24 para aqueles com instrução escolar.

Outro instrumento para rastreamento de alterações cognitivas é o Montreal Cognitive Assessment (MoCA) (NASREDDINE et al., 2005), que é mais sensível para detectar déficits cognitivos precoces como CCL ou TNL, que podem progredir para demência (FREITAS et al., 2010, 2013; ROALF et al., 2013). É um teste breve que avalia uma ampla gama de funções cognitivas (como as funções executivas, habilidades visuo-espaciais, nomeação, recuperação da memória, dígitos, sentença, raciocínio abstrato e orientação). O tempo do teste é estimado em 10 minutos e a pontuação máxima possível é de 30 pontos. No estudo original, utilizando-se o MoCA foram evidenciados dados de $87 \%$ de especificidade, como sensibilidade de $90 \%$ para detectar CCL de pessoas sem comprometimento cognitivo no ponto de corte de 26. Além disso, a sensibilidade para detectar casos de demência com MoCA 
foi de 100\% (NASREDDINE et al., 2005). Dados semelhantes foram encontrados para o Brasil, com resultados mostrando o MoCA como melhor que o MEEM para diferenciar demência dos casos de CCL (CECATO et al., 2014; MONTIEL et al., 2013). Não existem dados sobre as qualidades psicométricas do MoCA para populações de baixa escolaridade.

Os itens do MoCA possuem um nível de complexidade maior, principalmente por possuir maior número de tarefas de avaliação das funções executivas, maior exigência de habilidades linguísticas, do processamento visuo-espacial, atenção, concentração e memória de trabalho. Além disso, a tarefa de memória implica mais palavras e maior intervalo de tempo anterior à evocação (FREITAS et al., 2013).

Trata-se de um teste com um perfil maior de complexidade, mas ainda assim de fácil e rápida aplicação. Pela escassez de informações para populações de baixa escolaridade e por conveniência em sua aplicação este teste foi escolhido em detrimento de outros testes mais amplamente utilizados (como por exemplo o Addenbrooke's Cognitive Examination - Revised - ACE-R) (CARVALHO; CARAMELLI, 2007).

Sabe-se que o MoCA foi validado inicialmente em um grupo de idosos com alta escolaridade (média de 13 anos) para diferenciar o CCL e o envelhecimento cognitivo normal. Assim, o desempenho em muitos itens é fortemente dependente de escolarização formal, o que pode gerar alguns vieses quando o teste é realizado em indivíduos analfabetos ou com baixa escolaridade. Nesse sentido, foi desenvolvida uma nova versão do MoCA, chamado MoCA basic (JULAYANONT et al., 2015), substituindo as tarefas que dependiam de educação formal (como desenho do relógio, do cubo, subtrações, entre outras) por outras independentes (teste das frutas, trilha com números e pontos, entre outros), mantendo a avaliação dos mesmos domínios cognitivos que a versão anterior. O MoCA basic, após um teste piloto, foi aplicado a 85 indivíduos de 55-80 anos com menos de 5 anos de escolarização. Após o estudo, o teste mostrou-se como um válido para detectar casos de CCL em indivíduos de baixa escolaridade sem influência de idade ou nível educacional. No estudo, considerando o ponto de corte do escore como abaixo de $25(<25 / 30)$ o instrumento apresentou sensibilidade de $81 \%$ e especificidade de $86 \%$ para detectar casos de CCL com uma acurácia de 84\% (JULAYANONT et al., 2015). A versão brasileira está disponível desde 30 de novembro de 2015 e encontra-se no site www.mocatest.org. Este instrumento ainda não se encontra validado para o Brasil e sua execução foi avaliada em um teste piloto na população do presente estudo. 


\section{OBJETIVOS}

Os objetivos do estudo são:

(i) verificar a frequência de transtornos mentais em idosos, incluindo transtornos neurocognitivos, de acordo com os critérios do DSM-5;

(ii) analisar as qualidades psicométricas de dois instrumentos breves para rastreamento de transtornos neurocognitivos;

(iii) determinar a sensibilidade, especificidade do MoCA para discriminar idosos com e sem transtornos neurocognitivos;

(iv) determinar a sensibilidade, especificidade do MoCA-B para discriminar idosos com e sem transtornos neurocognitivos; 


\section{MÉTODO}

4.1 Contexto e local do estudo

O município de São Carlos, localizado no interior do estado de São Paulo, na região centro-leste possui 28.696 habitantes com mais de 60 anos segundo censo demográfico do IBGE de 2010, correspondendo a 12,92\% da população total. Esse estudo foi realizado na área de abrangência do PSF Jardim Guanabara, localizado no núcleo de saúde "Jardim Jóquei” da Rua Rio Araguaia, 750, no bairro Jardim Guanabara, região sudeste de São Carlos. Este bairro é caracterizado por possuir uma população de baixa renda financeira e alto índice de analfabetismo, apesar de o IDH da cidade ser de 0.805 , o $14^{\circ}$ maior do estado de São Paulo (IBGE, 2010).

Este estudo está inserido em uma pesquisa mais abrangente denominada "Cognição social e comparação dos critérios do DSM-IV e DSM-5 em idosos da atenção básica" coordenada pelo Prof. Dr. Marcos Hortes Nisihara Chagas do departamento de Gerontologia da Universidade Federal de São Carlos. Esta pesquisa está em execução desde o ano de 2016 e envolve pesquisadores de diversas áreas do conhecimento relacionadas a saúde, de diferentes níveis de formação (alunos de graduação, profissionais formados e pósgraduandos).

\subsection{Delineamento do Estudo}

Trata-se de um estudo observacional com desenho transversal.

\subsection{Participantes}

A área de abrangência do PSF Jardim Guanabara tem, segundo dados do SIAB de 2014, 317 moradores com 60 anos ou mais. Foram considerados elegíveis para o estudo todos 
os moradores da área de abrangência do referido PSF com 60 anos ou mais de idade, comprovada através dos documentos de identificação de validade em todo o território nacional, de ambos os sexos. Todos os indivíduos identificados como residentes da área citada e maiores de 60 anos foram procurados.

4.4 Critérios de Exclusão:

Foram excluídos do estudo aqueles sujeitos que:

a) não puderam ser localizados no endereço cadastrado; b) apresentassem alguma comorbidade clínica grave que o tornasse incapaz de se comunicar verbalmente; c) fossem acamados; d) fossem portadores de déficits visuais ou auditivos suficientemente graves que atrapalhassem a compreensão da entrevista e dos testes; e) se encontrassem internados no momento da pesquisa; f) recusassem participar.

\subsection{Instrumentos utilizados para avaliação}

\subsubsection{Entrevista clínica pelos critérios do DSM-5}

O diagnóstico de transtorno mental, incluindo os TNC, foram feitos utilizando-se os critérios do DSM-5 através de entrevista clínica minuciosa. Três psiquiatras ficaram responsáveis pela realização das entrevistas. Foi utilizado o "Guia para o exame diagnóstico segundo o DSM-5" publicado pela APA em 2014, o qual apresenta uma estrutura para investigação diagnóstica e traz questões de triagem para os transtornos presentes no DSM-5, incluindo os TNC (NUSSBAUM, 2014). Este guia foi adotado pelo fato de na época de realização das entrevistas ainda não existir um manual traduzido e validado de entrevista estruturada do DSM-5 para o português do Brasil.

Foram considerados para validação discriminativa dos instrumentos cognitivos os diagnósticos de TNM (demência) e TNL. 
Uma folha de respostas do instrumento de Entrevista clínica pelos critérios do DSM-5 é trazida no Anexo A.

\subsubsection{Mini Exame do Estado Mental (FOLSTEIN; FOLSTEIN; MCHUGH, 1975)}

O MEEM é o teste breve mais utilizado para rastreamento de declínio cognitivo e inclui os seguintes domínios: memória imediata e de evocação, orientação temporal e espacial, atenção e cálculo, linguagem-nomeação, repetição, leitura e escrita, compreensão e praxia, e capacidade visuo-construtiva (FOLSTEIN; FOLSTEIN; MCHUGH, 1975). Sua pontuação máxima é de 30 pontos e apresenta tempo médio de aplicação de 5 minutos.

\subsubsection{Montreal Cognitve Assessment (NASREDDINE et al., 2005)}

O MoCA foi publicado como uma ferramenta de triagem para o CCL em 2005 (NASREDDINE et al., 2005). É um instrumento rápido, prático e eficaz na diferenciação de adultos com envelhecimento cognitivo normal e com declínio cognitivo. O MoCA avalia oito diferentes domínios cognitivos (divididos em 12 itens): função executiva e capacidade visuoespacial; nomeação de animais; memória imediata; atenção; linguagem; abstração; evocação tardia; e orientação espacial e temporal. Seu escore varia de 0 a 30 pontos e o tempo médio de aplicação é de 10 minutos. No Brasil, o instrumento foi traduzido (SARMENTO, 2009) encontra-se validado com nota de corte proposta de 25 pontos (MEMÓRIA et al., 2013). (Anexo B)

\subsubsection{Montreal Cognitive Assessment - basic (JULAYANONT et al., 2015)}

O MoCA basic foi desenvolvido em 2015 como uma proposta de teste de rastreio desenvolvido para identificar TNC em populações com baixa escolaridade, incluindo analfabetos. O MoCA basic avalia os mesmos domínios cognitivos que o MoCA original: 
funções executivas, linguagem, orientação, cálculo, abstração, memória, percepção visual (em vez de habilidades visuoconstrutivas), atenção e concentração. O tempo necessário para administração é de 10-15 minutos e o escore total máximo é de 30 pontos. O teste está traduzido para português e está disponível no site da organização uma versão brasileira, mas ainda não há na literatura, até o presente momento, registros sobre sua validação na população brasileira. (Anexo C) - referência

O quadro 1 traz um breve resumo das principais características dos três instrumentos breves de rastreio cognitivo utilizados no estudo.

Quadro 1 - Propriedades dos instrumentos para rastreio cognitivo, de acordo com o ano de publicação, os domínios cognitivos avaliados, a pontuação máxima e a existência de validação para população brasileira.

\begin{tabular}{|c|c|c|c|}
\hline $\begin{array}{c}\text { Instrumento } \\
\text { breve de } \\
\text { rastreio } \\
\text { cognitivo }\end{array}$ & MEEM & MoCA & MoCA basic \\
\hline $\begin{array}{l}\text { Ano de } \\
\text { publicação }\end{array}$ & 1975 & 2005 & 2015 \\
\hline $\begin{array}{l}\text { Domínios } \\
\text { cognitivos } \\
\text { avaliados }\end{array}$ & $\begin{array}{l}\text { Memória imediata e de } \\
\text { evocação, orientação } \\
\text { temporal e espacial, } \\
\text { atenção e cálculo, } \\
\text { linguagem-nomeação, } \\
\text { repetição, leitura e escrita, } \\
\text { compreensão e praxia, e } \\
\text { capacidade visuo- } \\
\text { construtiva }\end{array}$ & $\begin{array}{l}\text { Função executiva e } \\
\text { capacidade visuo- } \\
\text { espacial; nomeação de } \\
\text { animais; memória } \\
\text { imediata; atenção; } \\
\text { linguagem; abstração; } \\
\text { evocação tardia; e } \\
\text { orientação espacial e } \\
\text { temporal }\end{array}$ & $\begin{array}{l}\text { Funções executivas, } \\
\text { linguagem, } \\
\text { orientação, cálculo, } \\
\text { abstração, memória, } \\
\text { percepção visual, } \\
\text { atenção e } \\
\text { concentração }\end{array}$ \\
\hline $\begin{array}{l}\text { Pontuação } \\
\text { máxima }\end{array}$ & 30 pontos & 30 pontos & 30 pontos \\
\hline $\begin{array}{l}\text { Tempo de } \\
\text { aplicação }\end{array}$ & 5 minutos & 10 minutos & 10 minutos \\
\hline $\begin{array}{l}\text { Validação } \\
\text { para } \\
\text { população } \\
\text { brasileira }\end{array}$ & $\operatorname{sim}$ & $\operatorname{sim}$ & não \\
\hline
\end{tabular}


Os idosos elegíveis para o estudo foram convidados a participar a partir de uma visita domiciliar realizada pelos pesquisadores do estudo. O grupo de pesquisadores era composto por quatro gerontólogos formados pela Universidade Federal de São Carlos, treinados por um professor graduado em Medicina e com especialização em Psiquiatria Geriátrica, e três médicos com residência médica em Psiquiatria pela Faculdade de Medicina de Ribeirão Preto. No primeiro contato com o idoso, os pesquisadores forneceram todas as explicações e dúvidas sobre a pesquisa e esclareceram que a não participação não iria afetar em nada seu atendimento na unidade de saúde. Todos os que aceitarem participar do estudo assinaram o termo de consentimento livre e esclarecido (TCLE) (Anexo D). Foi solicitado ao responsável da casa para que a avaliação fosse realizada no cômodo mais apropriado em relação à iluminação e acústica. Procedeu-se então a avaliação, que foi realizada em duas etapas, em dois momentos distintos. A coleta dos dados teve início em março de 2016 e término em fevereiro de 2017.

Na primeira etapa, os participantes forneceram dados sociodemográficos, responderam a testes de saúde global e foram submetidos a uma bateria cognitiva, que incluía o MEEM. Esta primeira avaliação teve duração média de 60 minutos e foi executada pelos quatro gerontólogos. A segunda etapa sucedeu a primeira em um prazo máximo de 60 dias, e foi composta pela visita ao idoso de um médico psiquiatra que realizou a avaliação clínica e investigação diagnóstica da presença de transtornos mentais segundo os critérios do DSM-5 conjuntamente a aplicação do MoCA e do MoCA basic. O tempo aproximado para execução desta segunda etapa foi de 30 a 50 minutos.

Sempre que possível, e quando era necessário tanto para fins éticos quanto para esclarecer o diagnóstico, um informante adicional (principalmente familiar / parente ou prestador de cuidados) também foi consultado.

A seguir, está apresentado um fluxograma do estudo (figura 1). 


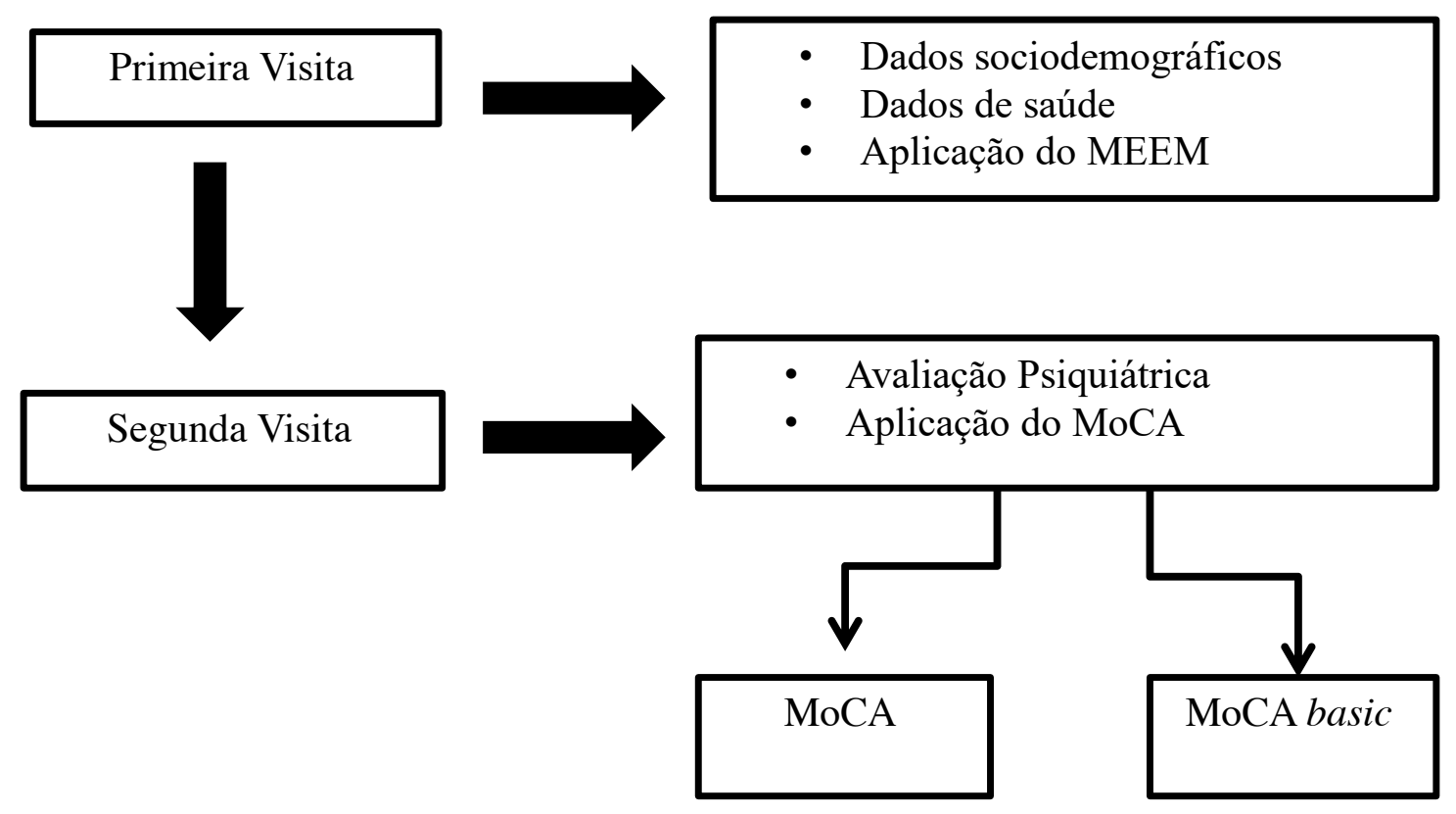

Figura 1 - Fluxograma referente a avaliação da amostra ao longo do estudo.

Do total de 317 idosos inicialmente elegíveis, foram avaliados 282 na primeira etapa e 271 na segunda etapa. Foi realizada a avaliação clínica diagnóstica psiquiátrica nos 271 idosos da segunda etapa, no entanto foi aplicado um total de 185 MoCA, sendo 104 MoCA e 81 MoCA basic. Na primeira etapa não se pode avaliar 35 indivíduos: não foram encontrados no endereço constando no cadastro de saúde 28 idosos (mudaram-se, faleceram, erro de cadastramento); recusaram a participar 5 idosos; e eram acamados dois idosos. Inicialmente, nesta etapa foi possível realizar 282 MEEM. Na segunda etapa, não foram avaliados 11 indivíduos por recusa em participar. Dos 271 idosos que aceitaram passar pela avaliação psiquiátrica inicialmente, 204 aceitaram avançar na avaliação diagnóstica e realizar um teste de rastreio cognitivo (ou MoCA ou MoCA basic), no entanto 13 desistiram ou não engajaram após iniciar o teste (principalmente se queixando da dificuldade dos itens), três eram portadores de TNM grave e três tinham déficit intelectual e por isso também foram excluídos. No final, totalizaram-se 185 MoCA adequadamente completados, 104 MoCA e 81 MoCA basic. Quanto aos 282 MEEM disponíveis inicialmente, 271 permaneceram para etapa de avaliação diagnóstica, mas após o diagnóstico, 6 MEEM foram excluídos pelos diagnósticos de TNM grave e pelo déficit intelectual, resultando em 265 MEEM realizados.

O fluxograma abaixo explicita participação na coleta de dados da amostra nas diferentes etapas da avaliação (figura 2). 


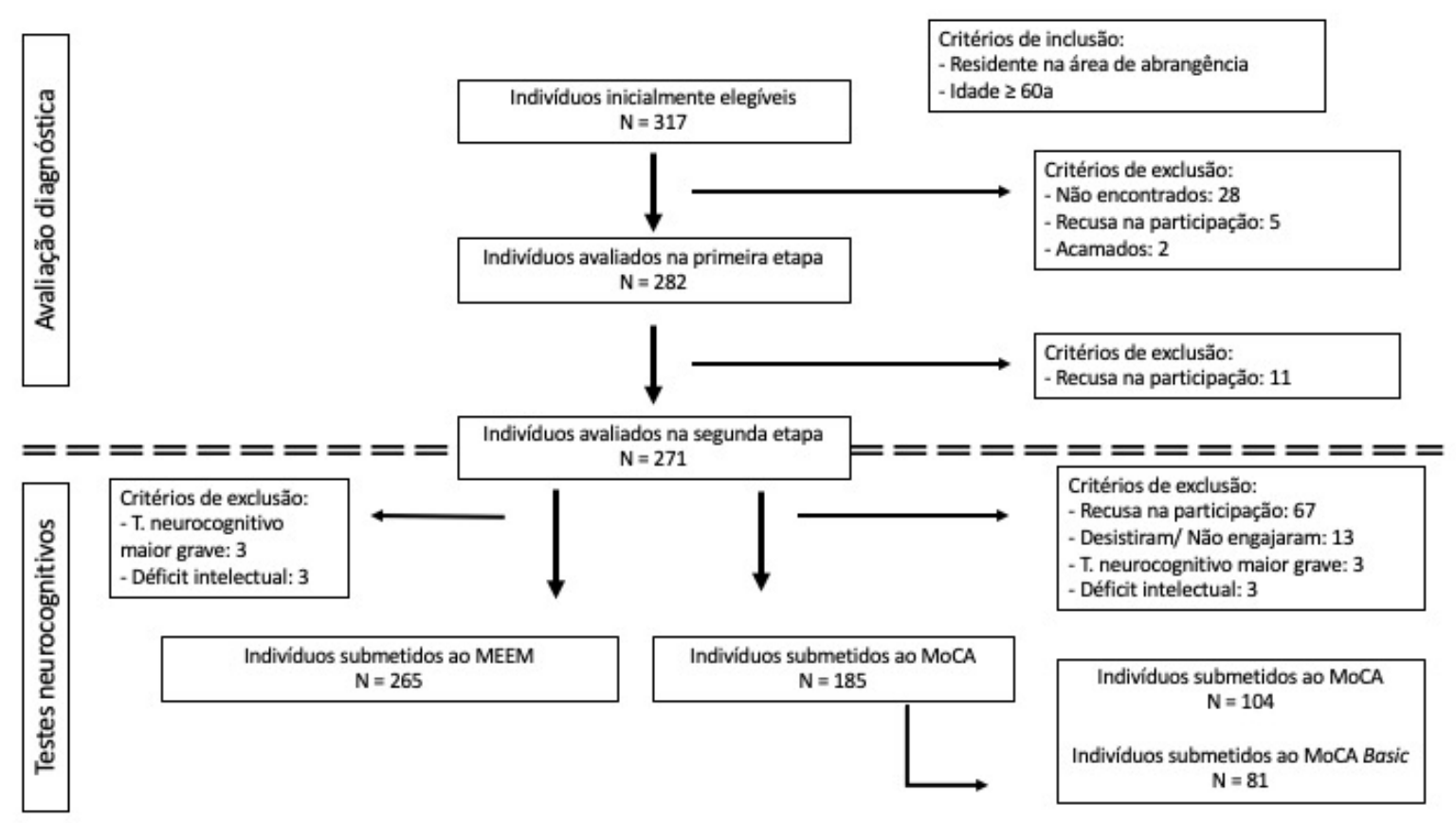

Figura 2 - Fluxograma da composição da amostra nas etapas do estudo.

Este estudo utilizou uma amostra populacional residente na área de abrangência da unidade do PSF Jardim Guanabara. Inicialmente, pretendia-se avaliar todos os idosos residentes da área, que totalizava 317 idosos. Esta foi definida como a população alvo do estudo. A taxa de resposta variou a cada etapa do estudo. Ao longo da operacionalização da pesquisa, a amostra sofreu perdas, reunindo, deste modo, diferentes números de indivíduos na população do estudo, de acordo com cada etapa. Na primeira etapa (coleta de dados sociodemográficos e aplicação do MEEM) foram avaliados 282 idosos, o que representa $88,9 \%$ da amostra inicial. Na segunda etapa (entrevista psiquiátrica + aplicação de um dos testes MoCA), foram avaliados 271 idosos, o que representa $85 \%$ da amostra inicial, e $96 \%$ da amostra que realizou a primeira etapa. O total de idosos que foram submetidos ao MoCA ou MoCA basic foi de 185 (58\% da amostra inicial, 68\% da amostra após a primeira etapa).

Os motivos mais frequentes para a perda amostral na primeira etapa foram a não localização do idoso no endereço cadastrado (erro no cadastro, mudança, internação hospitalar, falecimento) $(n=28)$, e a recusa em participar $(n=5)$. Para a segunda etapa. o motivo para a perda amostral foi a recusa do participante em passar por nova avaliação $(\mathrm{n}=11)$. Quanto a recusa para a testagem com o MoCA a desistência foi grande, com muita recusa $(n=67)$ ou não engajamento adequado no teste $(n=13)$. Outros motivos para perdas amostrais ou exclusão de participantes nas diferentes etapas foram o fato de o indivíduo ser 
acamado $(n=2)$, ou possuir quadro demencial ou déficit intelectual que comprometiam o entendimento da avalição $(\mathrm{n}=6)$.

A tabela 1 reuni os dados sobre o tamanho da amostra, de acordo com o número de participantes em cada etapa da pesquisa.

Tabela 1 - Composição amostral de cada etapa do estudo expressas em número de indivíduos incluídos e taxa de resposta em porcentagem, a partir de uma população de idosos atendidos por uma unidade do Programa Saúde da Família do bairro Jardim Guanabara em São Carlos - SP. Ribeirão Preto, 2020.

\begin{tabular}{lccc}
\hline \multicolumn{1}{c}{ Amostra } & $\begin{array}{c}\text { Tamanho da } \\
\text { amostra (N) }\end{array}$ & $\begin{array}{c}\text { \% da } \\
\text { população alvo }\end{array}$ & $\begin{array}{c}\text { \% da população } \\
\text { do estudo }\end{array}$ \\
\hline $\begin{array}{l}\text { População alvo } \\
\text { População do estudo }\end{array}$ & 317 idosos & $100 \%$ & - \\
$\begin{array}{l}\text { Primeira etapa } \\
\text { Segunda etapa }\end{array}$ & 282 idosos & $88,9 \%$ & $100 \%$ \\
$\begin{array}{l}\text { Entrevista } \\
\text { diagnóstica }\end{array}$ & 271 idosos & $85 \%$ & $96 \%$ \\
$\begin{array}{l}\text { Aplicação MoCA } \\
\text { - MoCA }\end{array}$ & 185 idosos & $58 \%$ & $68 \%$ \\
- MoCA basic & 104 testes & & \\
\hline
\end{tabular}

Este estudo tem como um dos objetivos a definição na prevalência dos transtornos mentais na amostra de idosos avaliada. Para isso, a amostra final (população do estudo) foi composta de um total de 271 idosos que entre março de 2016 e fevereiro de 2017 foram entrevistados por psiquiatras. O diagnóstico foi realizado a partir de avaliação psiquiátrica baseada nos critérios do DSM-5. Para as demais análises, como determinação das qualidades psicométricas e validade convergente dos dois instrumentos de rastreio de declínico cognitivo (testes neurocognitivos), foi considerado um total de 104 MoCA e 81 MoCA basic.

\subsection{Aspectos éticos}

A todos os participantes foi entregue o Termo de Consentimento Livre e Esclarecido (TCLE), fornecendo-lhes informações sobre as justificativas, objetivos, procedimentos, riscos e benefícios do estudo ao qual foram convidados a participarem. Só foram aceitos no estudo aqueles participantes que devidamente assinaram o TCLE. O estudo foi submetido a 
escrutínio e aprovado no Comitê de Ética em Pesquisa da Universidade Federal de São Carlos- CAAE: 48602515.5.0000.5504 (Anexo E).

Foi assegurado ao sujeito a total liberdade de retirar seu consentimento em qualquer momento no transcorrer da pesquisa e deixar de participar do estudo, sem que isso lhe trouxesse qualquer prejuízo. Do mesmo modo, a não participação no estudo não acarretou qualquer prejuízo no atendimento e seguimento no serviço em que o individuo estivesse sendo atendido, ou em qualquer outro.

Foram garantidos esclarecimentos sobre qualquer dúvida que surgisse no transcorrer do procedimento e informação atualizada sobre o estudo, ainda que isso viesse a afetar sua vontade de continuar participando. Da mesma forma, foi garantida a segurança de não serem identificados, bem como de que todas as informações fornecidas por eles estão mantidas sob caráter confidencial.

No presente trabalho não existiram situações que implicassem em indenização ou ressarcimento dos participantes.

Vale lembrar que todos os indivíduos que apresentaram alterações nos testes ou na avaliação psiquiátrica foram encaminhamentos para seguimento e tratamento adequado e investigação de possíveis causas de demência, bem como os familiares e acompanhantes presentes nas avalições foram orientados e instruídos a comparecerem ao núcleo de saúde com a maior brevidade possível. Os mesmos também seguem como candidatos a serem inseridos em programas de treinos cognitivos desenvolvidos pelos alunos do curso de Gerontologia da UFSCar.

\subsection{Análise estatística}

As informações sociodemográficas coletadas neste estudo serão expressas por estatística descritiva. Essas consistiram em classificação por grupos etários e na média de anos e desvio padrão de idade; escolaridade por grupos de anos de estudo e média e desvio padrão; número absoluto e percentual de sexo (masculino ou feminino) e de status ocupacional (aposentado ou não), além de informações sobre a renda individual em número salários mínimos dos indivíduos que compuseram a amostra.

As taxas de prevalência de transtornos psiquiátricos são apresentadas como frequências amostrais (número absoluto de casos e porcentagem simples). 
Os dados clínicos e sociodemográficos dos participantes (sexo, idade, aposentadoria, escolaridade) de acordo com cada grupo de transtorno neurocognitivo foram analisados por meio do teste $t$-student/Mann-Whitney para dados contínuos e pelo teste do qui-quadrado $\left(\mathrm{X}^{2}\right)$ para dados nominais.

A comparação do desempenho dos diferentes grupos nos instrumentos de rastreamento de declínio neurocognitivo (MEEM, MoCA e MoCA basic) foi feita pelo teste de KruskalWallis para vários grupos, seguido de Mann-Whiney para cada par.

Para determinar a validade discriminativa dos instrumentos de rastreamento de declínio de cognitivo (MoCA e MoCA basic) para a amostra estudada, foram determinados os valores de sensibilidade e especificidade nos diferentes pontos de corte considerando idosos sem ou com algum TNC e foi calculada área sob a curva ROC (Receiver Operating Characteristic) para cada teste comparando-se os diferentes grupos de indivíduos, de acordo com a categoria clínica. Os pontos de corte com o melhor equilíbrio entre sensibilidade e especificidade são apresentados, juntamente com os valores para os quatro pontos de corte abaixo e acima. Foram feitas comparações entre os indivíduos sem TNC versus os portadores de TNC específico (TNL ou TNC), e grupos entre sem TNC versus algum TNC (TNL ou TNM) e TNM versus não TNM (sem TNC e TNL).

A validade convergente do MoCA e MoCA basic foi realizada calculando-se o coeficiente de Spearman para dados com distribuição não paramétrica a partir das correlações dos escores totais de cata teste com os escores do MEEM. Os valores de 0 a 0,3 foram considerados desprezíveis, de 0,3 a 0,5 fracos, de 0,5 a 0,7 moderados, de 0,7 a 0,9 fortes e acima de 0,9 muito fortes (MUKAKA, 2012).

As análises estatísticas foram e serão realizadas usando-se o pacote estatístico SPSS, versão 21.0. O nível de significância considerado será de $\mathrm{p} \leq 0,05$. 


\section{RESULTADOS}

Dados sociodemográficos

A amostra era constituída de 58,30\% (N=158) de mulheres e 41,70\% de homens $(\mathrm{N}=$ 113), com maioria de 70,47\% ( $\mathrm{N}=191)$ de aposentados. A média de idade foi de 70,56 anos (DP: $\pm 7,81$ ) e a média de escolaridade foi de 3,09 anos (DP: $\pm 2,97$ ). A maior parte dos indivíduos tinha renda entre 1 e 3 salários mínimos. Os dados sociodemográficos da amostra estão explicitados na tabela 2.

Tabela 2 - Características sociodemográficas, expressas em número de indivíduos, porcentagem, anos e desvio padrão de uma amostra de 271 idosos atendidos por uma unidade do Programa Saúde da Família do bairro Jardim Guanabara em São Carlos SP. Ribeirão Preto, 2020.

\begin{tabular}{|c|c|c|c|}
\hline \multicolumn{4}{|l|}{ Característica } \\
\hline & & $\begin{array}{c}\text { Número de } \\
\text { indivíduos }(\mathbf{N})\end{array}$ & $\begin{array}{c}\text { Porcentagem de } \\
\text { indivíduos }(\%)\end{array}$ \\
\hline \multicolumn{4}{|l|}{ Sexo } \\
\hline & Masculino & $\mathrm{N}=113$ & $41,70 \%$ \\
\hline & Feminino & $\mathrm{N}=158$ & $58,30 \%$ \\
\hline & Total & $\mathrm{N}=271$ & $100,00 \%$ \\
\hline \multicolumn{4}{|l|}{ Aposentadoria } \\
\hline & Aposentado & $N=191$ & $70,48 \%$ \\
\hline & Não aposentado & $\mathrm{N}=80$ & $29,52 \%$ \\
\hline & Total & $\mathrm{N}=271$ & $100,00 \%$ \\
\hline \multirow{2}{*}{\multicolumn{4}{|c|}{$\begin{array}{c}\text { Idade } \\
\text { Grupos etários }\end{array}$}} \\
\hline & & & \\
\hline & $60-64$ anos & $\mathrm{N}=72$ & $26,57 \%$ \\
\hline & $65-69$ anos & $\mathrm{N}=79$ & $29,15 \%$ \\
\hline & $70-74$ anos & $\mathrm{N}=53$ & $19,56 \%$ \\
\hline & $75-79$ anos & $\mathrm{N}=23$ & $8,49 \%$ \\
\hline & $80-84$ anos & $N=26$ & $9,59 \%$ \\
\hline & $85-89$ anos & $\mathrm{N}=13$ & $4,80 \%$ \\
\hline & $>90+$ & $\mathrm{N}=5$ & $1,85 \%$ \\
\hline & TOTAL & $N=271$ & $100,00 \%$ \\
\hline \multirow[t]{3}{*}{ Idade (anos) } & Mínima & 60 anos & \\
\hline & Máxima & 93 anos & \\
\hline & Média + DP & $70,56 \pm 7,81$ & \\
\hline
\end{tabular}


Tabela 2 - Características sociodemográficas, expressas em número de indivíduos, porcentagem, anos e desvio padrão de uma amostra de 271 idosos atendidos por uma unidade do Programa Saúde da Família do bairro Jardim Guanabara em São Carlos SP. Ribeirão Preto, 2020 (continuação).

\section{Escolaridade}

\begin{tabular}{cccc} 
& Analfabeto & $\mathrm{N}=69$ & $25,46 \%$ \\
& $1-4$ anos & $\mathrm{N}=153$ & $56,46 \%$ \\
& $5-8$ anos & $\mathrm{N}=34$ & $12,55 \%$ \\
& $9-11$ anos & $\mathrm{N}=12$ & $4,43 \%$ \\
& $>12+$ & $\mathrm{N}=3$ & $1,11 \%$ \\
& Total: & $\mathrm{N}=271$ & \\
\hline Escolariadade & Máxima: & 15 & \\
(anos) & Mínima: & 0 (analfabeto) & \\
& Média $+\mathrm{DP}$ & $3,09 \pm 2,97$ & $5,17 \%$ \\
\hline Renda (reais) & & & $75,28 \%$ \\
$<1$ sal. min. & $<880$ & $\mathrm{~N}=14$ & $16,97 \%$ \\
$1-3$ sal. min. & $880-2640$ & $\mathrm{~N}=204$ & $2,58 \%$ \\
3-5 sal. min. & $2640-4440$ & $\mathrm{~N}=46$ & $100,00 \%$ \\
$>$ 5+ sal. min. & $>4400$ & $\mathrm{~N}=7$ & Conclusão
\end{tabular}

\section{Prevalência de transtornos mentais}

De acordo com a avaliação diagnóstica, a prevalência geral para algum transtorno psiquiátricos atual foi de 55,3\% ( $=150)$. Cerca de 38,38\% (N=104) da amostra tinha apenas um diagnóstico, enquanto $16,97 \% \quad(\mathrm{~N}=46)$ apresentavam dois ou mais transtornos comórbidos. Cerca de 26,94\% (N=73) não possuía nenhum histórico ou transtorno atual e cerca de $17,7 \%(\mathrm{~N}=48)$ tinha algum diagnóstico prévio durante a vida (atualmente remitido), o que totalizava $73,06 \%(\mathrm{~N}=198)$ da amostra que teve ou tem algum histórico psiquiátrico.

Os transtornos psiquiátricos mais comuns foram os TNC, presentes em 33,58\% $(\mathrm{N}=91)$ dos idosos, transtornos de ansiedade em 25,46\% (N=69), transtornos do humor em $21,03 \%(\mathrm{~N}=57)$, sendo depressivo $19,19 \%(\mathrm{~N}=52)$, transtornos de sono em 14,76\% $(\mathrm{N}=40)$ e transtornos do uso de substâncias em 11,07\% $(\mathrm{N}=30)$.

Dos TNC, 21,77\% (N=59) eram TNL e 11,81\% ( $\mathrm{N}=32)$ eram TNM. Os TNC foram comórbidos a outros transtornos em $11,80 \%(\mathrm{~N}=32)$ da amostra e eram o único diagnóstico atual em $21,77 \%(\mathrm{~N}=59)$ da amostra.

Quanto aos tipos de transtornos de ansiedade, o transtorno de ansiedade generalizada (TAG) estava presente em 14,76\% ( $\mathrm{N}=40)$ dos idosos e o de fobia específica em 9,59\% $(\mathrm{N}=26)$. A Fobia Social (Transtorno de Ansiedade Social) foi diagnosticada em $1,85 \%$ da 
amostra $(\mathrm{N}=5)$ e o Transtorno de pânico em $0,74 \%(\mathrm{~N}=2)$.

Quanto aos transtornos de humor, a prevalência de Episódio Depressivo Maior (EDM) atual foi de 5,9\% ( $\mathrm{N}=16)$. O Transtorno depressivo persistente (distímico) foi diagnosticado em 3,32\% (N=9). Cerca de 9,96\% ( $\mathrm{N}=27)$ da amostra tinha história de um EDM prévio diagnosticado. O diagnóstico de transtorno bipolar teve prevalência de 1,85\% (N=5), todos eutímicos.

Dos transtornos associados ao uso de substâncias, 9,23\% ( $\mathrm{N}=25 \%)$ eram relacionados ao uso de nicotina e 4,80\% ( $\mathrm{N}=13)$ ao álcool. Não foi encontrado o uso de outras substâncias psicotrópicas na amostra.

Os demais transtornos somaram 8,49\%. Os transtornos psicóticos contaram com $2,95 \%(\mathrm{~N}=8)$, sendo $1,85 \%$ dos indivíduos $(\mathrm{N}=5)$ de esquizofrenia e 1,10\% $(\mathrm{N}=3)$ de outros transtornos psicóticos. Transtornos relacionados ao trauma e estresse apareceram em 2,21\% $(\mathrm{N}=6)$; transtornos dissociativos, de sintoma somático e o transtorno obsessivo compulsivo (TOC) tiveram igual frequência de 0,37\% (N=1). Foi possível diagnosticar déficit intelectual com frequência de $1,11 \%(\mathrm{~N}=3)$ dos idosos e transtorno de personalidade em $0,37 \%(\mathrm{~N}=1)$. Não foi diagnosticado nenhum caso de transtorno alimentar.

A tabela 3 sintetiza os principais dados sobre a prevalência dos transtornos mentais encontrados na amostra, e a tabela 4 traz os dados adicionais de diagnósticos específicos.

Tabela 3 - Prevalência de transtornos mentais por categorias, expressa em número de indivíduos e porcentagem, em uma amostra de 271 idosos atendidos por uma unidade do Programa Saúde da Família do bairro Jardim Guanabara em São Carlos - SP. Ribeirão Preto, 2020.

\begin{tabular}{lcc}
\hline \multicolumn{1}{c}{ Prevalência de transtorno mental } & $\begin{array}{c}\text { Número de } \\
\text { indivíduos (N) }\end{array}$ & $\begin{array}{c}\text { Porcentagem dos } \\
\text { indivíduos (\%) }\end{array}$ \\
\hline Idosos com algum transtorno mental atual & 150 & $55,35 \%$ \\
$\quad$ Apenas um diagnóstico & 104 & $38,38 \%$ \\
$\quad$ Dois ou mais diagnósticos & 46 & $16,97 \% \%$ \\
Idosos com transtorno mental prévio & 48 & $17,71 \%$ \\
Idosos com histórico positivo para & & \\
transtorno mental & 198 & $73,06 \%$ \\
Idosos sem histórico de transtorno mental & 73 & $26,94 \%$ \\
Total & 271 & $100 \%$ \\
\hline Prevalência dos transtornos mentais & Número de & Porcentagem dos \\
por categorias & indivíduos (N) & indivíduos (\%) \\
\hline T. neurocognitivos & 91 & $33,58 \%$ \\
T. de ansiedade & 69 & $25,46 \%$ \\
T. depressivos & 52 & $19,19 \%$ \\
T. do sono & 40 & $14,76 \%$ \\
T. do uso de substâncias & 30 & $11,07 \%$ \\
Demais transtornos mentais & 23 & $8,49 \%$ \\
\hline
\end{tabular}


Tabela 4 - Prevalência de transtornos mentais específicos, expressa em número de indivíduos e porcentagem, em uma amostra de 271 idosos atendidos por uma unidade do Programa Saúde da Família do bairro Jardim Guanabara em São Carlos - SP. Ribeirão Preto, 2020.

\begin{tabular}{|c|c|c|}
\hline $\begin{array}{l}\text { Prevalência dos transtornos mentais por } \\
\text { categoria e diagnósticos }\end{array}$ & $\begin{array}{c}\text { Número de } \\
\text { indivíduos }(\mathbf{N})\end{array}$ & $\begin{array}{c}\text { Porcentagem dos } \\
\text { indivíduos }(\%)\end{array}$ \\
\hline Transtornos neurocognitivos & 91 & $33,58 \%$ \\
\hline T. neurocognitivo leve & 59 & $21,77 \%$ \\
\hline T. neurocognitivo maior & 32 & $11,81 \%$ \\
\hline Transtornos de ansiedade & 69 & $25,46 \%$ \\
\hline T. de ansiedade generalizada & 40 & $14,76 \%$ \\
\hline Fobia específica & 26 & $9,59 \%$ \\
\hline Fobia social & 5 & $1,85 \%$ \\
\hline Transtorno do pânico & 2 & $0,74 \% \%$ \\
\hline Agorafobia & 0 & 0 \\
\hline Transtornos do Humor & 57 & $21,03 \%$ \\
\hline Transtorno depressivo & 52 & $19,18 \%$ \\
\hline EDM atual & 16 & $5,90 \%$ \\
\hline $\begin{array}{l}\text { Transtorno depressivo persistente } \\
\text { (distímico) }\end{array}$ & 9 & $3,32 \%$ \\
\hline EDM prévio & 27 & $9,96 \%$ \\
\hline \multicolumn{3}{|l|}{ Transtorno afetivo bipolar } \\
\hline Eutímico & 5 & $1,85 \%$ \\
\hline Mania / EDM & 0 & 0 \\
\hline Transtorno do sono & 40 & $14,76 \%$ \\
\hline Transtorno do uso de substâncias & 30 & $11,07 \%$ \\
\hline Relacionado ao álcool & 13 & $4,80 \%$ \\
\hline Relacionado a nicotina & 25 & $9,23 \%$ \\
\hline Outras substâncias & 0 & 0 \\
\hline Transtornos psicóticos & 8 & $2,95 \%$ \\
\hline Esquizofrenia & 5 & $1,85 \%$ \\
\hline Outras psicoses & 3 & $1,1 \%$ \\
\hline Transtornos relacionados ao trauma e stress & 6 & $2,21 \%$ \\
\hline Transtorno de sintomas somático & 1 & $0,37 \%$ \\
\hline Transtorno obsessivo-compulsivo & 1 & $0,37 \%$ \\
\hline Transtorno dissociativo & 1 & $0,37 \%$ \\
\hline Déficit intelectual & 3 & $1,11 \%$ \\
\hline Transtorno de personalidade & 1 & $0,37 \%$ \\
\hline Transtorno alimentar & 0 & 0 \\
\hline
\end{tabular}


A tabela 5 apresenta os dados sociodemográficos e resume os escores alcançados dos testes de rastreio cognitivo de toda a amostra e dividida pelos grupos: transtorno neurocognitivo maior (TNM), transtorno neurocognitivo leve (TNL) e sem transtorno neurocognitivo (sem TNC). O Mini-Exame do Estado mental foi realizado em 265 idosos, enquanto o MoCA em 185, sendo 104 na sua versão convencional (MoCA) e 81 na versão "basic" (MoCA basic).

Tabela 5 - Variáveis sociodemográficas e desempenho nos testes neurocognitivos em toda amostra e em cada grupo dos 271 idosos atendidos por uma unidade do Programa Saúde da Família do bairro Jardim Guanabara em São Carlos - SP. Ribeirão Preto, 2020.

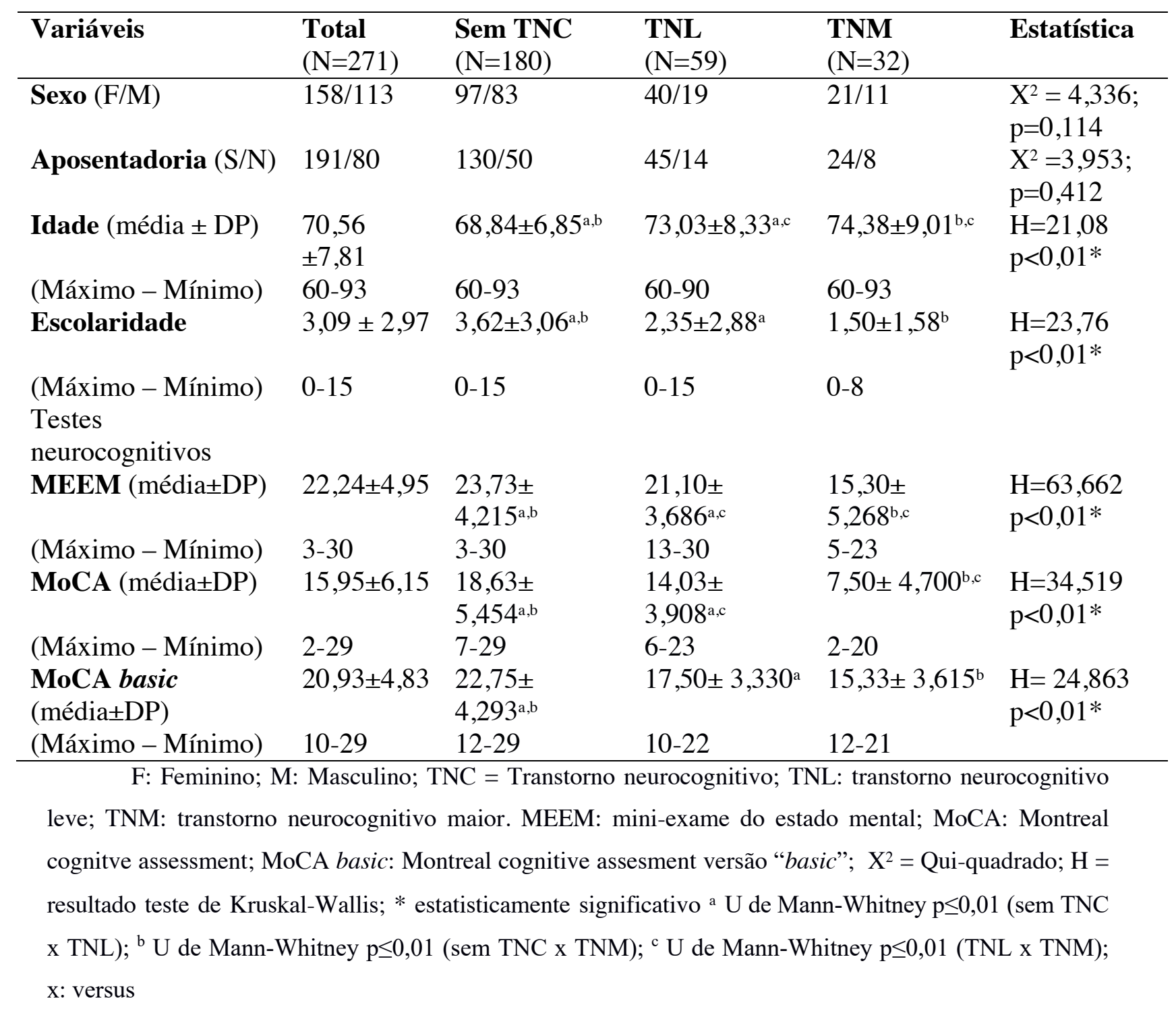

A distribuição na amostra e entre os grupos dos anos de escolaridade, idade e escores totais nos testes neurocognitivos em pelo menos um dos grupos foi não paramétrica. 
Não houve diferença estatisticamente significativa entre os grupos em relação ao sexo ou status de aposentadoria. Os grupos diferiram com relação a idade e escolaridade. $\mathrm{Na}$ análise pos hoc com teste de Mann Whitney para verificar a diferença dos grupos dois a dois, observou-se que no grupo de idosos sem TNC predominaram idosos mais jovens e com maior escolaridade, já nos grupos TNL e TNM predominaram os idosos mais velhos e com menor escolaridades, sendo isto mais intenso no grupo TNM (mais velhos e com menor escolaridade).

O desempenho dos participantes nos testes neurocognitivos foram diferentes entre alguns grupos na análise inicial. Na análise pos hoc dois a dois, observou-se que o desempenho total no MEEM e no MoCA foi diferente entre o grupo de idosos sem TNC e os com TNL; entre os sem TNC e os TNM; e entre os idosos com TNL e TNM. Já o desempenho total no MoCA basic foi diferente apenas comparando-se os idosos sem TNC e os idosos com TNM e TNL, mas não entre os idosos dos dois grupos clínicos (com TNL e os com TNM).

Nos grupos clínicos, TNL ou TNM concentraram os piores desempenhos nos testes neurcognitivos (menores escores), o que é revelado pelas menores médias aritméticas nesses grupos. As pontuações no MoCA foram menores em toda amostra e em todos os grupos quando comparados ao desempenho no MEEM e no MoCA basic. O desempenho no MEEM foi melhor em toda a amostra e em todos os grupos. O desempenho no MoCA basic foi intermediário, pior que o desempenho no MEEM, mas melhor que o do MoCA, no entanto no grupo com TNM a média foi próxima a do MEEM.

As pontuações mínimas no MEEM e MoCA foram 3 e 2, respectivamente, enquanto no MoCA o menor valor atingido foi de 10 .

No geral, pontuações mais baixas foram significativas para pertencer a um grupo clínico, sendo que quanto mais baixa a pontuação mais intensa era o prejuízo clínico (pior desempenho nos participantes do grupo com TNM), exceto para o MoCA basic, no qual não houve diferença estatisticamente significativa dos escores do grupo TNL e TNM.

Características psicométricos do MoCA e MoCA basic

A figura 3 apresenta a curva ROC relativa ao MoCA apresentando a validade discriminativa entre os grupos sem TNC e com TNM. A área sob a curva foi de 0,932 
( $\mathrm{p}<0,001 ;$ IC95 \% 0,842-1,000), sendo considerada excelente (METZ, 1978).

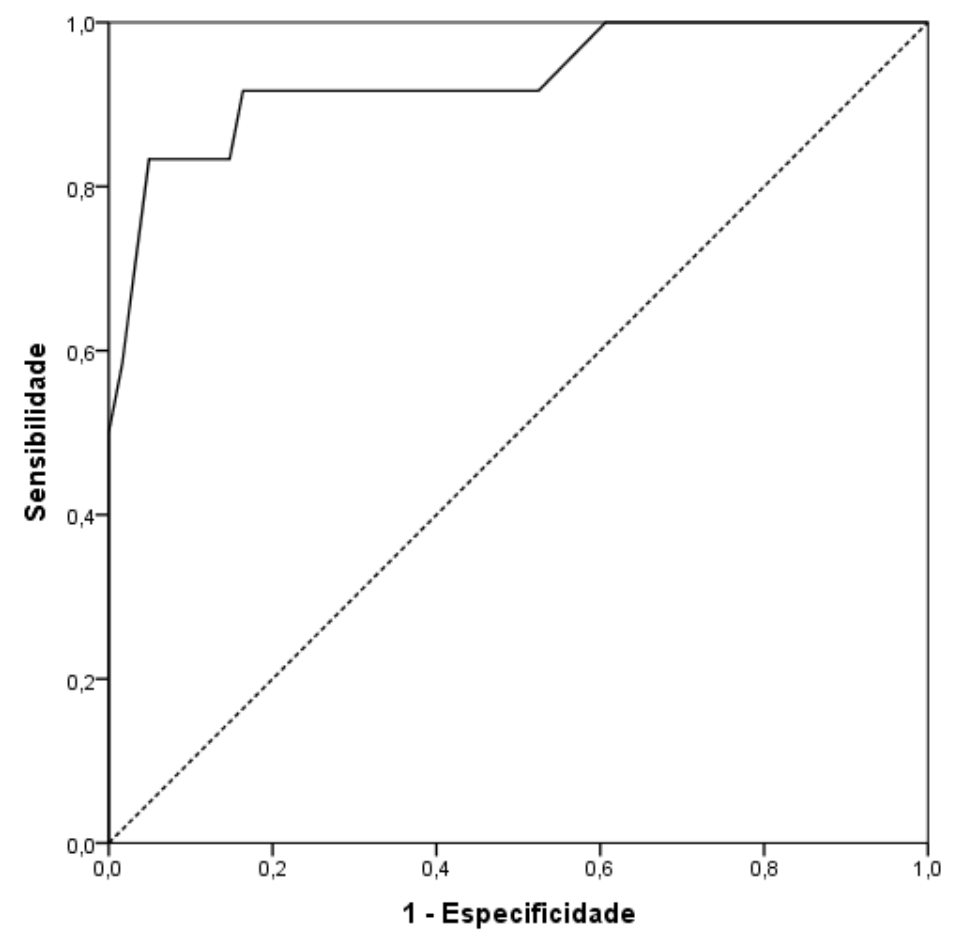

Figura 3 - Curva ROC do MoCA tendo-se como referência os grupos sem TNC e TNM.

A tabela 6 apresenta os valores de sensibilidade e especificidade referente a diferentes pontos de corte do MoCA para discriminar indivíduos com TNM e sem TNC. O ponto de corte que apresenta melhor equilíbrio entre a sensibilidade e especificidade foi nove, sendo que a nota de corte maior ou igual a 11 não altera a sensibilidade, já a partir de 12 aumenta a sensibilidade em $9 \%$, ou seja, quanto maior a pontuação, menor a probabilidade do indivíduo ser diagnosticado com TNM, assim como nota menor ou igual a oito, aumenta em 3\% a especificidade, aumentando as chances do indivíduo possuir TNM.

Tabela 6 - Valores de sensibilidade e especificidade expressa em porcentagem por ponto de corte para a pontuação no MoCA de uma amostra de indivíduos com TNM e sem TNC, submetidos ao teste. Ribeirão Preto, 2020.

\begin{tabular}{llllllllll}
\hline Ponto de corte & $<\mathbf{5}$ & $\mathbf{< 6}$ & $\mathbf{<}$ & $\mathbf{< 8}$ & $\mathbf{< 9}$ & $\mathbf{< 1 0}$ & $<\mathbf{1 1}$ & $<\mathbf{1 2}$ & $<\mathbf{1 3}$ \\
\hline Sensibilidade (\%) & $25 \%$ & $50 \%$ & $58 \%$ & $58 \%$ & $83 \%$ & $83 \%$ & $83 \%$ & $92 \%$ & $92 \%$ \\
Especificidade (\%) & $100 \%$ & $100 \%$ & $100 \%$ & $98 \%$ & $95 \%$ & $90 \%$ & $86 \%$ & $85 \%$ & $80 \%$ \\
\hline
\end{tabular}


A figura 4, por sua vez, apresenta a curva ROC relativa ao MoCA, considerando-se os grupos de idosos sem TNC e com TNL. A área da curva foi de 0,753 ( $p<0,001$; IC95\%: 0,654-0,853), sendo considerada regular (METZ, 1978).

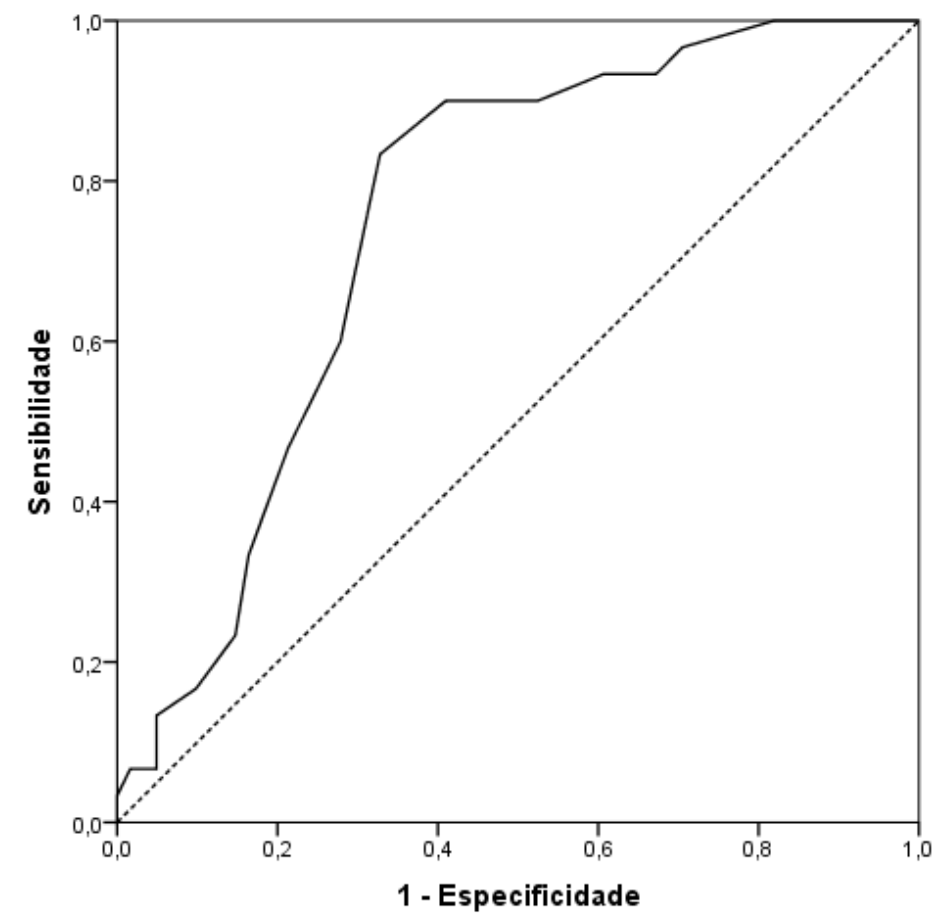

Figura 4 - Curva ROC do MoCA tendo-se como referência os grupos sem TNC e com TNL.

A Tabela 7 apresenta os valores de sensibilidade e especificidade referente a diferentes pontos do MoCA entre os grupos sem TNC e com TNL. O ponto de corte que apresenta melhor equilíbrio entre a sensibilidade e especificidade foi 16. Isto implica em considerar a presença do TNL em sujeitos que apresentem uma pontuação abaixo ou igual 16. A sensibilidade em valores a partir de 17 fica em 90\%, mas a especificidade fica em $60 \%$.

Tabela 7 - Valores de sensibilidade e especificidade expressa em porcentagem por ponto de corte para a pontuação no MoCA de uma amostra de indivíduos com TNL e sem TNC, submetidos ao teste. Ribeirão Preto, 2020.

\begin{tabular}{llllllllll}
\hline Ponto de corte & $<\mathbf{1 2}$ & $\mathbf{< 1 3}$ & $\mathbf{< 1 4}$ & $\mathbf{< 1 5}$ & $\mathbf{< 1 6} *$ & $<\mathbf{1 7}$ & $<\mathbf{1 8}$ & $<\mathbf{1 9}$ & $<\mathbf{2 0}$ \\
\hline Sensibilidade (\%) & $33 \%$ & $47 \%$ & $50 \%$ & $60 \%$ & $83 \%$ & $90 \%$ & $90 \%$ & $90 \%$ & $93 \%$ \\
Especificidade (\%) & $84 \%$ & $79 \%$ & $77 \%$ & $73 \%$ & $68 \%$ & $60 \%$ & $53 \%$ & $48 \%$ & $40 \%$ \\
\hline
\end{tabular}


A figura 5 apresenta a curva ROC relativa ao MoCA, considerando os dois grupos clínicos em contraste, os indivíduos com TNL e os com TNM. A área sob a curva foi de 0,876 ( $\mathrm{p}<0,001$; IC95\% 0,727 - 1,025); sendo considerada como boa (METZ, 1978).

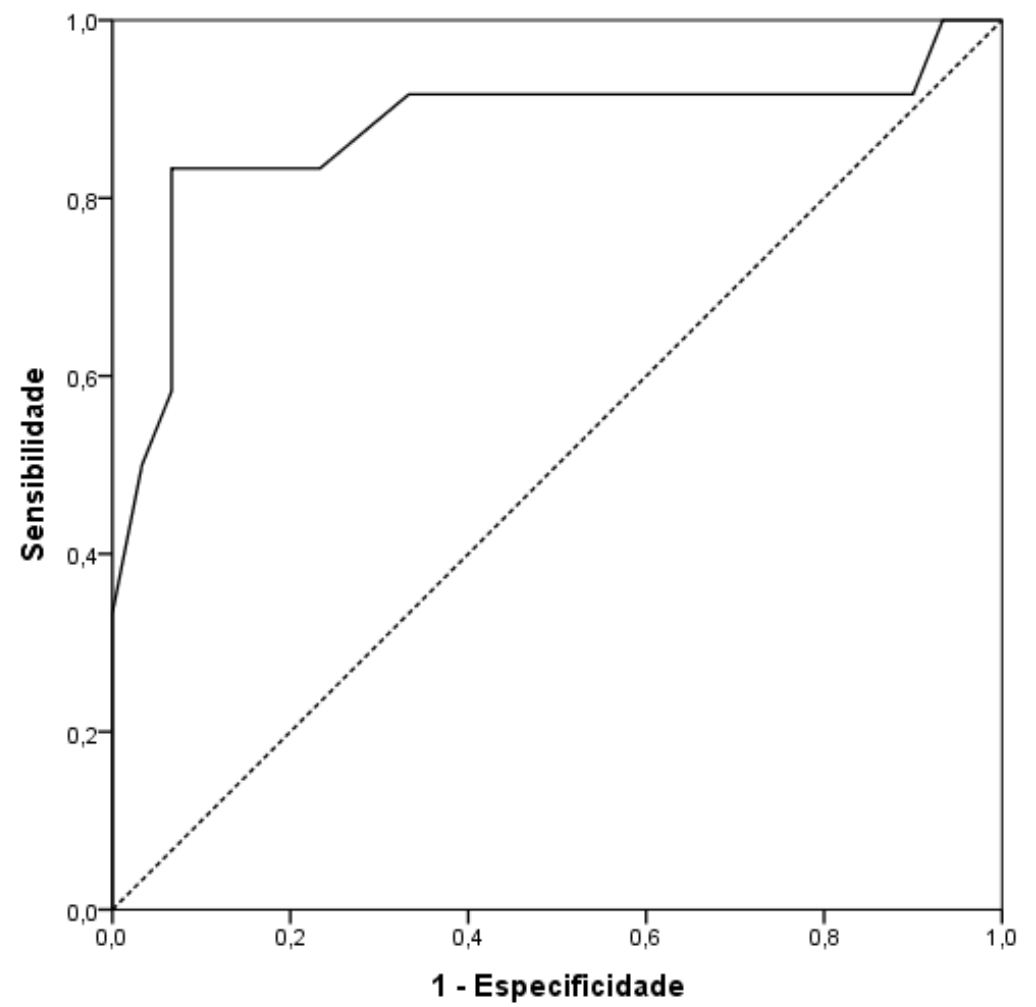

Figura 5 - Curva ROC do MoCA tendo-se como referência os grupos com TNL e com TNM.

A tabela 8 , por sua vez, traz os valores de sensibilidade e especificidade referente a diferentes pontos de corte do MoCA para discriminar indivíduos com TNL e com TNM. O ponto de corte que apresenta melhor equilíbrio entre a sensibilidade e especificidade foi oito. Notas de corte nove e dez não altera a sensibilidade. Apenas a partir de 12 ocorre aumento na sensibilidade, que passa a ser de $92 \%$. Notas de corte menores que oito aumentam a especificidade, mas comprometem a sensibilidade.

Tabela 8 - Valores de sensibilidade e especificidade expressa em porcentagem por ponto de corte para a pontuação no MoCA de uma amostra de indivíduos com TNL e com TNM submetidos ao teste. Ribeirão Preto, 2020.

\begin{tabular}{lllllllllll}
\hline Ponto de corte & $<4$ & $<5$ & $<6$ & $<7$ & $<\mathbf{8}^{*}$ & $<\mathbf{9}$ & $<\mathbf{1 0}$ & $<\mathbf{1 1}$ & $<\mathbf{1 2}$ \\
\hline Sensibilidade (\%) & $25 \%$ & $33 \%$ & $50 \%$ & $58 \%$ & $83 \%$ & $83 \%$ & $83 \%$ & $83 \%$ & $92 \%$ \\
Especificidade (\%) & $100 \%$ & $100 \%$ & $97 \%$ & $93 \%$ & $93 \%$ & $87 \%$ & $83 \%$ & $77 \%$ & $67 \%$
\end{tabular}


Já a figura 6 traz dados da validade discriminativa do MoCA relativos à comparação entre o grupo sem TNC e os dois grupos clínicos - com algum TNC (portadores de TNL ou TNM). A área sob a curva ROC teve um valor de 0,800 ( $\mathrm{p}<0,001 ; \mathrm{IC} 95 \% 0,716-0,884$ ). Conclui-se que é boa (METZ, 1978).

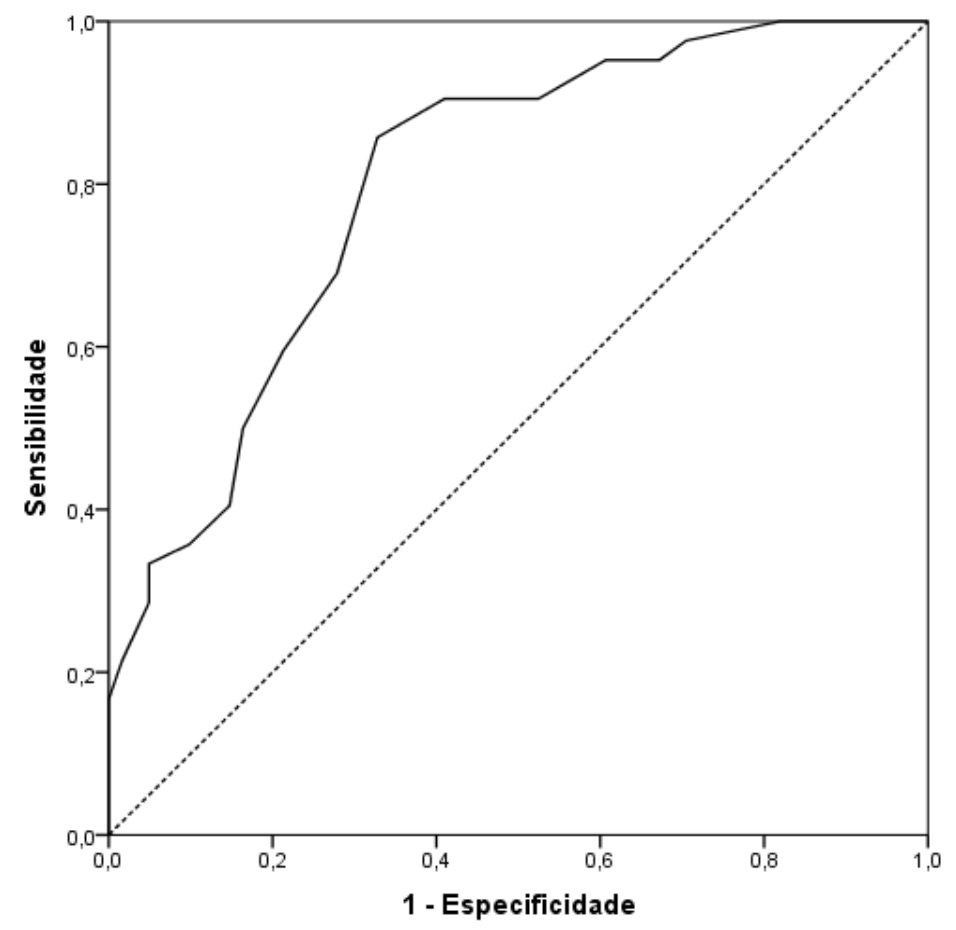

Figura 6 - Curva ROC do MoCA tendo-se como referência os grupos sem TNC e com algum TNC (TNL ou TNM).

A tabela 9 traz os valores de sensibilidade e especificidade de pontos de corte do MoCA para discriminar indivíduos sem TNC e os com algum TNC (TNL ou TNM). O ponto de corte que apresenta melhor equilíbrio entre a sensibilidade e especificidade foi 16 . A escolha como nota de corte do valor 17 aumenta a sensibilidade em 5\%. Notas de corte menores que 16 aumentam a especificidade, em $4 \%$ para o valor de 15 , mas comprometem a sensibilidade.

Tabela 9 - Valores de sensibilidade e especificidade expressa em porcentagem por ponto de corte para a pontuação no MoCA de uma amostra submetida ao teste para discriminar indivíduos sem TNC de indivíduos com algum TNC (TNM ou TNL). Ribeirão Preto, 2020.

\begin{tabular}{llllllllll}
\hline Ponto de corte & $<\mathbf{1 2}$ & $\mathbf{< 1 3}$ & $\mathbf{< 1 4}$ & $\mathbf{< 1 5}$ & $\mathbf{< 1 6}$ & $\mathbf{< 1 7}$ & $<\mathbf{1 8}$ & $<\mathbf{1 9}$ & $<\mathbf{2 0}$ \\
\hline Sensibilidade (\%) & $51 \%$ & $58 \%$ & $61 \%$ & $68 \%$ & $85 \%$ & $90 \%$ & $90 \%$ & $90 \%$ & $95 \%$ \\
Especificidade (\%) & $84 \%$ & $78 \%$ & $76 \%$ & $71 \%$ & $67 \%$ & $59 \%$ & $52 \%$ & $48 \%$ & $40 \%$ \\
\hline
\end{tabular}


A figura 7 mostra a curva ROC para o MoCA, considerando em contraste o grupo com TNM e o grupo de indivíduos sem TNM, formado pelos outros dois grupos (portadores de TNL e sem TNC). A área sob a curva ROC foi de 0,914 ( $\mathrm{p}<0,001$; IC 95\% 0,807 - 1,021) sendo, portanto, considerada excelente (METZ, 1978).

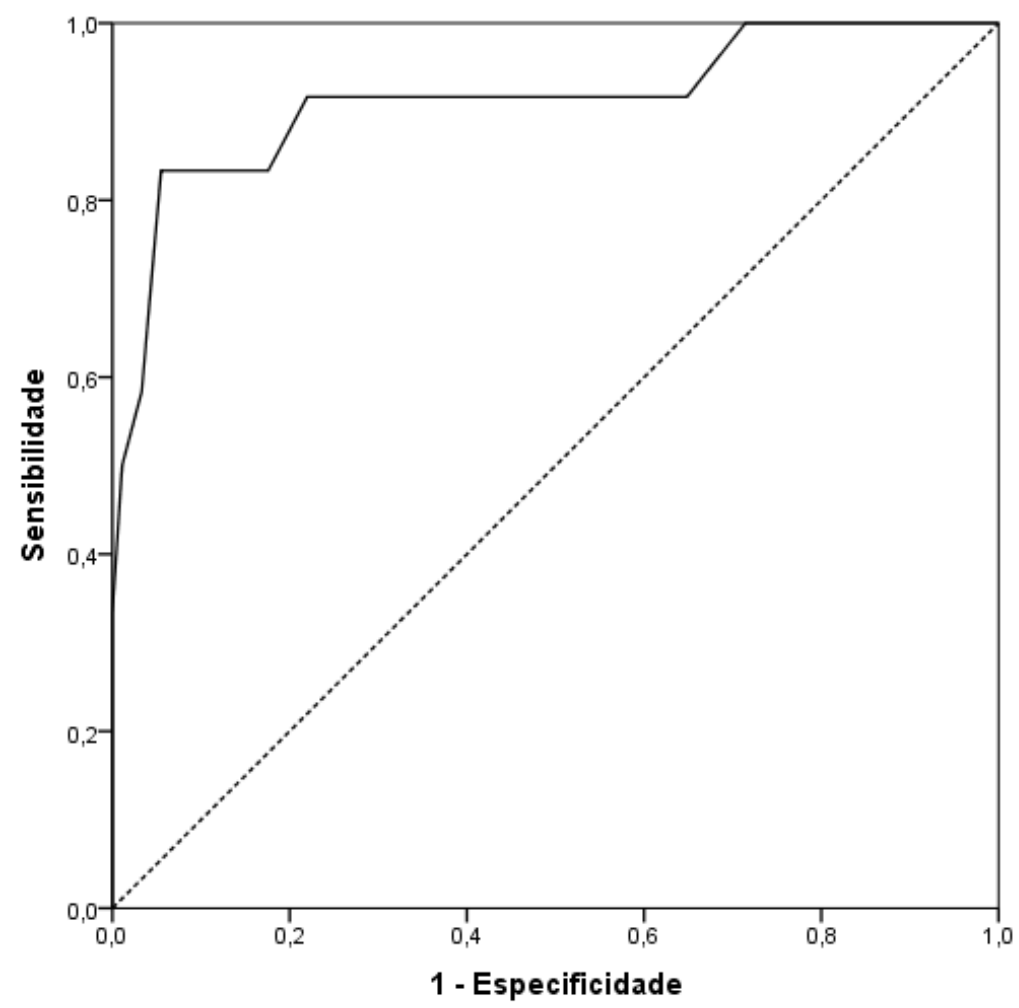

Figura 7 - Curva ROC do MoCA tendo-se como referência o grupo de indivíduos com TNM e um grupo sem TNM (indivíduos com TNL e sem TNC).

A tabela 10 explicita os achados para a sensibilidade e especificidade referente a diferentes pontos de corte do MoCA para discriminar indivíduos com TNM e o restante dos indivíduos (com TNL ou sem TNC). O ponto de corte que apresenta melhor equilíbrio entre a sensibilidade e especificidade foi oito. Notas de corte 9 e 10 não alteram a sensibilidade. Apenas a partir de 12 ocorre aumento na sensibilidade, que passa a ser de 92\%. Notas de corte menores que oito aumentam a especificidade, mas comprometem a sensibilidade.

Tabela 10 - Valores de sensibilidade e especificidade expressa em porcentagem por ponto de corte para a pontuação no MoCA de uma amostra para discriminar indivíduos com TNM e o restante (sem TNC ou com TNL) submetidos ao teste. Ribeirão Preto, 2020.

\begin{tabular}{lllllllllll}
\hline Ponto de corte & $<4$ & $<5$ & $<6$ & $<7$ & $<8 *$ & $<9$ & $<10$ & $<\mathbf{1 1}$ & $<\mathbf{1 2}$ \\
\hline Sensibilidade (\%) & $25 \%$ & $33 \%$ & $50 \%$ & $58 \%$ & $83 \%$ & $83 \%$ & $83 \%$ & $83 \%$ & $91 \%$ \\
Especificidade (\%) & $100 \%$ & $100 \%$ & $99 \%$ & $97 \%$ & $95 \%$ & $92 \%$ & $88 \%$ & $82 \%$ & $78 \%$
\end{tabular}


A figura 8 apresenta a curva ROC relativo ao MoCA basic apresentando a validade discriminativa entre os grupos sem TNC e com TNM. A área sob a curva foi de 0,910 ( $\mathrm{p}<0,001$; IC95 \% 0,818-1.002), sendo considerada excelente (METZ, 1978).

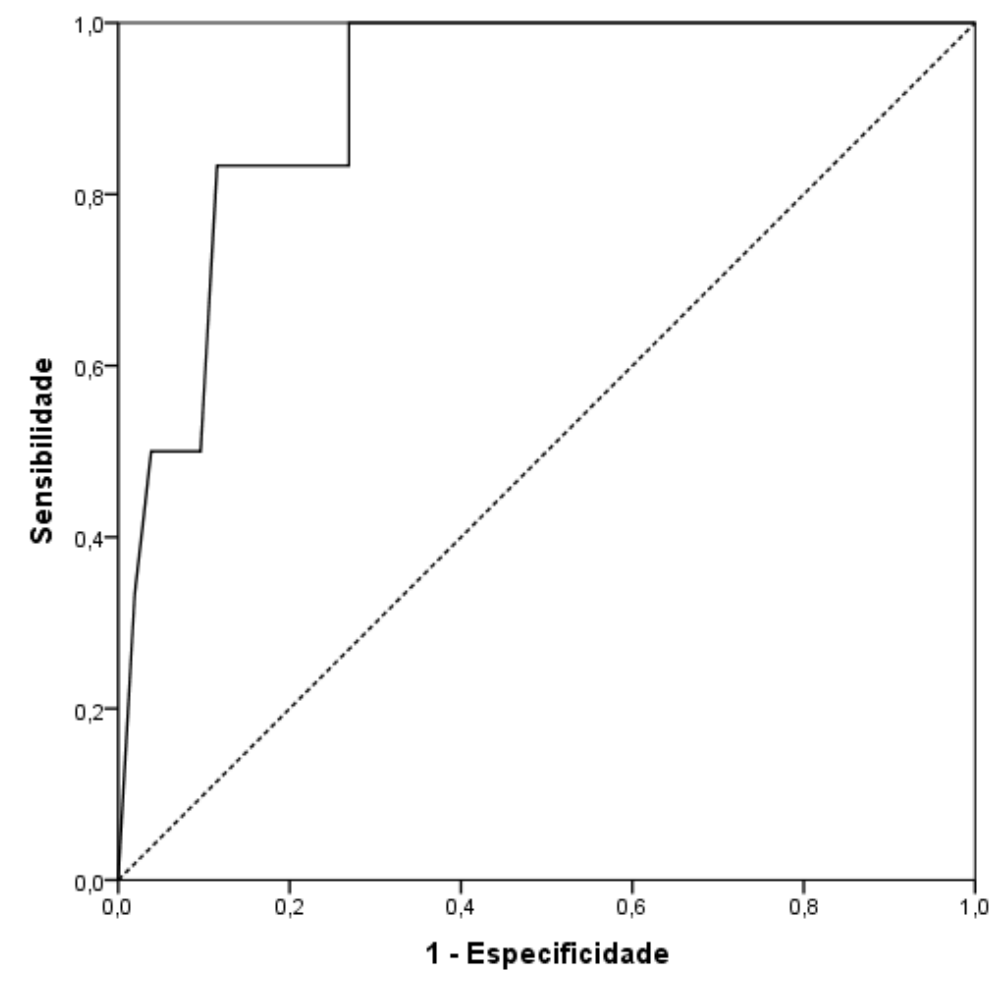

Figura 8 - Curva ROC do MoCA basic tendo-se como referência os grupos sem TNC e com TNM.

Na tabela 11, estão os valores de sensibilidade e especificidade para os diferentes pontos de corte de acordo com o escore no MoCA basic para discriminar os grupos de indivíduos sem TNC e os com TNM. O ponto de corte sugerido para discriminar os grupos é 21, pois é o que concilia melhor equilíbrio entre sensibilidade e especificidade. Adotar um ponto de corte acima de 21 não aumenta a sensibilidade, mas reduz a especificidade. Pontos de corte mais baixos trazem ganho para especificidade, mas de apenas $2 \%$ com a pontuação 19, com diminuição da sensibilidade.

Tabela 11 - Valores de sensibilidade e especificidade expressa em porcentagem por ponto de corte para a pontuação no MoCA basic de uma amostra de indivíduos com sem TNC e com TNM. Ribeirão Preto, 2020.

\begin{tabular}{llllllllll}
\hline Ponto de corte & $\mathbf{1 7}$ & $\mathbf{< 1 8}$ & $\mathbf{< 1 9}$ & $\mathbf{< 2 0}$ & $\mathbf{< 2 1} *$ & $\mathbf{2 2}$ & $\mathbf{< 2 3}$ & $<\mathbf{2 4}$ & $<\mathbf{2 5}$ \\
\hline Sensibilidade (\%) & $83 \%$ & $83 \%$ & $83 \%$ & $83 \%$ & $100 \%$ & $100 \%$ & $100 \%$ & $100 \%$ & $100 \%$ \\
Especificidade (\%) & $88 \%$ & $84 \%$ & $74 \%$ & $72 \%$ & $72 \%$ & $60 \%$ & $51 \%$ & $41 \%$ & $33 \%$ \\
\hline
\end{tabular}


A figura 9 por sua vez, apresenta a curva ROC relativa ao MoCA basic, considerandose os grupos de idosos sem TNC e com TNL. A área da curva foi de 0,834 ( $\mathrm{p}<0,001$; IC95\%: 0,742 - 0,927), sendo considerada boa (METZ, 1978).

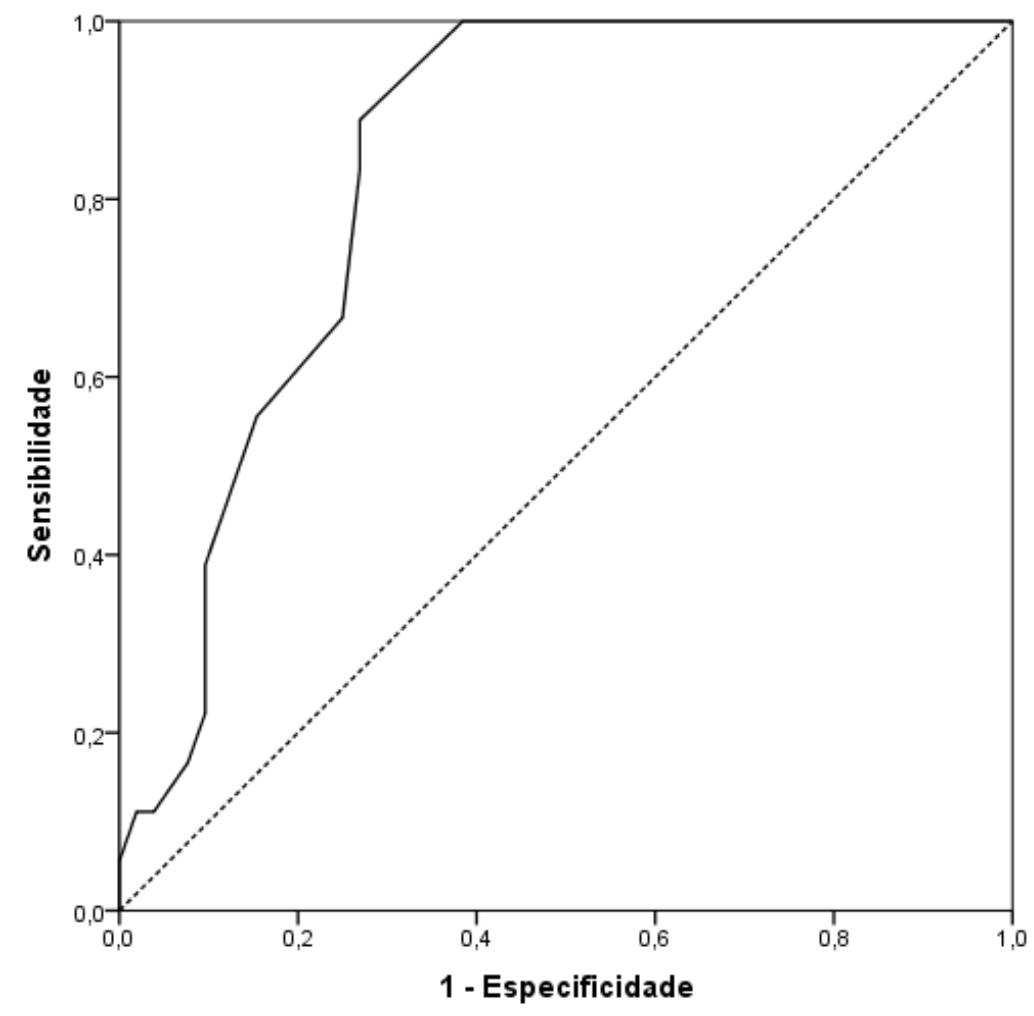

Figura 9 - Curva ROC do MoCA basic tendo-se como referência os grupos sem TNC e com TNL.

A Tabela 12 apresenta os valores de sensibilidade e especificidade referente a diferentes pontos do MoCA basic entre os grupos sem TNC e com TNL. O ponto de corte que apresenta melhor equilíbrio entre a sensibilidade e especificidade foi 21 . Isto implica em considerar a presença do TNL em sujeitos que apresentem uma pontuação abaixo ou igual 21. A sensibilidade em valores a partir de 22 fica em 100\%, mas a especificidade fica em $61 \%$.

Tabela 12 - Valores de sensibilidade e especificidade expressa em porcentagem por ponto de corte para a pontuação no MoCA basic de uma amostra de indivíduos com TNL e sem TNC. Ribeirão Preto, 2020.

\begin{tabular}{llllllllll}
\hline Ponto de corte & $<\mathbf{1 7}$ & $\mathbf{< 1 8}$ & $\mathbf{< 1 9}$ & $\mathbf{< 2 0}$ & $\mathbf{< 2 1}$ & $\mathbf{2 2 2}$ & $\mathbf{< 2 3}$ & $\mathbf{< 2 4}$ & $<\mathbf{2 5}$ \\
\hline Sensibilidade (\%) & $44 \%$ & $56 \%$ & $67 \%$ & $83 \%$ & $89 \%$ & $100 \%$ & $100 \%$ & $100 \%$ & $100 \%$ \\
Especificidade (\%) & $88 \%$ & $84 \%$ & $74 \%$ & $72 \%$ & $72 \%$ & $61 \%$ & $51 \%$ & $41 \%$ & $33 \%$ \\
\hline
\end{tabular}


A figura 10 apresenta a curva ROC relativa ao MoCA basic, considerando os dois grupos clínicos em contraste, os indivíduos com TNL e os com TNM. A área sob a curva foi de 0,671 ( $\mathrm{p}=$ 0,199; IC95\% 0,410 - 0,932); sendo considerada como ruim (METZ, 1978).

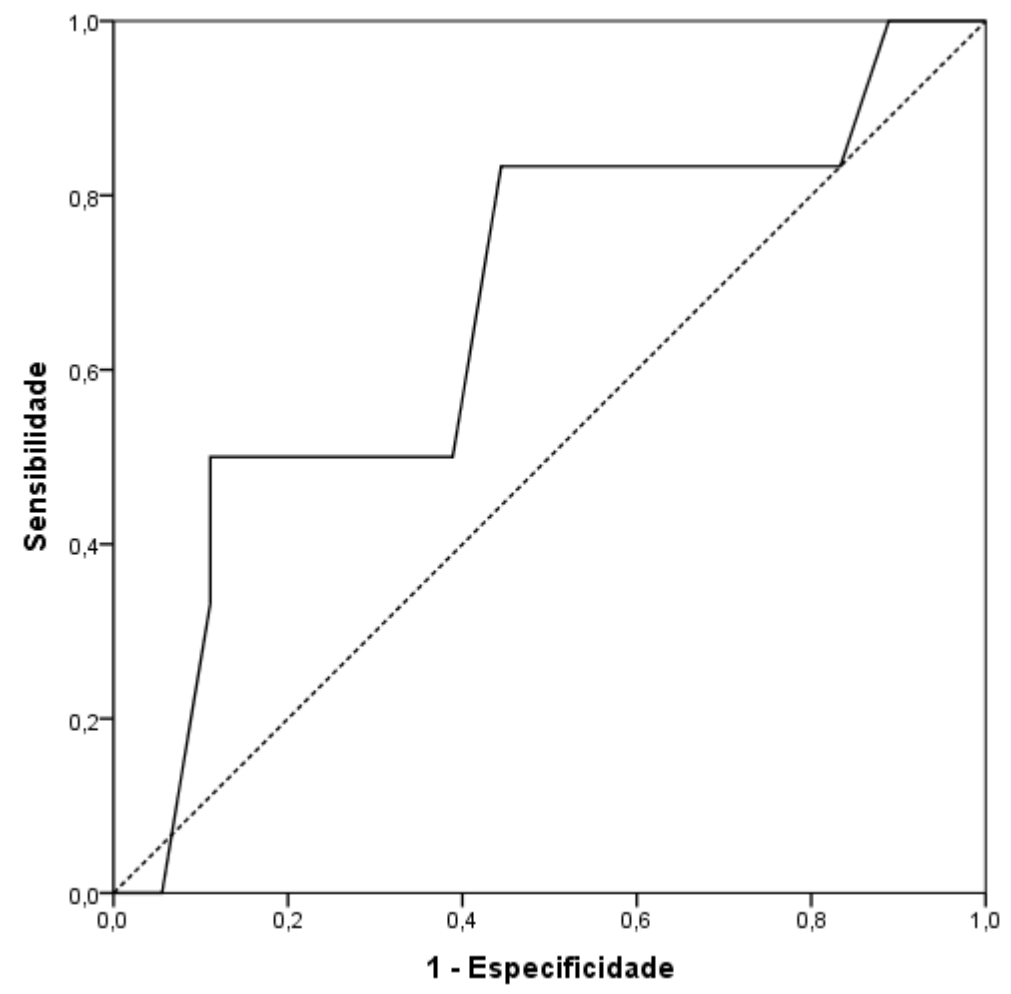

Figura 10 - Curva ROC do MoCA basic tendo-se como referência os grupos com TNL e com TNM.

A tabela 13 mostra os valores de sensibilidade e especificidade para a validade discriminativa do MoCA basic para indivíduos com TNL e com TNM. O ponto de corte que apresenta melhor equilíbrio entre a sensibilidade e especificidade foi 17. Notas de corte mais altas não alteram a sensibilidade, apenas para valor de corte a partir de 22, que passa a ser de 100\%. Notas de corte menores que 17 aumentam a especificidade em 5\% para a pontuação de 16, mas comprometem a sensibilidade.

Tabela 13 - Valores de sensibilidade e especificidade expressa em porcentagem por ponto de corte para a pontuação no MoCA basic de uma amostra de indivíduos com TNL e com TNM submetidos aos testes. Ribeirão Preto, 2020.

\begin{tabular}{|c|c|c|c|c|c|c|c|c|c|}
\hline Ponto de corte & $<13$ & $<14$ & $<15$ & $<16$ & $<17 *$ & $<18$ & $<19$ & $<20$ & $<21$ \\
\hline Sensibilidade (\%) & $50 \%$ & $50 \%$ & $50 \%$ & $50 \%$ & $83 \%$ & $83 \%$ & $83 \%$ & $83 \%$ & $100 \%$ \\
\hline Especificidade (\%) & $89 \%$ & $89 \%$ & $78 \%$ & $61 \%$ & $56 \%$ & $44 \%$ & $33 \%$ & $17 \%$ & $11 \%$ \\
\hline
\end{tabular}


Já a figura 11 traz dados da validade discriminativa do MoCA relativo à comparação entre o grupo sem TNC e os dois grupos clínicos - com algum TNC (portadores de TNL ou TNM). A área sob a curva ROC teve um valor de 0,853 ( $\mathrm{p}<0,001 ; \mathrm{IC} 95 \% 0,770-0,936$ ). Conclui-se que é boa (METZ, 1978).

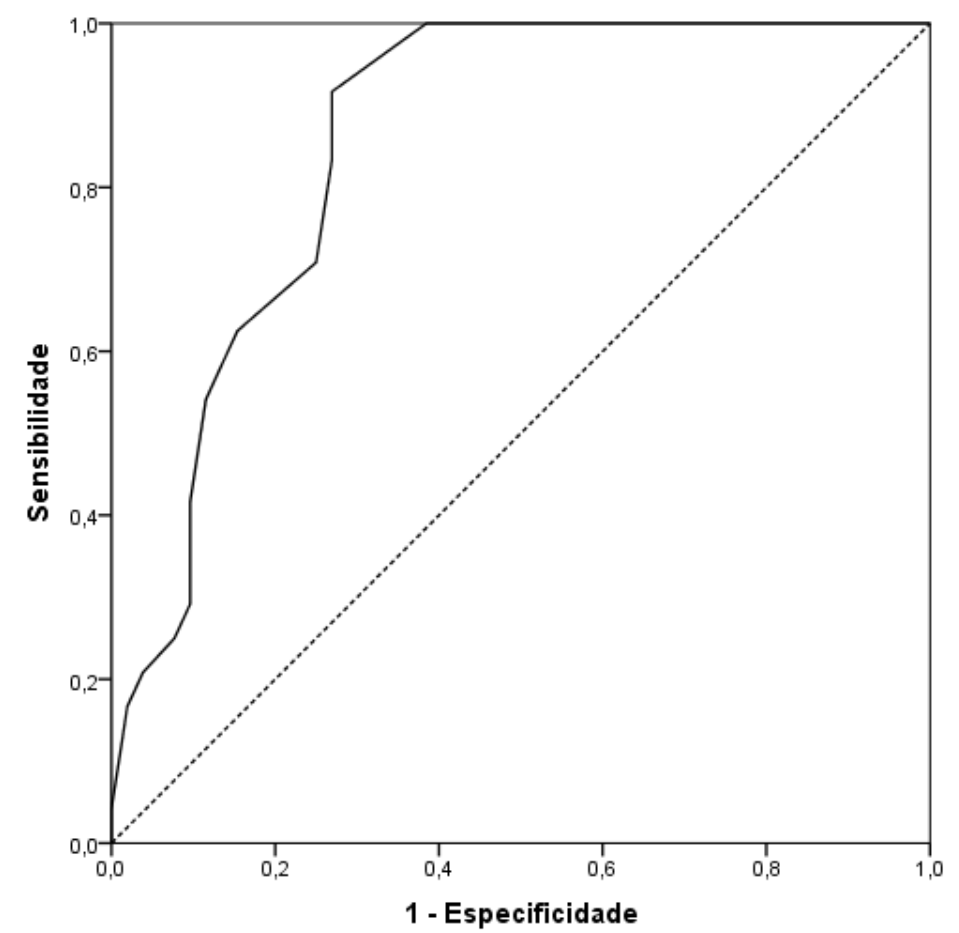

Figura 11 - Curva ROC do MoCA basic tendo-se como referência os grupos sem TNC e com algum TNC (TNL ou TNM).

Na Tabela 14 são mostrados os valores de sensibilidade e especificidade de pontos de corte do MoCA para discriminar indivíduos sem TNC e os com algum TNC (TNL ou TNM). O ponto de corte que apresenta melhor equilíbrio entre a sensibilidade e especificidade foi 21 . A escolha como nota de corte do valor 22 aumenta a sensibilidade em 8\%, mas a especificidade diminui $11 \%$. Notas de corte menores que 21 aumentam a especificidade, em $2 \%$ para o valor de 19 , mas comprometem a sensibilidade.

Tabela 14 - Valores de sensibilidade e especificidade expressa em porcentagem por ponto de corte para a pontuação no MoCA basic de uma amostra de indivíduos sem TNC e com algum TNC (TNM ou TNL) submetidos ao teste. Ribeirão Preto, 2020.

\begin{tabular}{|c|c|c|c|c|c|c|c|c|c|}
\hline Ponto de corte & $<17$ & $<\mathbf{1 8}$ & $<19$ & $<\mathbf{2 0}$ & $<21 *$ & $<22$ & $<23$ & $<24$ & $<25$ \\
\hline Sensibilidade (\%) & $54 \%$ & $62 \%$ & $71 \%$ & $83 \%$ & $92 \%$ & $100 \%$ & $100 \%$ & $100 \%$ & $100 \%$ \\
\hline Especificidade (\%) & $88 \%$ & $85 \%$ & $74 \%$ & $72 \%$ & $72 \%$ & $61 \%$ & $51 \%$ & $41 \%$ & $33 \%$ \\
\hline
\end{tabular}


Por último, a figura 12 mostra a curva ROC para o MoCA basic relativo à comparação entre o grupo de indivíduos com TNM e o grupo de indivíduos sem TNM (sem TNC e com TNL). A área sob a curva ROC foi de 0,848 ( $\mathrm{p}<0,001$; IC 95\% 0,720 - 0,976) sendo, portanto, considerada como boa (METZ, 1978).

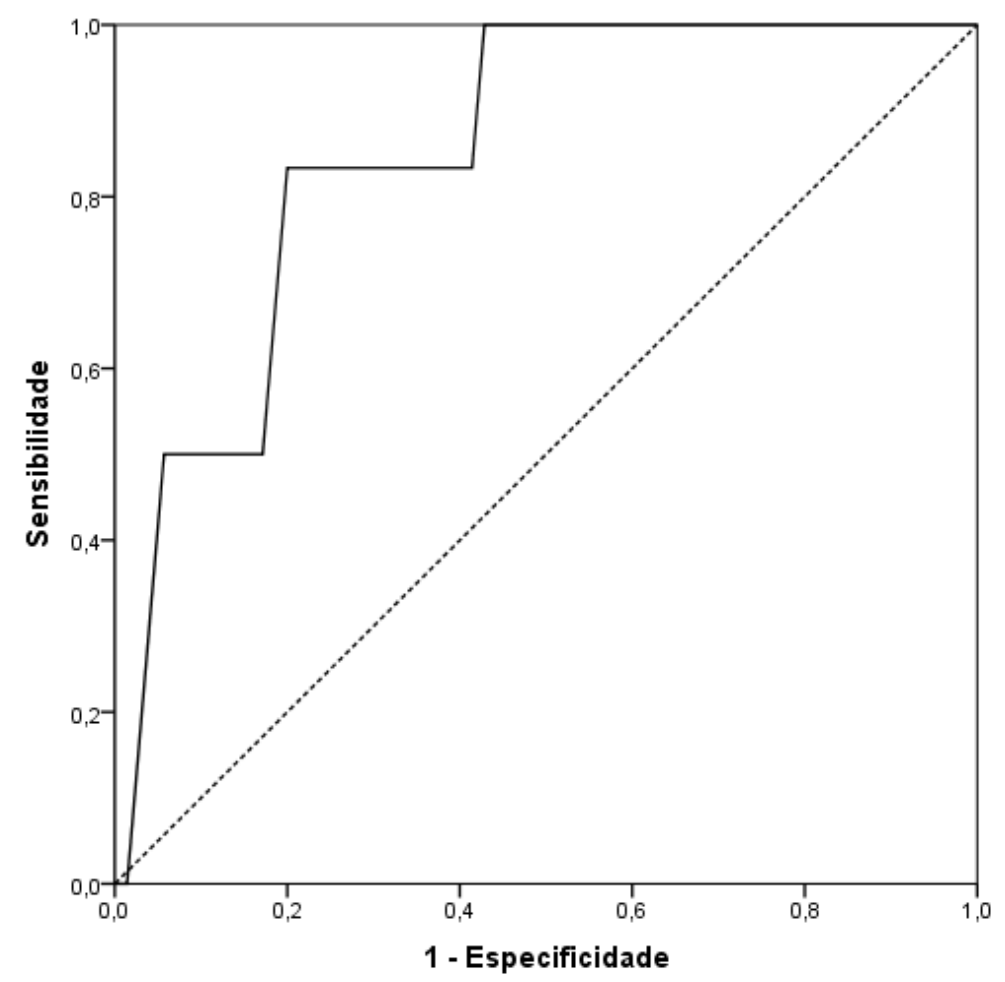

Figura 12 - Curva ROC do MoCA basic tendo-se como referência o grupo de indivíduos com TNM e um grupo composto por indivíduos sem TNM (com TNL e sem TNC).

Por último, a tabela 15 mostra os resultados de sensibilidade e especificidade para os diferentes pontos de corte adotados para discriminar o grupo dos indivíduos com TNM e o grupo do restante dos indivíduos, isto é, aqueles sem TNC ou com TNL. O ponto de corte sugerido é de 17 , pois é o que concilia melhor a sensibilidade e especificidade. Notas de corte 18 e 19 não alteram a sensibilidade. Apenas a partir de 21 ocorre aumento na sensibilidade, que passa a ser de $100 \%$. Notas de corte menores que 17 aumentam pouco a especificidade e comprometem mais a sensibilidade.

Tabela 15 - Valores de sensibilidade e especificidade expressa em porcentagem por ponto de corte para a pontuação no MoCA basic de uma amostra para discriminação de indivíduos com TNM e o restante (sem TNC ou com TNL) submetidos ao teste. Ribeirão Preto, 2020.

\begin{tabular}{llllllllll}
\hline Ponto de corte & $\mathbf{1 3}$ & $\mathbf{< 1 4}$ & $\mathbf{< 1 5}$ & $\mathbf{< 1 6}$ & $\mathbf{< 1 7} *$ & $\mathbf{< 1 8}$ & $\boldsymbol{< 1 9}$ & $<\mathbf{2 0}$ & $<\mathbf{2 1}$ \\
\hline Sensibilidade (\%) & $50 \%$ & $50 \%$ & $50 \%$ & $50 \%$ & $83 \%$ & $83 \%$ & $83 \%$ & $83 \%$ & $100 \%$ \\
Especificidade (\%) & $94 \%$ & $90 \%$ & $87 \%$ & $83 \%$ & $80 \%$ & $74 \%$ & $64 \%$ & $58 \%$ & $56 \%$
\end{tabular}


A validade convergente para os testes neurocognitivos de rastreio de declínio cognitivo MoCA e MoCA basic foi calculado através do coeficiente de correlação ("rô") de Spearman, comparando-se os escores do MEEM e de cada teste. Para o MoCA o coeficiente foi de $\mathrm{r}=0,698(\mathrm{p}<0,01)$ e para o MoCA basic de $\mathrm{r}=0,647(\mathrm{p}<0,01)$. Para ambos a correlação é considerada como moderada.

A figura 13 e a figura 14 mostram a correlação dos escores de desempenho do MoCA e do MoCA basic, respectivamente, com os escores do MEEM de todos os participantes avaliados.

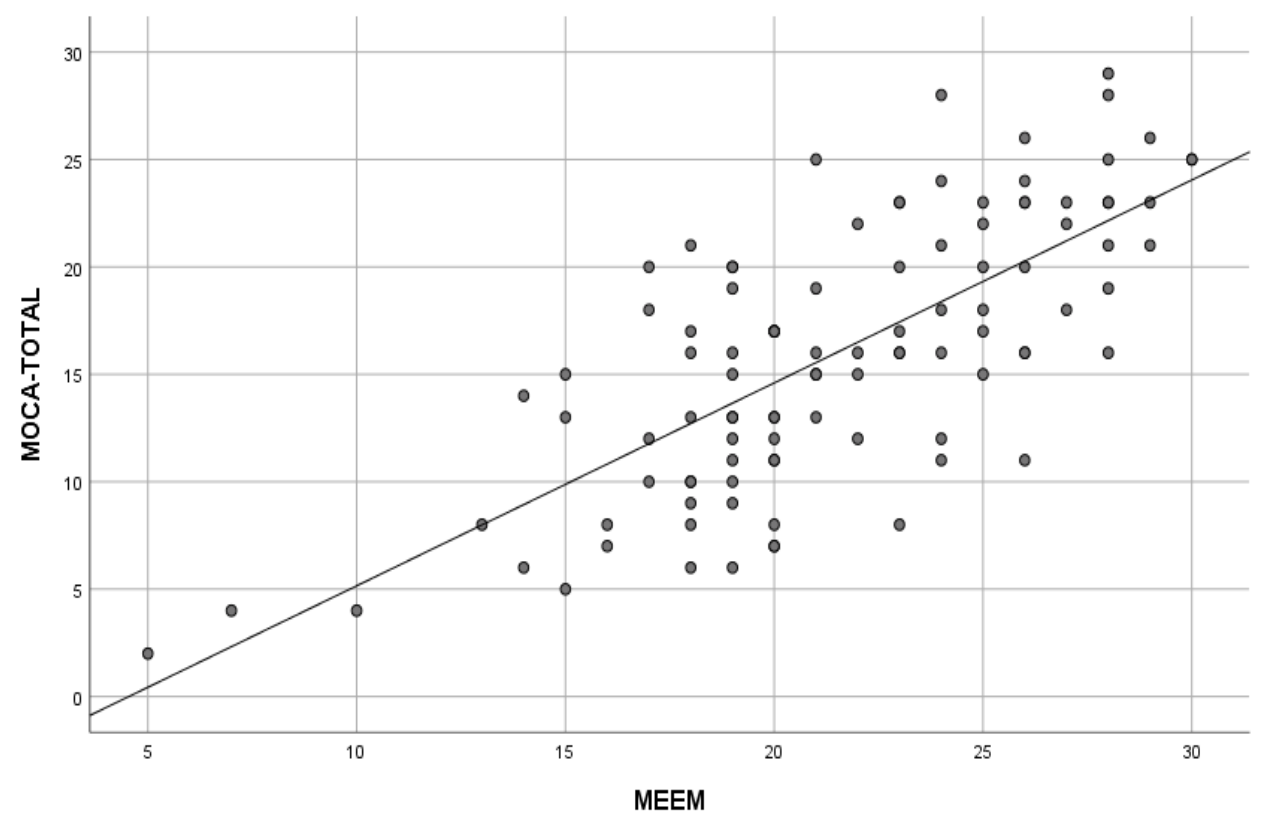

Figura 13. Gráfico de dispersão dos escores totais no MoCA em relação aos escores totais no MEEM em toda amostra de idosos avaliados. 


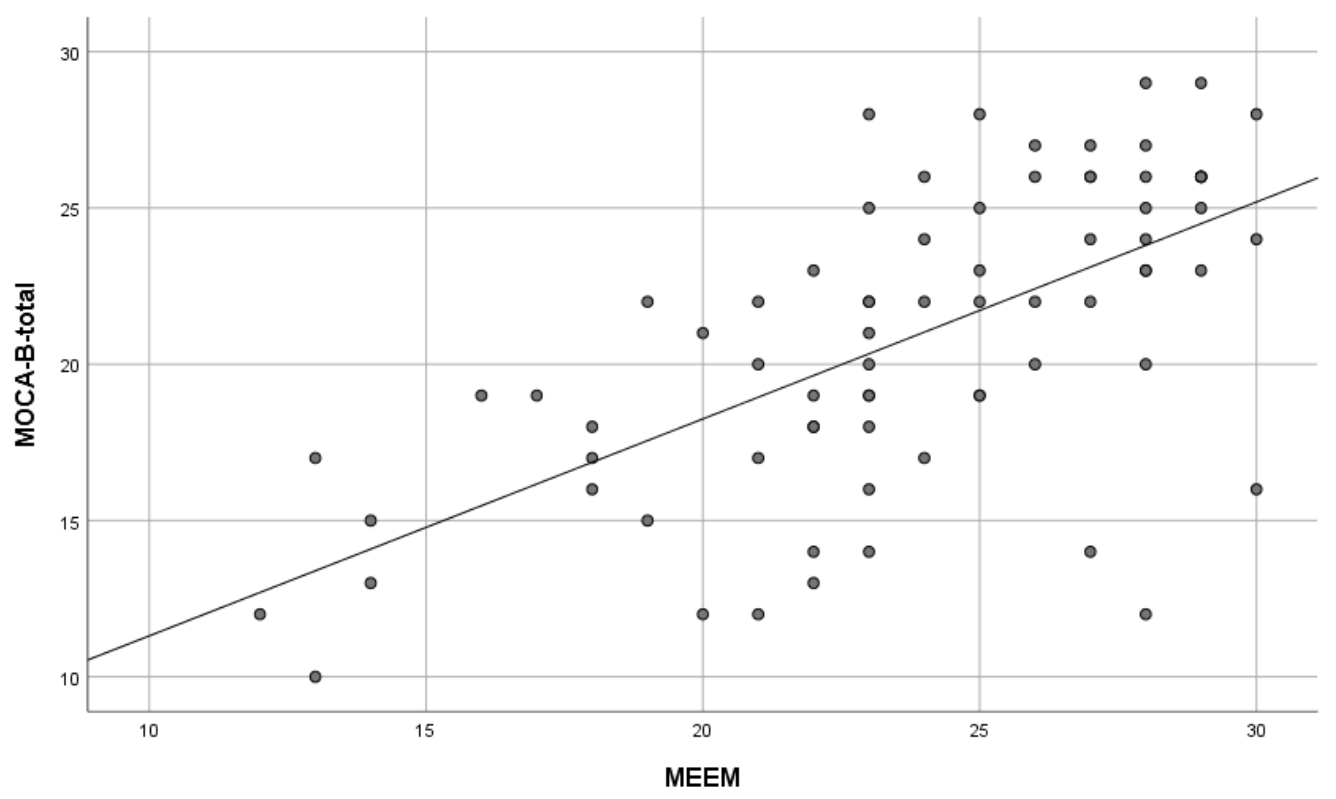

Figura 14. Gráfico de dispersão dos escores totais no MoCA basic em relação aos escores totais no MEEM em toda amostra de idosos avaliados. 


\section{DISCUSSÃ̃}

\section{$\underline{\text { Dados sociodemográficos }}$}

Como mostrado na tabela 2, a nossa amostra caracterizou-se como predominante composta de mulheres, aposentados, de baixa escolaridade e renda; e com média de idade de 70 anos.

O perfil demográfico dos idosos no Brasil é marcado pela predominância de mulheres, evento conhecido como feminização do envelhecimento. De acordo com o último censo populacional de 2010, na parcela da população com mais de 60 anos de idade, as mulheres destacaram os homens não apenas na quantidade total de população (mulheres: 11.438.701 e homens: 9.150.180), mas também em cada 5 intervalos de cinco anos examinados (IBGE 2011). A expectativa de vida é maior para as mulheres como resultado da mortalidade por sexo, uma vez que os homens têm maior mortalidade nas idades mais jovens de suas vidas, principalmente devido a mortes violentas. Os mesmos resultados foram encontrados em populações idosas de outras cidades brasileiras em estudos semelhantes (CAMPOS; GONÇALVES, 2018; SILVA; DAL PRÁ, 2014).

A média de idade de nossa população de idosos foi de 70 anos, com predomínio de indivíduos nas três faixas etárias mais jovens (60-64; 65-69; 70-75 anos). O mesmo ocorre para a população brasileira (IBGE, 2015). A expectativa de vida aumentou em todo o mundo. Segundo dados do Banco Mundial, a expectativa de vida é de 72 anos para todo o mundo e, no Brasil, o indicador é de 76 anos (THE WORLD BANK GROUP, 2018). Esse incremento de anos na expectativa de vida se deve a quedas nas taxas de mortalidade, resultado direto das melhorias nas condições gerais de vida e também dos avanços da medicina e dos cuidados de saúde (BATISTA; ALMEIDA; LANCMAN, 2011).

O maior número de aposentados está dentro do esperado para esse segmento etário da população brasileira, uma vez que, de acordo com os requisitos de seguridade social, a maioria dos indivíduos com mais de 60 anos é elegível para a aposentadoria (com base na idade ou no número de anos de trabalho). Conforme relatado por Pilger, Menon, e Mathias (2011), o número de idosos que auferem qualquer tipo de benefício financeiro previdenciário atinge $76,8 \%$, valor próximo ao encontrado neste estudo. Por outro lado, 29,52\% da amostra 
foi encontrada como não aposentada, o que é uma tendência recente de mudança no status de trabalho do idoso, como demonstrado em outros estudos e informações do último censo que sinalizou queda no número de idosos que recebem benefícios de seguridade social ao longo dos anos (caiu de $62,7 \%$ para 53,8\%, enquanto a participação no contingente de trabalho de indivíduos de 60 a 64 anos aumentou de 47,6\% para 52,3 \%) (IBGE, 2016; PILGER; MENON; MATHIAS, 2011).

Foi encontrada predominância de baixo nível educacional, com a maioria de analfabetos ou tendo até 4 anos de estudo com média de 3 anos de escolaridade. Apesar das melhorias nos indicadores educacionais do Brasil, os níveis de analfabetismo ou baixa educação formal nos idosos permanecem altos e sabe-se que metade da população idosa urbana é atingida pelo analfabetismo funcional (DE ARRUDA; AVANSI, 2014; DI PIERRO, 2008; PERES, 2011). De acordo com dados do Índice de Analfabetos Funcionais, entre todos os analfabetos funcionais 53\% têm 50 anos ou mais (LIMA; MONTENEGRO; CATELLI, 2018). O analfabetismo entre as pessoas com 60 anos ou mais era de 19,3\% em 2017 e 20,4\% em 2016 e quase $42,6 \%$ dos analfabetos do Brasil eram idosos (IBGE, 2010). Entre os fatores possivelmente associados a isso, citam-se as desigualdades sociais do século passado e o baixo acesso ao sistema educacional formal anteriormente e, hoje em dia, a ausência de ações direcionadas ao problema da educação dos idosos (DE ARRUDA; AVANSI, 2014; PERES, 2011; SOUZA, 1999). Taxas semelhantes de baixa escolaridade foram evidenciados em outros estudos semelhantes (BOTTINO et al., 2008; LOPES et al., 2012; SCAZUFCA et al., 2008).

Outro aspecto socioeconômico encontrado em nossa população foi predomínio de renda de até três salários mínimos. Segundo o relatório "Síntese de Indicadores Sociais Uma análise das condições de vida da população brasileira" (IBGE 2019), isto é uma realidade em todo o Brasil e os idosos estão entre os perfis populacionais que estão mais propensos a possuir um rendimento monetário inferior, e piores condições de vida (MELO; FERREIRA; TEIXEIRA, 2014).

Os dados sociodemográficos aqui trazidos dizem respeito a realidade dos idosos de um bairro de periferia da cidade de São Carlos, que, no seu processo de urbanização e crescimento, teve a ocupação dos subúrbios feita principalmente por pessoas pobres, sem acesso à educação e que começaram a trabalhar desde muito jovens. Como resultado, essa mesma população envelheceu se mantendo uma população com baixa escolaridade e baixa renda (DA SILVA, 2005; FERNANDES; CORTÊS, 2000; OSÓRIO; SOUZA JÚNIOR, 
2014). No entanto, quando comparado aos dados sociodemográficos para os idosos do Brasil nossos resultados são semelhantes e representativos.

\section{Prevalência dos transtornos mentais}

É sabido que os distúrbios psiquiátricos, mesmo com prevalências menores comparados as faixas etárias mais jovens, estão entre as doenças mais prevalentes na população idosa (NAUGHTON; BENNETT; FEELY, 2006; REYNOLDS et al., 2015). Estudos epidemiológicos com delineamento transversal são uteis para fornecer informações acerca das prevalências de diversas doenças e assim inferir o perfil de acometimento dos idosos (GILMARTIN-THOMAS; LIEW; HOPPER, 2018; PEARCE, 2012). O presente estudo segue metodologia semelhante a utilizada previamente em outros estudos (GONÇALVES; KAPCZINSKI, 2008; SILVA et al., 2018).

A prevalência de transtornos mentais na população idosa estudada foi alta. Cerca de $55,35 \%$ apresentavam pelo menos um diagnóstico no momento da avaliação. Esta taxa equiparou-se a prevalências encontradas para as doenças mais comuns dessa faixa etária, como Hipertensão Arterial, que chega a mais de 53\% (LEBRÃO; LAURENTI, 2005). A maioria $(38,38 \%)$ foi diagnosticada com apenas um transtorno, enquanto quase $17 \%$ eram portadores de um ou mais transtornos. Os transtornos mais comuns foram por ordem de frequência: os TNC, sendo o TNL mais frequente que o TNM, os transtornos de ansiedade e os transtornos de humor, seguidos de insônia e transtorno do uso de substâncias. Cerca de $73 \%$ dos idosos foram diagnosticados com algum transtorno psiquiátrico em algum momento da vida (atual ou previamente). Os idosos que não apresentaram nenhum histórico de transtorno psiquiátrico foi de aproximadamente $27 \%$ (Tabela 2).

Há alguns estudos que avaliaram especificamente a população idosa como o realizado por Costa et al., (2007). Os autores avaliaram uma população da cidade de Bambuí-MG com mais de 75 anos e encontrou uma prevalência geral no último mês para os transtornos mentais investigados (transtorno depressivos, ansiosos, somatoformes e insônia) de 24,5\%. No estudo "European MentDis-ICF65+" realizado por Andreas et al., (2017), os pesquisadores avaliaram idosos de 65 a 84 anos em diferentes cidades de quatro países europeus (Inglaterra, Espanha, Itália e Alemanha) e mais Israel e Suíça, mas excluíram TNC, aplicando o instrumento Composite International Diagnostic Interview, baseado no DSM-IV. Quase um 
quarto da amostra foi diagnosticada com algum transtorno mental atual (23,3\%, IC 95\% 19,926,7), com as maiores taxas de prevalência encontradas em Genebra $(30,4 \%)$. Excluindo os idosos portadores apenas de TNC (TNL ou TNM), a prevalência geral para algum outro transtorno psiquiátrico atual na nossa amostra seria de $24,13 \%$, próximo aos valores reportados nos dois estudos.

$\mathrm{Na}$ literatura, as prevalências encontradas para os transtornos mentais em idosos em geral são mais baixas que entre os mais jovens, mas os resultados dos estudos são heterogêneos e em sua maioria restritos aos transtornos mais comuns como os depressivos ou ansiosos (VOLKERT et al., 2013). Estudos epidemiológicos mais comumente trazem resultados mostrando uma diminuição de prevalência nos transtornos psiquiátricos como o passar dos anos (MCDOWELL et al., 2014), com as maiores taxas concentrando-se durante a vida adulta, defendendo que a prevalência obedeceria um formato de "U" invertido (REYNOLDS et al., 2015), o que foi encontrado inclusive em estudos no Brasil (ANDRADE et al., 2002a, 2012). No entanto, estudos mais recentes mostram que há um novo aumento sobretudo entre os idosos mais velhos (TAMPUBOLON; MAHARANI, 2017).

Há a possibilidade de que em muitos estudos taxas de transtornos mentais em idosos estejam subestimadas. Críticas são feitas pelo uso de instrumentos que não são adequados para a população idosa (O'CONNOR; PARSLOW, 2009; WITTCHEN et al., 2015); pela não inclusão de todos os diagnósticos nos inquéritos (ANDREAS et al., 2017; REYNOLDS et al., 2015). Há também uma discussão sobre possíveis controvérsias em como as questões de representatividade amostrais foram abordadas em trabalhos epidemiológicos recentes que incluíram idosos com ou sem TNC. Cuidados especiais devem ser tomados no trabalho de campo em populações idosas para evitar a sub-representação da parcela cognitivamente prejudicada em estudos comunitários (RIEDEL-HELLER; BUSSE; ANGERMEYER, 2000).

Altas prevalências de transtornos metais em idosos em geral são encontradas quando se tomam como referência estudos que pesquisam os chamados "transtornos mentais comuns", por exemplo, o estudo de Silva et al., (2018) que relatou uma alta prevalência geral, de 55,8\% e o de Vasconcelos-Rocha et al., (2012) que encontrou a taxa de 32,1\%. Todavia, é importante frisar que este diagnóstico não é baseado nos mesmos critérios dos diagnósticos específicos dos manuais diagnósticos (DSM ou da CID). Trata-se um constructo que engloba um conjunto dimensional e não categórico, baseado na presença de sintomas: incluindo ansiedade, insônia, fadiga, irritabilidade, esquecimento, dificuldade de concentração e queixas somáticas. Este fato aponta para uma questão que é a existência de uma lacuna entre a ocorrência de sintomas clinicamente relevantes e os casos de diagnóstico com base nos 
sistemas de classificação (WITTCHEN et al., 2015). No nosso estudo, pela avaliação ter sido feita por especialistas (equipe de três psiquiatras), muitas queixas que poderiam ter sido consideradas como "subclínicas" foram devidamente exploradas e diagnosticadas. Há uma discussão de que em muitos estudos os idosos atribuem falsamente ansiedade e depressão a doenças médicas gerais e que os manuais diagnósticos utilizados para as entrevistas falham em capturar importantes morbidades psicológicas (O’CONNOR, 2006).

Nossa taxa de idosos que já tiveram algum transtorno mental prévio foi de $17,71 \%$ e com qualquer histórico para algum transtorno mental (atual ou prévio) na vida a parcela da amostra acometida sobe para $52 \%$ e para $73 \%$ se incluídos TNC. Sem contar TNC, nossas taxas foram semelhantes as de Andreas et al., (2017) que reportou taxas de 47\% para pelo menos um transtorno psiquiátrico durante a vida em idosos de 65 a 84 anos, sendo que essa taxa chegou a 55\% na Suíça. Nossas taxas, foram mais altas que as encontradas em outros estudos como no estudo São Paulo Megacity de Andrade et al., (2012). Neste último, para a parcela com mais de 65 anos a taxa de transtorno mental durante a vida foi de apenas $33 \%$. No estudo de Kessler et al., (2005) essa taxa foi de $26 \%$ para os indivíduos com mais de 60 anos, mas para presença de transtornos apenas no último ano.

As diferenças são provavelmente devido a diferenças metodológicas. Nos três estudos citados, estão excluídos idosos que possuíam algum comprometimento cognitivo (em geral uma pontuação abaixo do ponto de corte no MEEM). Também o tempo para a inclusão ou não dos transtornos (último mês, último ano, toda a vida), diferentes faixas etárias incluídas ou excluídas (como 60-65 anos ou acima de 85 anos). É importante frisar que nossos resultados trazem dados sobre outras categorias diagnósticas que frequentemente são excluídas de trabalhos populacionais de larga escala. Outro fator que contribui para essas assimetrias são o uso de instrumentos ou entrevistas estruturadas e delineamento em duas fases (uma fase de triagem e outra de avaliação diagnóstica) que podem gerar prevalências diferentes.

No nosso estudo, a comorbidade entre os transtornos psiquiátricos ocorreu em aproximadamente $17 \%$ da amostra, menor comparado a parcela com apenas um diagnóstico que foi maior que o dobro $(38,38 \%)$. Nos estudos que exploraram as taxas de comorbidades entre os transtornos psiquiátricos em idosos as taxas chegaram a $16,8 \%$ para dois ou mais e $6,2 \%$ para três ou mais transtornos psiquiátricos na parcela de indivíduos do estudo com mais de 65 anos, ao longo da vida (VIANA; ANDRADE, 2012). Entre idosos, apesar de a ocorrência concomitante de dois ou mais diagnósticos psiquiátricos ser menos frequente, o estudo de Kessler et al., (2010) apontou para a frequente associação entre depressão, ansiedade, transtorno bipolar e transtorno do pânico nessa faixa etária. 


\section{Prevalência e características clínicas dos transtornos neurocognitivos}

Encontramos alta prevalência dos TNC na população examinada (de 33,58\%), sendo 11,81\% para TNM e 21,77\% para TNL. Quando consideramos apenas o diagnóstico de TNM, encontramos uma prevalência de $11,81 \%$. Este valor foi maior que a maioria dos valores de outros países e estudos de prevalência global de demência relatados na literatura (PRINCE et al., 2013), mas está situada entre a maioria dos estudos brasileiros anteriores sobre prevalência de demência (TNM), segundo informações de duas revisões sistemáticas (BOFF; SEKYIA; BOTTINO, 2015; FAGUNDES et al., 2011).

É sabido que há diferenças nas prevalências entre as diferentes regiões do mundo. A maioria das taxas de prevalência estimada para demência (TNM) nos países do mundo situase entre 5\% e 7\% (PRINCE et al., 2013). No entanto, taxas mais altas são encontradas na América Latina, como 7,1\% e de 8,5\% (NITRINI et al., 2009; PRINCE et al., 2013; RODRIGUEZ et al., 2008).

Outros países latino-americanos vizinhos relataram prevalências com valores variáveis, mas próximos aos nossos, como 5,7\% e 13\% na Venezuela (MAESTRE et al., 2002; NITRINI et al., 2009; RODRIGUEZ et al., 2008); 6,85\% e 9,3\% no Peru (RODRIGUEZ et al., 2008), 4,38 e 7\% no Chile (FUENTES; ALBALA, 2014), 8,3\% e 10,5\% na Argentina (BARTOLONI et al., 2014; MANGONE; ARIZAGA, 1999). No México, país de características semelhantes ao Brasil, foi descrita uma prevalência de $6,1 \%$ (MEJIA-ARANGO; GUTIERREZ, 2011).

Quando analisamos os dados disponíveis para o Brasil, os resultados são heterogêneos. Há duas revisões sistemáticas disponíveis sobre a prevalência de TNC na comunidade no Brasil. Fagundes et al., (2011) analisaram 11 estudos transversais de base populacional e a prevalência variou de 2,0 \% (RAMOS-CERQUEIRA et al., 2005) a 49,6\% (MAGALHÃES et al., 2008). Se considerarmos apenas os cinco estudos de melhor qualidade metodológica, as taxas de prevalência variaram de 5,1\% (SCAZUFCA et al., 2008) a 19\% (LOPES et al., 2007). Na revisão de Boff, Sekyia e Bottino (2015), oito estudos foram incluídos com prevalências variando de $5,1 \%$ e $17,5 \%$.

Outros estudos como o de Burlá et al., (2013), após uma revisão de diversos estudos disponíveis e extrapolação de dados, advoga uma taxa de prevalência para demência no Brasil de 7,6\%. Segundo a análise de Chaimovicz e Burdorf (2015), a partir da prevalência 
observada de $5,1 \%$ a $8,3 \%$ nos estudos analisados, seria possível inferir que a taxa ajustada de demência no Brasil estaria entre os valores de $15,2 \%$ a $16,3 \%$.

As características sociodemográficas da população incluída no nosso estudo foi similar as dos demais estudos disponíveis avaliando a prevalência de demência em outras cidades do Brasil, onde predominou sexo feminino, idosos mais jovens, abaixo dos 75 anos e de baixa escolaridade, em sua maioria analfabetos e com menos de quatro anos de escolaridade (BOTTINO et al., 2008; CORREA RIBEIRO et al., 2013; HERRERA et al., 2002; LEBRÃO; LAURENTI, 2005; LOPES et al., 2012; RAMOS-CERQUEIRA et al., 2005; SCAZUFCA et al., 2008a).

Assim, a taxa por nós encontrada está de acordo com o reportado previamente e com o esperado para o país, no entanto, nossa prevalência foi maior que a de outros estudos no estado de São Paulo, como os valores de 5,1\% e 6,6\% encontrados no estudo de Scazufca et al., (2008) e de 3,4\% no estudo de Lebrão e Laurenti (2005), ambos na cidade de São Paulo. Nas cidades do interior, o estudo de Herrera et al., (2002), na cidade de Catanduva - SP, revelou uma prevalência de 7,1\%. Nossa prevalência observada foi menor que a taxa de 5,9\% encontrada por Lopes et al., (2012) na cidade de Ribeirão Preto - SP. No entanto quando esta taxa foi ajustada, a prevalência estimada foi de $12,5 \%$. Há de se destacar que neste último, a população de analfabetos era de apenas $10 \%$, menor do que a do nosso estudo, o que poderia explicar a menor prevalência comparada com a nossa uma vez que baixa escolaridade é um fator associado a quadros de TNC (BOFF; SEKYIA; BOTTINO, 2015).

Outros estudos trouxeram prevalências maiores que as nossas, como 12,9\% para Bottino et al., (2008) e o estudo de César et al., (2016) na cidade de Tremembé, que tinha uma amostra de idade e escolaridade semelhante a nossa, mas encontrou uma taxa de prevalência de $17,5 \%$, maior que a nossa.

A diferença entre a nossa taxa e a de estudos anteriores possivelmente decorrem de diversos fatores, mas principalmente por fatores metodológicos - tipo de delineamento (por exemplo, se o estudo é em uma etapa ou duas etapas); métodos de coleta de dados; locais de amostragem, entrevistas diagnósticas estruturadas ou abertas; tipos e tamanhos de amostras (em relação à área, período de estudo, diferentes idades incluídas); além de diferenças sociodemográficas, culturais, regionais e étnicas. Estes fatores são frequentemente apontados como razões para heterogeneidade dos achados entre os estudos (BOFF; SEKYIA; BOTTINO, 2015; FAGUNDES et al., 2011; HERRERA et al., 2002; JACOB et al., 2007).

As características sociodemográficas da população analisada nos estudos podem influenciar os resultados, pois a inclusão de um maior o número de indivíduos com idades 
mais avançadas pode aumentar a probabilidade do diagnóstico, já que a idade é o fator de risco mais importante para demência. Outros fatores socioeconômicos como baixa renda e baixa escolaridade, também são conhecidos como fatores associados à demência.

Comparando os resultados de estudos com método de amostragem semelhante, nossos resultados foram maiores que os encontrados por Ramos-Cerqueira et al., (2005) na cidade de Pirajú - SP, com idosos atendidos pelo serviço de saúde da família que trouxe uma prevalência de $2 \%$. Neste estudo, no entanto, não foi descrito como foi feita a amostragem, e a seleção foi feita por agente comunitários após um treinamento que discutiram com um psiquiatra para o diagnóstico pelo DSM-IV. Ainda, encontramos uma taxa maior que os resultados de Scazufca et al., (2008) que analisou os idosos do Bairro do Butantã na cidade de São Paulo - SP, usando o questionário Community Screening Instrument for Dementia e critérios do DSM-IV, uma prevalência observada de 5,1\% e estimada de $6,6 \%$.

Estudos de outros estados também trazem taxas indicando alta prevalência de TNM, mas provavelmente associado à maior média de idade dos participantes. Os dados do estudo de Teixeira et al., (2009) na cidade de Caeté - MG, reportou uma prevalência de 27,5\%, bem maior do que nossa, mas amostra era constituída de idosos maiores de 75 anos de idade. $\mathrm{O}$ estudo de Correa-Ribeiro et al., (2013) reportou uma taxa de 16,9\% de prevalência para demência entre idosos usuários de um plano de saúde privado do Rio de Janeiro - RJ, explicando que isso ocorreu porque a amostra predominaria de idosos mais velhos, com idade acima de 80 anos. O estudo de Benedetti et al., (2008) em Florianópolis - SC, reportou uma taxa de $13,8 \%$.

Embora o diagnóstico do TNM seja eminentemente através da avaliação clínica, em pesquisas epidemiológicas é frequentemente utilizado escalas e questionários. Analisando estudos com metodologia semelhante ao nosso, um estudo na cidade de Tremembé - SP fez o diagnóstico de demência por meio de uma avaliação clínica, semelhante à que fizemos, e encontrou uma taxa de demência de 17,5\%, embora eles usassem questionários para avaliar a funcionalidade (critério necessário para o diagnóstico), o que fizemos avaliando extensivamente as queixas e declínio da capacidade funcional (CÉSAR et al., 2016).

Ainda há poucos estudos utilizando os critérios diagnósticos atualizados segundo o DSM-5, então é difícil fazer a comparação com estudos prévios. Espera-se que as mudanças nos critérios do DSM-IV e DSM-5 causem diferenças na prevalência de demência (TNM), embora esse efeito não tenha sido encontrado na metodologia proposta por Chagas, Pessoa e Almeida (2018), que encontraram taxas semelhantes, quando aplicados os critérios do DSMIV e 5, revelando que o declínio da funcionalidade exerce um efeito mais pronunciado do que 
o declínio dos domínios cognitivos detectados através de testagens para o diagnóstico. Outros sistemas de classificação de doença que foram utilizados nos estudos foram diversas versões do DSM (DSM-III-TR; DSM-IV e DSM-IV TR) e a CID-10.

A influência do critério diagnóstico adotado é demonstrada no estudo de Rodriguez et al. (2008), em os alotes demonstraram diferentes escores para o mesmo país e população de acordo com o sistema de classificação adotado, com menor prevalência segundo os critérios do DSM-IV. Este estudo sugere que, em comparação com o algoritmo de demência do grupo de pesquisa 10/66, o critério de demência do DSM-IV pode subestimar a prevalência de demência. O estudo de Jacob et al. (2007), também encontrou taxas diferentes na mesma população, usando três critérios diagnósticos diferentes.

A comparação como a literatura é difícil devido a grande variabilidade dos resultados disponíveis e por nossos resultados serem a frequência absoluta dos transtornos encontrados. Entretanto, acreditamos que nossa taxa de prevalência de demência está em conformidade com os resultados da literatura e tem validade externa, podendo, dentro das limitações do estudo, retratar a realidade das taxas da população brasileira. Meta-análises e estudos de revisão mostraram alta variabilidade entre diferentes países e dentro do mesmo país (LOPES et al., 2007).

Um estudo antigo, mas emblemático é o de Murphy e Veras (1994), que utilizando um instrumento chamado Brazil Old Age Schedule (BOAS) revelou diferenças importantes na prevalência de TNM entre bairros na mesma cidade, evidenciando influência do nível socioeconômico (5,95\% para Copacabana; 9,84\% para Méier; 29,75\% para o bairro de Santa Cruz - bairro mais desfavorecido) (VERAS; MURPHY, 1994).

A prevalência de TNL em nossa amostra foi de 21,77\% $(\mathrm{N}=59)$. Até o presente momento não há estudos com a prevalência de acordo com os critérios do DSM-5, para fins de comparação. Segundo o DSM-5, o TNL é reconhecido com um nível menos grave de prejuízo cognitivo, e sofreram as mesmas atualizações que os critérios de TNM, com acréscimo de atenção complexa e cognição social como domínios cognitivos.

É possível comparar com estudos anteriores na população brasileira que investigaram a prevalência de CCL (ou em inglês MCI), e o comprometimento cognitivo sem demência (ou em inglês CIND) evidenciando que os valores deste estudo são maiores que os reportados em estudos anteriores.

O estudo de Chaves et al., (2009), em Porto Alegre - RS, encontrou uma prevalência para MCI de 13,2 por 1.000 habitantes, achando como fatores de risco associados para o diagnóstico a baixa escolaridade e escores mais baixos no MEEM. O estudo de Diniz et al., 
(2008) encontrou uma prevalência de 36\% numa amostra clínica de idosos atendidos em um ambulatório de memória. Outras taxas trazidas foram em São Paulo, de 5,8 \% (BOTTINO et al., 2005) e em Tremembé - SP, de 15,6\% (CÉSAR et al., 2016). O estudo de Godinho et al., (2012) relatou uma prevalência de 6,4\% em uma população estudada por maior risco de progressão para demência.

Os dados de CIND disponíveis para o Brasil trazem taxas variáveis. Os autores Bottino et al., (2008) e Lopes et al., (2012) ao investigarem a prevalência de demência também reportaram a prevalência para CIND, de 1,6\% e 1,4\% em suas amostras, respectivamente. Lebrão e Laurenti (2005) relataram prevalência de 3,5\% na cidade de São Paulo. O estudo de César et al., (2016), na cidade de Tremembé - SP, encontrou uma taxa de $19,5 \%$.

É possível que, novamente, as diferenças entre o valor que encontramos e os dos estudos citados sejam devido a questões metodológicas e características sociodemográficas da amostra. Diferentes critérios adotados ao longo dos anos; as definições de cada transtorno; local do estudo, tamanhos e tipos de amostra (amostra clínica ou populacional); instrumentos de medida; e pontos de corte adotados estão entre os fatores que contribuem para as diferenças entre as taxas (FORLENZA et al., 2013; WARD et al., 2012).

Características sociodemográficas da amostra também influenciam e contribuem para a variabilidade de achados, pois mesmo estudos que utilizaram o mesmo critério diagnóstico e metodologia de pesquisa, as taxas encontradas foram diferentes entre os países. Isso mostra a influência de fatores intrínsecos da amostra, dentre eles: raça ou etnia, diferenças na aplicação do instrumento em cada local, nível educacional e idade que influencia no desempenho nos instrumentos de avaliação cognitiva (ASHBY-MITCHELL et al., 2015; FORLENZA et al., 2013; PESSOA et al., 2019).

Mesmo que nossa taxa tenha sido maior que estudos anteriores no Brasil, o valor está de acordo com o esperado de acordo com a prevalência estimada de 17,3\% de uma revisão e meta-análise recente, que incluiu estudos de prevalência de CIND e MCI de idosos na comunidade (PESSOA et al., 2019).

Esta revisão encontrou variação na prevalência de acordo com o critério adotado para definição diagnóstica. Estudos que consideraram queixa de memória como condição necessária mostraram prevalência de $15 \%$ e os estudos utilizando apenas queixas de declínio cognitivo de qualquer domínio, sem necessidade de queixa de memória, pareceu ser mais abrangente, com uma prevalência maior de 21,6\%. Como no DSM-5, a queixa do domínio de 
memória e aprendizagem não é mais um item essencial, é possível que esse seja o motivo de nossa taxa ter sido semelhante ao trazido nesta revisão.

Outras meta-análises também trouxeram valores variáveis para prevalência de MCI na comunidade. Segundo a revisão de Luck et al., (2010) esse valor foi de 1,7 a 22,6\%. Em sua revisão, Ward et al., (2012) encontraram variação na prevalência de MCI de 3\% a 42\%. Um grupo de autores analisou 11 coortes internacionais (estudos da Ásia, EUA, Europa e Austrália) tentando estimar diferentes taxas de prevalência de MCI de acordo com cada uma das três definições adotadas para MCI, encontrando menor variação entre os valores: de 6 a 12\% (SACHDEV et al., 2015).

Para países da América Latina as taxas também são variáveis: 13,6\% numa população acima de 50 anos em seguimento em Córdoba, Argentina (MÍAS et al., 2007); 6,45\% no México (JUAREZ-CEDILLO et al., 2013); 1,2\% na Venezuela (RODRIGUEZ et al., 2008). Em outros países em desenvolvimento, como na Índia, a taxa é de $26 \%$ para MCI (MOHAN et al., 2019). Mesmo em países desenvolvidos como EUA, já foram encontradas prevalências mais altas, como 21\% (KNOPMAN et al., 2016).

A revisão sistemática de Ward et al., (2012) encontrou taxas de prevalência de CIND de 5,1\% a 35,9\%. O estudo de Ashby-Mitchell et al., (2015) analisou dados de sete países da América Latina e encontrou prevalência menor para a Argentina, de 8,9\% e maior, de 21,3\%, para Barbados. No México, Mejia-Arango e Gutierrez (2011) reportaram uma prevalência de $25,1 \%$ a 28,7\% de CIND em uma população da comunidade com 50 anos ou mais.

De uma forma geral, é difícil estabelecer com exatidão que fatores podem ter contribuído em maior ou menor grau para as diferenças entre a prevalência de TNC na nossa amostra e os demais estudos. Encontramos uma prevalência significativa tanto para TNM quanto para TNL, o que mostra a importância da identificação desses transtornos na população idosa.

Críticas são feitas à metodologia dos estudos disponíveis, como: riscos de vieses; altas taxas de recusa; pontos de corte inadequados e acurácia duvidosa dos examinadores (BOFF; SEKYIA; BOTTINO, 2015). É possível que nos estudos de menor qualidade metodológica as estimativas de demência tenham sido superestimadas e é possível atribuir a grande heterogeneidade entre os estudos sobretudo pelas diferentes idades de inclusão (alguns estudos com população acima de 60 anos, outros 65 e outros até de 75 anos) e níveis econômicos incluídos nas amostras (FAGUNDES et al., 2011). 
Além de determinar a prevalência dos TNC, avaliamos algumas características da nossa amostra (clínicas e sociodemográficas) em cada grupo de idosos de acordo com o diagnóstico do declínio cognitivo.

$\mathrm{Na}$ nossa amostra, idade e escolaridade foram estatisticamente diferentes entre os três grupos de idosos. Escolaridade mais baixa foi mais encontrada nos grupos com diagnóstico de TNM e TNC, comparados ao grupo sem TNC; e no grupo com TNM a média de escolaridade foi mais baixa que a do grupo com TNL. A média de idade do grupo com TNL foi maior que a do grupo sem TNC. No grupo com TNM, a média de idade foi maior se comparada tanto com o grupo sem TNC quanto com o grupo com TNL. Para os indivíduos mais velhos, maior a associação com um dos TNC e maior risco para o de maior gravidade. Não foi demonstrada diferença estatisticamente significativa quando ao sexo e status ocupacional (aposentado ou não).

A associação de idade e baixa escolaridade com os TNC é descrita na literatura, com estudos mostrando a associação tanto com TNM (demência) (BOFF; SEKYIA; BOTTINO, 2015; LOPES et al., 2012; SCAZUFCA; ALMEIDA; MENEZES, 2010), quanto com TNL (BRUCKI, 2013; CÉSAR et al., 2016a; MANLY et al., 2005; SACHDEV et al., 2015; WARD et al., 2012).

É de se esperar que a frequência de diagnóstico de TNC seja menor entre aqueles com maior escolaridade, uma vez que uma maior capacidade de reserva cerebral de pessoas instruídas poderia adiar o início da demência. Os idosos mais instruídos podem receber mais estímulos cerebrais ao longo da vida. Há ainda possíveis fatores relacionados à educação como o estilo de vida, exposição ocupacional, morbidade e cuidados da saúde, que teriam efeitos protetores (ZAITOUN et al., 2008).

Quanto a diferença de idade e escolaridade entre o grupo de idosos com TNM e TNL, semelhante ao que encontramos, no estudo de Diniz et al., (2008) que comparou pacientes com TNC por Doença de Alzheimer (DA) com um grupo controle e outro com TNL (chamado de MCI), o grupo de pacientes com DA eram mais velhos e menos instruídos do que o grupo MCI e dos controles. Já no estudo com a população de Tremembé - SP, a idade foi diferente entre os grupos com demência, CIND e grupo controle. No entanto, um pior nível educacional só foi significativo entre o grupo controle e os grupos TNC, mas não entre os grupos com demência e CIND (CÉSAR et al., 2016).

A associação entre sexo e TNC é controversa. Em diversos estudos com a população brasileira não foi encontrada associação com sexo (BOTTINO et al., 2008; CORREARIBEIRO et al., 2013; LOPES et al., 2012). O estudo de Mejia-Arango e Gutierrez (2011) 
encontrou associação com sexo feminino e demência até a idade de 80 anos, quando a prevalência de demência passou a ser associada ao sexo masculino. Esse mesmo estudo encontrou que baixa escolaridade estava associada ao diagnóstico de CIND e de demência. Em outro estudo, sexo feminino, idade e menor escolaridade foram associados a demência (FRATIGLIONI; WINBLAD; VON STRAUSS, 2007). De uma forma geral, a associação com o sexo é encontrada em alguns estudos, mas não em outros, portanto não é possível estabelecer o gênero como fator associado à demência (BOFF; SEKYIA; BOTTINO, 2015).

Quanto a associação entre sexo e TNL, alguns estudos estão disponíveis, mas investigaram a associação ou com CIND ou com MCI. No estudo de César et al., (2016), não foi encontrada associação entre gênero e diagnóstico de CIND. Num estudo de revisão incluindo 56 estudos, os autores concluíram que o único achado estatisticamente significativo relativo à associação entre gênero e o diagnóstico de TNL, foi que as mulheres teriam uma maior prevalência apenas para MCI do tipo não amnésico. Este trabalho aponta que para entender melhor as diferenças entre os gêneros nos estágios pré-clínicos da demência (TNL), os estudos devem caracterizar melhor a etiologia do comprometimento cognitivo (AU; DALE-MCGRATH; TIERNEY, 2017).

Quanto a associação entre o status de aposentadoria e a presença ou não de diagnóstico de TNC, não foi encontrada para nossa amostra associação entre o estar ou não aposentado e ter ou não algum TNC. Em alguns estudos na literatura, há evidências de uma diminuição significativa no risco de desenvolver demência associada à idade mais avançada na aposentadoria (DUFOUIL et al., 2014) e também quando o tipo de trabalho é "qualificado" de instrução formal tanto para TNM (BICKEL; KURZ, 2009; SCAZUFCA; ALMEIDA; MENEZES, 2010; ZAITOUN et al., 2008), quanto para TNL (GRACIA-REBLED et al., 2018).

Isso tem apoio na teoria do "use ou perca" a qual advoga que engajar em atividades mentalmente desafiadoras (trabalhos menos "manuais") exerce um efeito protetor sobre a cognição. Uma ocupação com maiores requerimentos intelectuais pode ajudar a manter as funções cognitivas intactas durante mais tempo (HYUN et al., 2020).

O desempenho nos testes neurocognitivos foram diferentes entre os três grupos dois a dois para o MoCA e para o MEEM, porém não para o MoCA basic que não foi diferente entre o grupo com TNL e o grupo com TNM (Tabela 5). Uma vez que o prejuízo cognitivo é o centro do diagnóstico dos TNC, é de se esperar que os escores totais nos testes de rastreio sejam diferentes entre os grupos. 
Segundo o DSM-5, para caracterizar o transtorno o indivíduo tem que apresentar declínio cognitivo (seja na atenção complexa, função executiva, aprendizagem e memória, linguagem, perceptomotor ou cognição social) e sempre que possível esse declínio deve ser documentado através de uma teste neuropsicológico padronizado ou, em sua falta, outra avaliação quantificada (APA, 2013). Para o TNL, esse declínio é leve e sem prejuízo da funcionalidade, e para o TNM, é mais intenso, comprometendo a funcionalidade. Uma vez que estes testes neurocognitivos mensuram a performance cognitiva do indivíduo é de se esperar que eles se diferenciem entre os grupos de acordo com o grau de comprometimento (BUSTAMANTE et al., 2003; JULAYANONT et al., 2015b; KOSON et al., 2012; NASREDDINE et al., 2005).

Este fato ocorreu em nossa amostra, visto que piores escores do MEEM e do MoCA foram associados ao grupo clínico e com a maior deterioração cognitiva, o que é bem estabelecido na literatura. Outros estudos no Brasil mostraram a associação de pior performance em testes neurocognitivos e associação com o diagnóstico de TNC (CHAIMOWICZ; BURDORF, 2015; CORREA RIBEIRO et al., 2013; LOURENÇO; SANCHEZ, 2014).

É importante ressaltar que apesar de o MoCA ter sido desenvolvido para diferenciar indivíduos com suspeita de CCL (atualmente TNL) de indivíduos saudáveis, este tem sido usado também para diferenciar indivíduos CCL de indivíduos com demência (atual TNM) (O’DRISCOLL; SHAIKH, 2017).

O desempenho no MoCA basic não foi diferente entre os grupos TNL e TNM. Há duas possibilidades para esse achado. A primeira é que seja devido as próprias características psicométricas do instrumento, já que este foi desenvolvido para rastreio de TNL em indivíduos de baixa escolaridade e não para diferenciação de TNL e TNM. A segunda é devido a questões metodológicas do nosso estudo. Apenas seis indivíduos do subgrupo com TNM foram submetidos ao MoCA basic. Pela amostra pequena, a melhor avaliação do desempenho destes indivíduos no teste comparados com os com TNL pode ter sido comprometida.

\section{Prevalência dos transtornos ansiosos}

Os transtornos ansiosos foram a segunda categoria mais prevalente, atrás apenas dos 
TNC. Cerca de 25,46\% dos idosos avaliados tinha pelo menos um transtorno ansioso, com maior frequência do TAG (prevalência de 14,76\%), seguido das Fobias específicas $(9,6 \%)$, fobia social (ou transtorno de ansiedade social) foi diagnosticada em 1,85\% da amostra $(\mathrm{N}=5)$ e o transtorno de pânico em $0,74 \%(\mathrm{~N}=2)$ (Tabela 4). Apesar de outros estudos brasileiros também trazerem os transtornos ansiosos como os transtornos mentais mais frequentes na população idosa, algumas vezes alternando com os transtornos depressivos, nossa taxa de prevalência foi bastante alta se comparada à literatura. Além disso, o diagnóstico de TAG foi o mais prevalente dentre os transtornos ansiosos, posição ocupada na maioria dos estudos pelas Fobias específicas. Não tivemos nenhum caso de agorafobia.

No estudo de Andrade et al., (2012), o "São Paulo Megacity", na população da comunidade acima de 65 aos, o histórico de algum transtorno ansioso chegou a 19,8\%, sendo a categoria diagnóstica mais prevalente. A fobia específica foi o transtorno com maior prevalência durante a vida, de com $8,9 \%$, seguido do TAG com 4,5\%; agorafobia com 2,4\%; fobia social com $2 \%$ e transtorno do pânico, com $1 \%$. Num estudo avaliando atendimentos hospitalares, os transtornos ansiosos foram diagnosticados em 4,9\% dos idosos atendidos em um pronto-socorro psiquiátrico (BALDAÇARA et al., 2012). Na população com mais de 75 anos de Bambuí-MG, a prevalência para TAG no último mês variou de 3,8\% a 4,3\% (dependendo da faixa etária) e foi de 1,9\% para as fobias (incluindo fobias específicas, agorafobia e fobia social). Não foram avaliados outros transtornos ansiosos (COSTA et al., 2007).

Em estudos avaliando idosos americanos, os transtornos ansiosos também ficaram a frente dos demais transtornos psiquiátricos em prevalência, com valores de $7 \%$ a 15,3\% (GUM; KING-KALLIMANIS; KOHN, 2009; KESSLER et al., 2005; REYNOLDS et al., 2015). No estudo de Reynolds et al., (2015), a prevalência de fobias específicas foi maior, com 5,9\%; seguido do TAG, com $2,8 \%$, fobia social $1,45 \%$ e transtorno do pânico com $1,35 \%$. Agorafobia não foi avaliada.

Na metanálise de Volkert et al., (2013), os autores estimaram que as taxas de prevalência atual para cada transtorno eram: 4,52\% para as fobias específicas; $2,30 \%$ para o TAG; $1,31 \%$ para fobia social; $0.88 \%$ para transtorno de pânico; $0,53 \%$ para agorafobia.

No estudo Europeu, "MentDis ICF65+ study", a categoria dos transtornos ansiosos foi a mais prevalente, com prevalência para transtorno atual de $11,4 \%$, chegando a $13 \%$ para a população de idosos de Londres. A maior prevalência foi das fobias específicas, com 6,6\%; seguida da agorafobia, com $3,4 \%$ e por último o transtorno do pânico, com $1 \%$. O TAG e a 
fobia social não foram exploradas (ANDREAS et al., 2017). Prevalências maiores foram reportadas num estudo específico com idosos da comunidade de Montpellier, na França. A prevalência para os transtornos ansiosos foi de 14,2\% para o diagnóstico atual e de 29,4\% para prévio durante a vida. A prevalência para diagnóstico atual de fobias especificas e agorafobia foi de 10,1\%. Para TAG foi de 5,6\%; para fobia social foi de 1,2\% e para o transtorno do pânico foi de 0,3\% (RITCHIE et al., 2004). Num estudo mais recente, envolvendo idosos da comunidade na Suécia, as taxas encontradas para TAG variaram de 2,2 a 5,8\% (NILSSON et al., 2019).

Nos países em desenvolvimento, há uma variação substancial na prevalência da ansiedade. Em um estudo, os autores avaliaram 15.021 residentes com 65 anos ou mais em 11 locais de captação de 7 países (China, Índia, Cuba, República Dominicana, Venezuela, México e Peru). Os autores concluíram que a prevalência de ansiedade variou bastante entre os locais, oscilando de $0,1 \%$ na China a 9,6\% em áreas urbanas do Peru. Esta variação tão ampla entre os países mostra a possibilidade da influência de fatores geográficos, culturais e inerentes a cada população (PRINA et al., 2011).

Nossa prevalência para fobias específicas, foram semelhantes apenas as encontradas por nos estudos de Ritchie et al., (2004) e de Andrade et al., (2012). Também, apenas no estudo de Costa et al., (2007) ocorreu de a prevalência de TAG ser superior às de fobias específicas. Para o transtorno de pânico e fobia social, nossas taxas foram semelhantes às encontradas nos outros estudos. A prevalência para o transtorno de pânico aparece variando de $0,1 \%$ a $2 \%$ e, para a fobia social de $0,6 \%$ a $6,6 \%$ na literatura (WOLITZKY-TAYLOR et al., 2010).

É sabido que os transtornos ansiosos estão entre os diagnósticos psiquiátricos mais prevalentes na comunidade de uma maneira geral, mas quando comparados com grupos etários mais jovens, as prevalências em idosos são menores (GUM; KING-KALLIMANIS; KOHN, 2009; REYNOLDS et al., 2015; VIANA; ANDRADE, 2012).

No nosso estudo, as prevalências foram mais altas. Há explicações metodológicas para isso: características sociodemográficas da amostra (como idade); operacionalização do diagnóstico e o uso de uma entrevista clínica semiestruturada; a inclusão de indivíduos com outros transtornos psiquiátricos, incluindo os TNC para a avaliação; e fatores culturais e geográficos inerentes a nossa população.

Quanto à influência da idade da amostra, é possível que pelo fato de 55,72\% da amostra se concentrar nas duas faixas etárias mais jovens (72 indivíduos tinham entre 60 e 64 e 79 indivíduos entre 65 e 69 anos) os casos de transtornos ansiosos, especialmente, o TAG, 
tenham sido mais frequentes. No estudo de Reynolds et al., (2015) enquanto a prevalência para algum transtorno ansioso chegou a 14,81\% na faixa dos 55-64 anos, este valor caiu para 9,45\% nos de 65-74 anos, 8,40\% nos de 75-84 anos; e 7,15\% nos com mais de 85 anos. No estudo de Andrade et al., (2012), os transtornos ansiosos chegaram a acometer até 35\% dos entrevistados entre 55-64 anos, esta mesma taxa caiu para 19\% entre aqueles acima de 65 anos.

É possível que a idade produza mudanças na expressão clínica da ansiedade, pois com o envelhecimento poderia haver uma mudança do perfil de sintomas ansiosos entre os grupos de idosos mais jovens e mais velhos. Isso foi pesquisado para o TAG num estudo que concluiu que sintomas como excitação autonômica, tensão muscular e irritabilidade diminuíram com a idade (menos prevalentes entre os idosos mais velhos), enquanto a preocupação e a fadiga aumentaram. Dificuldades de concentração e distúrbios do sono permaneceram estáveis. A prevalência de TAG de acordo com a CID-10 tende a diminuir com a idade, enquanto de acordo com DSM-5 não mudou com a idade. Isso demonstra que o sistema de classificação utilizado pode-se provocar mudanças nas taxas de prevalência, o que torna difícil a comparação das taxas entre os estudos (NILSSON et al., 2019).

Essas diferenças na operacionalização do diagnóstico de ansiedade vão além da utilização de diferentes sistemas de classificação nosológico (CID ou DSM), mas incluem também a sensibilidade e decisão por parte de quem faz o diagnóstico (um entrevistador, ou no nosso caso, um psiquiatra) em incluir como diagnósticos, os sintomas considerados "subclínicos" por instrumentos e escalas de pesquisas (mesmo quando validados).

Segundo Grenier et al., (2011) as taxas de prevalência para qualquer transtorno de ansiedade entre idosos podem variar consideravelmente de acordo com os critérios utilizados. Nesse estudo, utilizando-se critérios de diagnóstico menos restritivos (mais abertos e não baseados em "sim" ou "não", com busca ativa de sintomas e interpretação das queixas), foi possível identificar sintomas de ansiedade clinicamente significativos em 26,2\% dos idosos avaliados; enquanto com os critérios do DSM-IV estritamente aplicados (o que ocorre em entrevistas de grandes inquéritos populacionais) apenas 5,6\% desses entrevistados seriam diagnosticados. Esse mesmo estudo mostrou ainda a influência da idade, uma vez que participantes com idades entre 65 e 74 anos tiveram respectivamente 1,5 vezes mais chances de relatar um transtorno de ansiedade em comparação aos respondedores maiores que 75 anos (GRENIER et al., 2011). Esta informação reforça a possibilidade de que o diagnóstico realizado por especialistas através de entrevista clínica baseada no DSM-5, mas não estruturada, possa ter levado a um maior número de diagnósticos de transtornos ansiosos, 
além de corroborar a possível influência da idade (fato de nossa amostra ter muitos idosos com menos de 75 anos).

O que se discute é que em muitos casos há dificuldade em distinguir entre ansiedade adaptativa e patológica, talvez porque os idosos, ou mesmo os médicos, atribuam os sintomas de ansiedade aos processos normais de envelhecimento. Isso poderia gerar diferenças nas definições e/ou capacidade dos entrevistadores em muitos estudos para detectar se a ansiedade é devida a uma condição médica geral, o que excluiria um indivíduo de ser diagnosticado com transtorno de ansiedade (WOLITZKY-TAYLOR et al., 2010).

Outra possibilidade para a grande prevalência encontrada, é que a inclusão na nossa amostra dos idosos portadores de algum TNC. Cerca de 11,80\% dos idosos portadores de algum TNC também eram portadores de outro transtorno psiquiátrico (como TAG e fobia específica). Estes indivíduos, em muitos estudos são deixados de fora, o que traz novamente a questão sobre a sub-representação e subestimação dos transtornos mentais da parcela cognitivamente prejudicada em estudos comunitários (RIEDEL-HELLER; BUSSE; ANGERMEYER, 2000).

Os transtornos de ansiedade são frequentemente comórbidos, com declínio cognitivo e demência entre os idosos. As estimativas de prevalência de transtornos de ansiedade em indivíduos com demência variam de 5 a $21 \%$. Além disso, inquéritos populacionais demonstraram que idosos com ansiedade clinicamente significativa apresentam pior funcionamento cognitivo (por ter comprometimento na memória de curto prazo). Assim, pelo pior desempenho em testes neurocognitivos utilizados na seleção da amostra, ficam de fora dos estudos populacionais (que estabelecem pontos de corte na seleção da amostra) (WOLITZKY-TAYLOR et al., 2010).

Cabe a ressalva de que mais pesquisas são necessárias para determinar se existem diferenças entre aqueles que atendem aos critérios diagnósticos suficientes para caracterizar um transtornos de ansiedade versus aqueles com sintomas clinicamente significativos que possam ser secundários à demência (como inquietação, agitação, fadiga, insônia, etc), como argumentam alguns pesquisadores (WOLITZKY-TAYLOR et al., 2010).

Ainda no tocante da comorbidade com outros transtornos, o uso de uma abordagem hierárquica para o diagnóstico em alguns estudos, poderia produzir estimativas de prevalência mais baixas para transtornos de ansiedade, excluindo da possibilidade de diagnóstico os indivíduos que atendessem os critérios de outro distúrbio mais alto na hierarquia. Isso é sobretudo comum para estudos que avaliam transtornos depressivos. Lenze et al. (2001) observaram que os diagnósticos de TAG não eram dados se os sintomas de TAG ocorressem 
apenas durante um EDM, mas encontraram que 27,5\% dos idosos com depressão atenderiam aos critérios de diagnóstico para TAG.

Num outro estudo brasileiro incluindo apenas octogenários na cidade de Veranópolis RS, a prevalência estimada de TAG foi de $10,6 \%$ e sua presença estava associada a uma maior ocorrência de depressão clinicamente diagnosticável, o que reforça a ideia de comorbidade entre os transtornos (XAVIER et al., 2001).

Quanto às fobias específicas, nossa taxa de prevalência foi maior que a encontrada na literatura, enquanto para agorafobia não tivemos nenhum caso. Além das possibilidades já discutidas acima sobre as diferenças dos nossos achados com os da literatura, há outras possíveis explicações. Apesar de as fobias específicas terem um início em geral na infância, atingindo seu pico de ocorrência na vida adulta, é possível que tenhamos nos deparado com grande número de casos crônicos. Sabe-se que as fobias persistem por vários anos ou mesmo décadas em 10 a $30 \%$ dos casos e apenas entre um décimo e um quarto das pessoas com fobias específicas recebem tratamento (EATON; BIENVENU; MILOYAN, 2018). É possível que fatores como a dificuldade de acesso a tratamento adequado para as fobias nos anos mais jovens possa ter levado a cronificação. A terapia de exposição é o tratamento atual de escolha para fobias específicas, tratamento que não está acessível para a maior parte da nossa amostra.

No caso da agorafobia, essa prevalência baixa pode ser devida ao fato de que a vida das pessoas mais velhas geralmente inclui menos exposição a situações profissionais ou sociais, e é mais fácil evitar situações estressantes e desconfortáveis. Ao contrário, eventos associados as fobias específicas, em geral, são situações não controláveis (como relacionadas ao clima, animais, situacionais, etc). Deve-se lembrar que em muitos lares que visitamos, os idosos permaneciam com uma rotina acomodada de seus afazeres, evitando situações desconfortáveis.

Outro fato que chama atenção, é a heterogeneidade entre taxas de prevalência na literatura mesmo nos estudos que utilizaram o mesmo protocolo de avaliação, de acordo com país. Por exemplo, enquanto em Hamburgo (Alemanha) a prevalência de agorafobia foi de $4,9 \%$, em quatro outras cidades não chegaram a 3\%, revelando que além do método, possíveis influências culturais e geográficas da população possam ocorrer (ANDREAS et al., 2017).

Durante o nosso estudo, quando havia alguma dúvida diagnóstica sobre os idosos avaliados, uma discussão entre os pesquisadores era realizada para que o diagnóstico fosse decidido em consenso e assim evitar erros diagnósticos.

O diagnóstico dos transtornos ansiosos em idosos por si só é um desafio. Portanto, profissionais trabalhando com idosos da comunidade tem de estar atentos para transtornos 
ansiosos que possam prejudicar o funcionamento social do idoso, mesmo que apenas alguns sintomas de ansiedade sejam relatados. Há indícios de que os transtornos de ansiedade tenham uma maior prevalência entre os idosos da comunidade do que o reportado na literatura, como mostrado por nossos resultados.

\section{Prevalência dos transtornos de humor}

A terceira categoria de transtornos mentais mais frequente a amostra foi a dos transtornos do humor, presente em 21,03\% (N=57), sendo o depressivo 19,19\% (N=52). Um EDM atual foi diagnosticado em de 5,9\% (N=16) da amostra, enquanto o transtorno depressivo persistente (distímico) foi diagnosticado em 3,32\% (N=9). Cerca de 9,96\% (N=27) da amostra tinham história de um EDM prévio diagnosticado. O diagnóstico TAB teve prevalência de 1,85\% (N=5), todos eutímicos. Nossos achados são semelhantes aos reportados em estudos prévios, tanto para os quadros depressivos (EDM atual, prévio ou distimia) quanto para TAB.

Os transtornos depressivos, dentro dos transtornos de humor, foram frequentes na amostra. Isso está em conformidade com a literatura. Dentre os diagnósticos psiquiátricos nos idosos, os transtornos depressivos estão entre os mais prevalentes, chegando a valores como 20,9\% e 38\% (LUPPA et al., 2012; SOLHAUG et al., 2012). Alguns estudos mostram aumento das taxas com a idade, enquanto outros relatam diminuição da prevalência comparado a indivíduos mais jovens (KESSLER et al., 2010).

As taxas para EDM em idosos são variáveis. Segundo uma metanálise, a prevalência ajustada em idosos seria de 3,29\% para EDM atual, 16,52\% para um EDM prévio e 1,3\% para distimia (VOLKERT et al., 2013). Nos EUA, três estudos com população idosa em escala nacional reportaram valores de 2,3\%,5,63\% e 10,6\% para um EDM atual e 0,5\%, 0,94\%, e 2,5\% para distimia (GUM; KING-KALLIMANIS; KOHN, 2009; KESSLER et al., 2005; REYNOLDS et al., 2015). Para países europeus, esses valores são de 6\% e 11,8\% para EDM atual e prévio; e 2,7\% para distimia atual (ANDREAS et al., 2017).

Taxas menores são encontradas em alguns estudos, como num estudo chinês recente em que a prevalência para EDM no último mês foi de 2,0\% e para um episódio durante a vida foi de 3,4\% (ZHANG et al., 2020). 
No Brasil, de acordo com uma extensa revisão, há uma diminuição nas taxas de prevalência de transtorno depressivo na população idosa da comunidade, mas as estimativas tendem a variar. Essa revisão sistemática de incluiu 17 estudos, 13 com sintomas depressivos clinicamente significativos, um com transtorno depressivo maior isoladamente e três com transtorno depressivo maior e distimia, resultando na avaliação de 15.491 idosos da comunidade em diversos estados do Brasil. A idade média dos participantes variou entre 66,5 e 84,0 anos. Foram encontradas taxas de prevalência combinada de: 7,0\% para EDM (variando de 3 a 15\% nos estudos); e 3,3\% para distimia (variando de 1,6\% a 4,6\% entre os estudos), valores próximos aos encontrados em nossa amostra.

Num estudo mais recente, os autores analisaram uma população com mais de 60 anos de áreas carentes de Porto Alegre - RS. A taxa encontrada foi de 16,3\% de para o grupo "transtorno depressivo" (ALEXANDRINO-SILVA et al., 2019). No nosso trabalho esse valor foi um pouco maior $(19,18 \%)$. A presença de um episódio depressivo prévio na nossa amostra foi de 9,96\%, semelhante ao reportado no trabalho de 11,8\% de Viana e Andrade (2012).

Como fatores indicados para as diferenças entre nossos achados com outros da literatura podemos supor que o uso de diferentes instrumentos diagnósticos, diferentes pontos de corte adotados nos instrumentos e a gravidade dos sintomas avaliados influenciaram a taxa de prevalência. Por exemplo, estudos em que se utilizam escalas que avaliam prevalência de sintomas depressivos e não a categoria diagnóstica do DSM tendem a encontrar maiores prevalências (DIAS et al., 2019). Outros fatores são: diferenças nas amostras (idade de inclusão, tamanho, método de recrutamento), dificuldade de diagnóstico (devido dificuldade em recordar os sintomas), e influência de comorbidades e limitações físicas (KESSLER et al., 2010).

As taxas para TAB em geral são mais baixas se comparada as faixas etárias mais jovens. Um estudo trouxe a prevalência de 1\% para TAB (GOLDSTEIN; HERRMANN; SHULMAN, 2006) e, de acordo com uma meta-análise, a prevalência ajustada para a população idosa é de 0,53\% (VOLKERT et al., 2013). Outra revisão encontrou valores que variavam de $0,08 \%$ a $0,05 \%$ nos grupos acima de 65 anos, e de $0,46 \%$ a $1,5 \%$ entre os adultos de 40-65 anos (DEPP; JESTE, 2004). No estudo com brasileiros, na parcela com mais de 65 anos, a prevalência para histórico de TAB foi de 0,5\% (VIANA; ANDRADE, 2012), um valor menor que o nosso. É possível que isso tenha sido por diferença na amostra, já que no nosso estudo incluiu idosos a partir de 60 anos.

Em outros estudos nos EUA, os valores para TAB foram de 0,2\%, 1\% e 1,49\%. (GUM; KING-KALLIMANIS; KOHN, 2009; KESSLER et al., 2005; REYNOLDS et al., 
2015). Em um estudo, europeu este valor foi um pouco maior que os demais: 4,4\%. Semelhante ao nosso estudo, nenhum idoso com TAB foi identificado com um algum episódio de humor atual (ANDREAS et al., 2017).

Problemas metodológicos comuns nos estudos publicados (como pequenas amostras, falta de medidas padronizadas, ênfase excessiva em pacientes internados e escassez de dados na comunidade) tornam a comparação entre os estudos difícil. No entanto, avaliando nossos resultados e avaliando a literatura é possível afirmar que fortes evidências indicam que o transtorno bipolar se torna menos comum com a idade, sendo responsável por 8 a $10 \%$ das admissões psiquiátricas tardias da vida (DEPP; JESTE, 2004).

\section{Prevalência dos demais transtornos mentais}

Os transtornos do sono foram a quarta categoria de diagnósticos mais prevalente, presente em 40 indivíduos (14,76\%). Aqui foram incluídos os distúrbios relacionados ao sono-vigília como insônia, hipopneia e apneia obstrutiva do sono, alteração do ritmo circadiano e as parassonias.

As queixas relacionadas ao sono são frequentes em estudos na população geral, chegando em alguns países a uma prevalência de 56\% (LÉGER et al., 2008). No Brasil, a frequência dos transtornos relacionados ao sono ao longo dos anos segundo um estudo em São Paulo chegou a 25\% (SANTOS-SILVA et al., 2010). Este valor foi maior que o nosso, mas a amostra era composta por diversas faixas etárias.

O nosso resultado está de acordo com um estudo transversal que investigou a prevalência de queixas de sono em idosos da comunidade nos países em desenvolvimento (Cuba, República Dominicana, Peru, Venezuela, México, China, Índia e Porto Rico). Após avaliar 16.680 residentes de 65 anos ou mais de idade, a prevalência variou de 9,1\% (China) a $37,7 \%$ (Índia). Isso mostra que os transtornos de sono entre os idosos são bastante frequentes (MAZZOTTI et al., 2012). Nossa taxa foi maior que os 10,2\% de prevalência para insônia do estudo de (COSTA et al., 2007). Porém, neste estudo, a amostra tinha apenas idosos de mais de 75 anos e contou apenas com o diagnóstico de insônia, não incluindo os outros distúrbios do sono.

A frequência considerável de transtornos do sono em idosos decorre da susceptibilidade dos idosos aos diversos transtornos do sono (MORAES, 2015). Segundo a 
literatura, a prevalência e impacto da Síndrome da Apneia Obstrutiva do Sono são maiores na população idosa (TUFIK et al., 2010), assim como da insônia (ENDESHAW et al., 2004; KAMEL; GAMMACK, 2006).

Em quinto lugar em frequência, ficaram os transtornos relacionado do uso de substâncias. A partir do DSM-5 houve uma mudança na denominação dessa categoria que antes era dividida em "abuso" e "dependência", padrão de diagnóstico categórico também utilizado na CID-10. Também, essa categoria passou a incorporar todos os critérios em uma única denominação "transtorno do uso", para a qual o indivíduo deve exibir dois sintomas/critérios da lista de 11 possíveis, nos últimos 12 meses, classificando de leve a grave de acordo com o número de critérios presentes na avaliação (2-3: leve; 4-5: moderado; 6 ou mais: grave). Há 10 substâncias possíveis envolvidas para esse transtorno.

Na nossa amostra, 11,07\% ( $=30)$ dos indivíduos caracterizam transtorno do uso de substância de qualquer gravidade, sendo o uso de tabaco/nicotina (presente em 9,23\% da amostra) quase que o dobro do uso de álcool (4,8\%). Nenhum participante relatou uso das demais substâncias (a saber: cafeína, Cannabis, alucinógenos, inalantes, opioides, sedativos e hipnóticos; e estimulantes).

Esperávamos que o uso e os problemas relacionados ao uso de álcool e outras substâncias fossem menos frequentes nas faixas etárias mais altas, que foi o que ocorreu. Em estudos anteriores, a prevalência do transtorno de uso de álcool e outras substâncias psicoativas aparece sob diversas denominações. Podemos fazer algumas comparações com nossos achados.

Seguindo a tendência dos demais transtornos mentais, as prevalências disponíveis na literatura para transtorno do uso de substâncias são menores que as achadas em populações mais jovens. Explicações para isso seriam a morte prematura que é maior entre usuários de substâncias e a menor tolerância física ao uso de substâncias, o que desestimula o uso (GUM; KING-KALLIMANIS; KOHN, 2009; RIEDEL-HELLER; BUSSE; ANGERMEYER, 2006; VIANA; ANDRADE, 2012; VOLKERT et al., 2013). Reforçando essa hipótese, a revisão Global Burden of Disease traz que os usuários de álcool, drogas ilícitas e sobretudo tabaco estão sob maior risco de mortalidade, especialmente o grupo dos idosos (REHM; TAYLOR; ROOM, 2006).

Encontramos o transtorno do uso de tabaco em 9,23\% da amostra, um valor próximo aos $13 \%$ de prevalência geral de uso de tabaco para idosos de uma meta-análise (MARINHO et al., 2010). Um resultado semelhante ao nosso foi relatado num estudo com 2.565 residentes de Singapura, com 60 anos ou mais, no qual a prevalência para uso atual de tabaco foi de 
9,5\% (PANG et al., 2016). Em outro estudo a prevalência para a dependência de nicotina numa amostra da população americana de 55 anos ou mais foi de 9,29\% (REYNOLDS et al., 2015).

Nossa taxa é compatível com o esperado para a idade já que a prevalência do uso de tabaco tende a diminuir nas faixas etárias mais velhas (DUBE et al., 2009). Para se ter uma ideia, segundo dados da OMS em seu "Relatório sobre uso de tabaco" de 2019, a prevalência para o uso de tabaco na população brasileira era de 23,2\% (OMS, 2019). Em um estudo na população brasileira, o transtorno de dependência a nicotina também foi a categoria diagnóstica e a substância mais frequente, com prevalências para toda vida e no último mês de $25 \%$ e 9,2\%, respectivamente (ANDRADE et al., 2002).

No entanto, taxas maiores já foram trazidas em estudos brasileiros. Um amplo estudo envolvendo 400 indivíduos trouxe dados sobre o uso de tabaco e idosos da comunidade no Brasil. Quase $60 \%$ da amostra já havia fumado alguma vez na vida e a prevalência de uso atual de tabaco foi de $24,3 \%$. A maioria $(94,3 \%)$ dos usuários de tabaco fumava todos os dias e 34,3\% consumiam mais de 20 cigarros por dia (MADRUGA et al., 2010).

Uma possível explicação para nossos valores mais baixos seja que diagnosticamos "transtorno relacionado ao uso de tabaco", em vez do simples uso de tabaco, o que requer um padrão de uso mal adaptado e com problemas para a saúde física, relacionamento interpessoal, ocupacional, legais, etc. Esse critério necessário não foi preenchido por muitos idosos e seus acompanhantes que não identificavam consequências danosas do uso, falhando assim em caracterizar o diagnóstico. Infelizmente, a percepção errônea de que fumar não traz prejuízos ainda é comum. Para se ter uma ideia, no mesmo estudo citado acima, cerca de $28 \%$ dos idosos fumantes consideraram que fumar não é tão prejudicial à saúde quanto é anunciado, e 17\% discordaram que sua saúde melhoraria se parassem de fumar (MADRUGA et al., 2010).

Quanto ao uso de álcool em idosos, estudos de revisão apontam para prevalência variando de $0,5 \%$ a $3,3 \%$ para países Europeus, mas os dados são escassos. Em estudos que avaliam outras denominações como "uso de risco" e "problemas com álcool" essas taxas podem chegar a 19\% (RIEDEL-HELLER; BUSSE; ANGERMEYER, 2006). Em outra revisão a prevalência dos transtornos relacionados ao uso de álcool e outras substâncias, foi de $11,71 \%$ para uso durante a vida e de $0,96 \%$ para uso atual. Para o álcool, o uso atual foi de 0,96\% e para uso atual de outras substâncias foi de 0,34\% (VOLKERT et al., 2013).

A nossa prevalência de uso de nicotina foi maior quando comparada ao uso de álcool. Contrariando nossos achados, alguns estudos mostram maior prevalência do uso de álcool, mas o uso de outras drogas fica em terceiro lugar. No México, investigando idosos da 
comunidade, os pesquisadores constataram que $63,5 \%$ de todos os participantes já usaram álcool, 45,4\% já usaram tabaco e 3,5\% já usaram alguma droga. Cerca de um em cada dois homens e uma em cada quatro mulheres usaram álcool nos últimos 12 meses, um em cada 10 idosos usou tabaco e apenas um em cada 100 usou qualquer tipo de droga nos últimos 12 meses (BORGES et al., 2014).

A prevalência para transtorno do uso do álcool na nossa amostra de 4,8\% foi intermediária a de outros estudos com idosos de outros países, considerando o período dos últimos 12 meses. Nos EUA, a taxa de 3,48\% foi encontrada para "dependência ou abuso" de álcool nos últimos 12 meses (REYNOLDS et al., 2015). Na Europa, um estudo avaliou a prevalência atual (no último mês), em 12 meses e ao longo da vida, do uso, abuso e dependência de álcool em pessoas de 65 a 84 anos, segundo critérios do DSM-IV-TR. A prevalência observada foi a seguinte: atual, 1,1\%; 12 meses, 5,3\%; e ao longo da vida, 8,8\% (MUÑOZ et al., 2018). Segundo uma revisão, a prevalência dos transtornos relacionado ao uso de álcool foi de $11,71 \%$ para uso durante a vida e de $0,96 \%$ para uso atual (VOLKERT et al., 2013).

Comparado com os valores da população geral, nossos valores foram menores, o que está em conformidade com a literatura. Um estudo que analisou sintomas de abuso ou dependência de álcool no ultimo ano encontrou menores valores para o grupo mais velho: $20 \%$ de prevalência (dependência 3,4\%, abuso 4,0\% e dependência subclínica 12,5\%) nos adultos com idades entre 50 e 64 anos e 15,4\% de prevalência (dependência 1,3\%, abuso $2,1 \%$ e dependência subclínica 12,0\%) naqueles como mais de 65 anos (BLAZER; WU, 2011).

No estudo de Viana e Andrade, (2012), história de uso durante toda a vida de álcool, separadas como abuso e dependência, foram de 7,0\% e 2,1\%, respectivamente, para os maiores de 65 anos. Para outras drogas, esse valor foi de zero nas duas categorias. Os valores para o grupo de 50-64 anos foram de 8,4\% para uso abusivo de álcool e 3,7\% para dependência de álcool; e $0,8 \%$ e $0,2 \%$ para uso abusivo e dependência de outras drogas. Isso mostra a queda nos valores com a idade também em estudos do Brasil.

Especificamente com outros estudos na população idosa, é difícil a comparação devido aos diversos termos utilizados nos trabalhos, mas há alguns dados disponíveis. Em uma pesquisa na cidade de Ribeirão Preto, com 1.145 residentes da comunidade acima de 60 anos de características sociodemográficas semelhantes a nossa (idade média de 70 anos, predominando de mulheres e com baixa escolaridade), foi encontrada uma história prévia de uso de álcool em $51 \%$ da amostra, sendo que $8,2 \%$ da amostra foi caracterizada como "uso 
pesado de álcool” (LOPES et al., 2010). Essa avaliação foi feita considerando pontuação positiva para dois ou mais pontos no questionário CAGE; acrônimo referente às suas quatro perguntas Cut-down, Annoyed by criticism, Guilty e Eye-opener. Esse ponto de corte teria uma boa relação com o diagnóstico de dependência de álcool segundo o DSM-IV (PAZ FILHO et al., 2001). É possível que por adotar esse critério mais amplo, os valores para "uso pesado de álcool” tenham sido maiores que os nossos para transtorno do uso do álcool.

Outro estudo brasileiro, transversal, realizado com 10.537 idosos analisou o padrão de consumo de álcool entre idosos (60 anos ou mais), classificando o consumo de bebidas alcoólicas em "não uso", "uso leve/ moderado" e "uso de risco, e acordo com a frequência e o número de doses de álcool ingerido na semana. A prevalência para uso leve/moderado e de risco foi de 9,4\% e 4,6\%, respectivamente (NORONHA et al., 2019). Juntando esses valores, o total foi maior que o nosso, más é possível que isso tenha se devido ao fato de que neste trabalho a classificação foi feita baseada apenas na quantidade de álcool consumido e não na presença no número dos critérios diagnósticos estabelecidos para a classificação do transtorno de uso de álcool como leve, moderado ou grave.

As comparações são difíceis pelas diferenças metodológicas entre os estudos, uma vez que as taxas de prevalência mudam dependendo da restrição do diagnóstico. O nosso estudo se diferencia dos demais pelo fato de adotarmos o novo DSM como referencial diagnóstico e fazer uma entrevista e não a aplicação de questionários. São os possíveis fatores para divergências do nosso trabalho com a literatura: diferenças nos conceitos e definições adotadas para os transtornos relacionados ao uso de álcool e tabaco; aplicação de diferentes questionários; diferentes medidas de uso; e diferenças na idade da população incluída.

Não encontramos nenhum caso de uso de outras substâncias além de álcool e nicotina. Isto está em conformidade com a literatura. Segundo uma revisão, os indivíduos mais velhos (acima de 65 anos) da comunidade tinham taxas muito menores de prevalências nos estudos nacionais para uso de drogas ilícitas: 0,7\% para maconha e 0,04\% para cocaína, e <0,02\% para inalantes, alucinógenos, metanfetamina e heroína (WU; BLAZER, 2011). Em outra revisão a prevalência para uso atual de outras substâncias foi 0,34\% (VOLKERT et al., 2013).

Em nossa amostra, a maior dificuldade de acesso a drogas ilícitas pode também ser uma explicação para essa ausência de casos. Semelhante à nossa amostra, outros estudos também não encontraram nenhum uso de substancias na população acima de 65 anos, inclusive no estudo com população brasileira (GUM; KING-KALLIMANIS; KOHN, 2009; VIANA; ANDRADE, 2012). 
O transtorno do uso de álcool e de outras substâncias, no final da vida, tem recebido relativamente pouca atenção. Apesar de os idosos apresentarem menores taxa de prevalência se compararmos com os outros transtornos mentais ou com os valores para as populações mais jovens, nossos achados sugerem que o transtorno do uso de nicotina e de álcool não desaparecem com a idade e não são incomuns entre os idosos. Portanto, torna-se necessário identificar adequadamente estas condições e desenvolver programas de intervenção apropriados para esse grupo populacional (como programas de apoio para cessação). Isso é preocupante, dada a probabilidade de uma maior taxa de distúrbios físicos e por seus efeitos em outras doenças, que podem ser agravados com o uso do álcool e do tabaco (REHM; TAYLOR; ROOM, 2006).

A prevalência de transtornos psicóticos na amostra foi de 2,95\%, sendo $1,85 \%$ de Esquizofrenia e $1,1 \%$ de outras psicoses. Estes valores estão em conformidade com a literatura. Segundo estudos, as estimativas de prevalência comunitária para Esquizofrenia em indivíduos com idade 65 anos ou mais foi considerado baixo, variando de 0,04 a 2,6\% nos trabalhos. Este valor aumenta se forem incluídos todos os "sintomas psicóticos" como um grupo, podendo chegar a 10\% (RIEDEL-HELLER; BUSSE; ANGERMEYER, 2006). Em uma meta-análise, as taxas para a psicose atual foram de $1,7 \%$ e de $4,7 \%$ para a psicose durante a vida (VOLKERT et al., 2013). As síndromes psicóticas no final da vida parecem ser um grupo heterogêneo de distúrbios. As taxas de prevalência variam de acordo com a definição do caso e os métodos de identificação de casos utilizados.

A prevalência para transtornos relacionados ao trauma e ao estresse foram de 2,21\%, também semelhante ao relatado de $1,60 \%$ - 2,5\% para TEPT (GUM; KING-KALLIMANIS; KOHN, 2009; VIANA; ANDRADE, 2012; VOLKERT et al., 2013). Transtorno de sintoma somático, dissociativo e TOC tiveram a mesma prevalência de $0,37 \%$, valores diferentes aos da literatura. Para TOC, o valor encontrado foi maior (2,5\%), em um trabalho, mas era para prevalência ao longo da vida (VIANA; ANDRADE, 2012). Para TOC atual (últimos 6 meses), outro estudo reportou prevalência de 0,5 a $1 \%$ (RIEDEL-HELLER; BUSSE; ANGERMEYER, 2006). Um trabalho brasileiro encontrou 1,8\% para transtorno somatoforme (hoje incluído na categoria de transtorno de sintoma somático) entre idosos da comunidade (CASTRO-COSTA et al., 2007). Em uma revisão, as prevalências para esta categoria variaram de 0 a 13\% (RIEDEL-HELLER; BUSSE; ANGERMEYER, 2006). 
Outro objetivo do nosso estudo foi determinar as características psicométricas em nossa amostra de dois instrumentos de rastreio de declínio neurocognitivo: MoCA e o MoCA basic.

É importante analisar as propriedades de um instrumento no contexto cultural a que se propõe a sua utilização. Devido as especificidades socioculturais, sabe-se que fatores regionais podem propiciar habilidades e/ou dificuldades específicas de cada população (BUSTAMANTE et al., 2003; MACHADO et al., 2018).

A partir de métodos gráficos, como a construção da curva ROC, podemos analisar a validade discriminativa do instrumento de rastreio. Quanto melhor o teste, mais a área sob a curva ROC se aproxima de 1 . Se o valor da área sob a curva ROC for acima de 0,9, a capacidade de identificar uma alteração pelo teste é considerada excelente; entre 0,8 e 0,9, é considerada boa; entre 0,7 e 0,8 é considerada regular e entre 0,6 e 0,7 é considerada ruim. Valores entre 0,5 e 0,6 consideram o teste como reprovado (METZ, 1978).

Dentre as propriedades psicométricas de um instrumento, podemos determinar a sensibilidade e especificidade para cada ponto de corte adotado para diferenciar os indivíduos acometidos dos não acometidos. Sabe-se que sensibilidade é a probabilidade de um teste apresentar resultado positivo em um individuo acometido por uma doença e especificidade é a probabilidade de o teste apresentar resultado negativo em paciente sem doença (LOPES et al., 2014).

Em nossa avaliação, a área sob a curva ROC para o MoCA foi de 0,932 na diferenciação entre indivíduos com TNM e indivíduos sem TNC, sendo, portanto, considerado excelente (Figura 3). O ponto de corte 9 apresentou sensibilidade de $83 \%$ e especificidade de $95 \%$. Se o ponto de corte adotado for 12 , a sensibilidade passa a ser de $92 \%$ e a sensibilidade $85 \%$ (Tabela 6). O teste mostrou-se então com boa acurácia na discriminação de portadores de TNM na amostra de idosos de baixa escolaridade da comunidade.

Apesar de inicialmente o MoCA ter sido proposto como um ferramenta para auxílio na identificação de indivíduos com CCL (atualmente TNL), como uma alternativa a outros testes de rastreio que apresentavam baixa sensibilidade para identificar esse transtorno, mesmo no estudo de validação do MoCA também foram incluídos um grupo e pacientes com DA em estágio leve para analisar como o instrumento se apresentava para esses indivíduos (NASREDDINE et al., 2005).

O uso no rastreio de casos de demência (ou TNM) tem sido ampliado para outras condições além da DA, como demência por corpúsculos de Lewy, variante comportamental 
da demência frontotemporal, demência vascular e demência mista. Em alguns países, o MoCA foi validado exclusivamente para a detecção de quadros de TNM, como em Taiwan, Filipinas e Siri-Lanka (O'DRISCOLL; SHAIKH, 2017). Esse teste tem sido usado com sucesso inclusivo na identificação de quadros de comprometimento cognitivo decorrente da doença de Parkinson, doença de Huntington e da infecção pelo vírus da imunodeficiência humana (HIV) (BROWN et al., 2016; GLUHM et al., 2013; KIM et al., 2016).

O melhor ponto de corte nessa análise em nossa amostra foi de 9, valor abaixo do estudo original. No estudo inicial de Nasredinne et al. (2005), na comparação entre os indivíduos sem TNC e os portadores de DA leve (atualmente incluídos na categoria TNM), com ponto de corte menor que 26, o MoCA mostrou sensibilidade de $100 \%$ e especificidade $87 \%$. As pontuações dos idosos de nossa amostra foram mais baixas que as do estudo original, e foi estatisticamente diferente entre os três grupos, com os escores mais baixos predominando no grupo TNM (Média $=7,5 \pm 4,7$ ) (Tabela 5).

É possível que esse pior desempenho no teste evidenciado pelas baixas pontuações tenha a ver com uma série de fatores. Inicialmente, pode ser devido ao próprio comprometimento cognitivo decorrente da condição clínica. Apesar de os indivíduos com grau avançado de acometimento terem sido excluídos da realização dos testes, em nosso estudo foram incluídos indivíduos com TNM de várias intensidades de acometimento e não apenas casos leves, como no estudo original.

Outra possibilidade, é que a baixa escolaridade tenha contribuído de forma importante para o pior desempenho, já que o MoCA possui itens de maior complexidade, com mais itens de memória em sua avaliação, além de aspectos de função executiva. Siedlecki et al., (2009) argumentam que a reserva cognitiva está fortemente correlacionada com as funções executivas, e a reserva cognitiva está intimamente ligada a escolaridade. Podemos pensar que o MoCA foi mais complexo para esta população pois se compararmos com as maiores médias no MEEM, tanto do grupo TNM $(15,30 \pm 5,26)$ quanto dos outros dois (TNL e sem TNC) (Tabela 5).

É importante contextualizar que o MoCA foi originalmente validado no Canadá, por Nasredinne et al., (2005), numa amostra de 94 pacientes com CCL, 93 pacientes com doença de Alzheimer (DA) leve (frequentadores de um serviço ambulatorial especializado) e 90 idosos sem comprometimento cognitivo (da comunidade). A média de escolaridade dos participantes foi de 10 anos no grupo com DA leve, 12 anos no grupo com CCL e 13 anos no grupo de controles saudáveis. 
As análises iniciais indicaram que pessoas com 12 anos de educação ou menos tiveram pior desempenho no MoCA, e por isso, para corrigir os efeitos da educação, foi adicionado um ponto na pontuação total do MoCA para esses participantes. A partir do desempenho pior dos indivíduos com menor escolaridade e a soma de um ponto adicional podemos concluir que a educação afeta no desempenho desse teste. No Brasil, as pontuações sugeridas por outros estudos para diferenciação tanto de TNM quanto de TNL e indivíduos sem TNC também tem sido menor que o estudo original.

A adaptação do MoCA para o Brasil e aplicação inicial da sua versão brasileira foi feita por um grupo de pesquisadores, envolvendo uma amostra de pacientes idosos (>60 anos) de um ambulatório especializado, com diagnóstico de CCL e de controles sem CCL e sem demência, frequentadores de um serviço educacional para idosos ligado uma universidade. Nessa ocasião, foram excluídos indivíduos analfabetos e com escolaridade inferior a quatro anos. Os motivos para isso foram por desempenho aquém do esperado e dificuldades em várias questões, resultando em menores pontuações e maior tempo para realização do exame. A média escolaridade dos participantes foi de 7,6 e 9,5 anos nos grupos controle e CCL, respectivamente (SARMENTO, 2009).

A versão brasileira do MoCA foi posteriormente validada numa amostra de 112 idosos (>65 anos) com mais de 4 anos de escolaridade (a média de anos escolaridade variou de 11 a 13 anos entre os grupos). Foram incluídos não só indivíduos sem comprometimento cognitivo e portadores de CCL, mas também portadores de DA, recrutados de ambulatórios médicos e por anúncios em meios de comunicação (MEMÓRIA et al., 2013).

Assim, até o momento, não existem informações sobre o MoCA para população de baixa escolaridade, o que torna difícil a generalização. Alguns estudos propõem que é necessário estabelecer pontos de corte mais específicos e adequados para cada critério, como por exemplo para cada idade (ROALF et al., 2013).

No estudo de Memória et al., (2013), a área sob a curva do MoCA para a identificação de casos de doença de Alzheimer foi de 0,99 (IC 95\% = 0,98-1,00). Com o uso do ponto de corte de 22 pontos, exibiu alta sensibilidade (91\%) e especificidade (100\%). Um outro estudo brasileiro foi realizado por Martinelli et al., (2012), e avaliou o MoCA para diferenciar DA e controles, mostrando sensibilidade de $98 \%$ e especificidade $100 \%$, com ponto de corte 23 . A área sob a curva foi de 0,993 . Neste estudo foram excluídos idosos com escolaridade menor que 4 anos.

Sendo assim, esses estudos mostraram a validade do MoCA para discriminar TNM na população brasileira, mas até o nosso estudo não havia dados sobre os idosos de baixa 
escolaridade, que mostra a validade, mas com um ponto de corte mais baixo. Se o ponto de corte a ser a adotado for 12 , a sensibilidade fica maior, com uma especificidade ainda aceitável, adequado para um instrumento de rastreio.

A prática de adotar diferentes pontos de corte já foi avaliada em uma revisão sistemática que incluiu 18 estudos que investigaram a habilidade do MoCA para diferenciar indivíduos saudáveis de indivíduos com TNM por diversas causas. Os pontos de corte variaram de 13 a 26. A sensibilidade variou de 75\% (com especificidade de 53\%) a 100\% (com especificidade de 89\%). A especificidade variou de 57\% (sensibilidade de $75 \%$ ) a 100\% (com sensibilidade de 94\%) (O’DRISCOLL; SHAIKH, 2017).

Para a diferenciação entre os indivíduos com TNL daqueles sem TNC em nossa amostra, a área sob a curva ROC de 0,753 , portanto regular (Figura 4). A pontuação de 16 como apresentou o melhor equilíbrio entre a sensibilidade (83\%) e especificidade (68\%). Com o ponto de corte 17 a sensibilidade é de $90 \%$ e a especificidade é de $60 \%$. Para o valor de 20 , a sensibilidade é de 93\%, mas a especificidade apenas 40\% (Tabela 7).

Comparado com os casos de TNM, o MoCA apresentou uma validade discriminativa menor para identificar os casos de TNL já que a área sob a curva ROC foi menor, mas ainda assim foi regular. Isso mostra que o MoCA pode ser uma ferramenta válida para o seu propósito inicial (diferenciar TNL de indivíduos saudáveis), mesmo em amostras com baixa escolaridade.

O valor da área sob a curva encontrada por nós não foi menor que a encontrada no estudo de adaptação do MoCA para o Brasil. Na análise de Sarmento (2009), a área sob a curva ROC foi de 0,732 (IC = 0,623 a 0,840). O ponto de corte proposto foi de 24 (sensibilidade: 70,0\%; especificidade: 62,5\%). A menor área sob a curva mostra que o instrumento, mesmo em pessoas com maior escolaridade, apresentou uma validade discriminativa menor. É possível isso seja decorrente da própria dificuldade na discriminação do TNL a partir de um teste de rastreio, pois nesse transtorno o declínio cognitivo é em estágios iniciais e com menos prejuízo.

Em outros estudos, a validade discriminativa do MoCA mostrou-se melhor. No estudo de validação a área sob a curva ROC para a identificação de CCL foi maior, de 0,82 (IC = $0,67-0,94$ ) e a sensibilidade foi de $81 \%$ (especificidade $77 \%$ ) com o ponto de corte foi de 25 (MEMÓRIA et al., 2013). Uma maior área sob a curva foi encontrada no estudo de Martinelli et al., (2012): 0,943. A sensibilidade e especificidade para do MoCA ao diferenciar CCL e controles foi de $82 \%$ e $92 \%$ com o ponto de corte 25 . 
A identificação do TNL a partir dos instrumentos de rastreio de declínio cognitivo é um desafio, mas o MoCA permanece como um instrumento com boa validade, se comparado aos outros disponíveis. No estudo de Memória et al. (2013), só o CAMCOG, (Cambridge Cognitive Examination) apresentou uma área sob a curva maior (de 0,93; IC = 0,87-1,00) que o MoCA na discriminação de CCL e controles, mas o mesmo não aconteceu no estudo de Martinelli et al., (2012), no qual o MoCA foi superior. O MEEM nos dois estudos apresentou validade discriminativa menor.

Um estudo encontrou uma menor validade discriminativa do MoCA para diferenciar TNL versus controles (área $=0,89$ ) quando comparado a TNM versus controles (área $>0,99$ ), mas ainda assim com bons resultados. Os demais testes também apresentaram valores menores para “TNL vs. Controles". Segundo este estudo, o MoCA foi melhor que o MEEM para discriminar, mas não superior à bateria cognitiva CERAD (do inglês Consortium to Establish a Registry of Alzheimer's Disease) (ROALF et al., 2013).

Na revisão sistemática de O’Driscoll e Shaik (2017), os autores incluíram 16 estudos que aplicaram o MoCA para identificar TNL vs. controles, e reunindo os dados de todos os estudos chegaram a um valor para a área sob a curva ROC de 0,879, mas indicando grande heterogeneidade entre os estudos.

Sendo assim, é possível considerar que o MoCA, por ser um teste de rastreio de rápida e fácil aplicação, além de fácil acesso e realização pode ser útil a profissionais da atenção primária no rastreio de TNL. É uma alternativa acessível, já que não há a necessidade de amplo treinamento para sua aplicação. Tampouco é exigido que seja realizado por profissionais especializados, como uma avaliação neuropsicológica, recurso que infelizmente não é acessível na maioria dos serviços do nosso país. A importância de se identificar esses indivíduos torna-se evidente pelo maior risco que essas pessoas apresentam de evoluir para TNM ou apresentar outras complicações de saúde (PETERSEN et al., 2014).

Entretanto, observações tem de ser feitas sobre o ponto de corte escolhido. Em nossa análise, o ponto de corte foi de 16, com uma sensibilidade e especificidade semelhante as de Sarmento (2009), e de Memória et al. (2013), mas menores que a de Marinelli et al. (2012). Segundo O'Driscoll e Shaik, (2017), entre os estudos a sensibilidade do MoCA para identificar TNL versus controles variou de 55\% (com uma especificidade de 76\%) a $96 \%$ (com uma especificidade de 76\%) e a especificidade entre 19\% (com sensibilidade de 96\%) e 97\% (com sensibilidade de 91\%), e os pontos de corte variaram de 13 a 28 . No estudo original, o ponto de corte proposto para o MoCA foi de 26 (escores iguais ou menores que 25 
indicam comprometimento), e tinha sensibilidade de $90 \%$ e especificidade de $87 \%$ (NASREDDINE et al., 2005).

Os estudos em países da América do Sul usaram pontos de corte de 23 a 26, todos com amostras de alta escolaridade. Num estudo com a população colombiana, os autores chegam a sugerir que o ponto adicional deveria ser adicionado para aqueles com menos de 11 anos de escolaridade, em vez de 12 anos como sugerido originalmente (GIL et al., 2015; O'DRISCOLL; SHAIKH, 2017).

Quando comparamos com os estudos anteriores no Brasil, o ponto de corte foi mais baixo, o que possivelmente tem a ver com o fator de nossa amostra possuir menor escolaridade. Novamente, não há dados sobre o MoCA em populações de baixa escolaridade.

A pontuação no MoCA foi estatisticamente diferente entre os grupos sem TNC e o grupo com TNL $(18,63 \pm 5,45$ vs. 14,03 $\pm 3,90)$ o que mostra que este último apresentava os indivíduos com pior desempenho e, portanto, maior comprometimento cognitivo. A escolaridade e a idade também foram estatisticamente diferentes, e isso pode ter contribuído para o pior desempenho no MoCA dos indivíduos com TNL, que ficaram com médias de idade maior e escolaridade menor. Comparando-se com a média dos escores do MEEM, a média dos escores no MoCA foram menores, nos dois grupos, o que pode ter a ver com a maior complexidade do MoCA. No estudo de Sarmento (2009), a média dos escores no MoCA do grupo CCL foi de 22,58 ( $\mathrm{DP}=2,19)$ e no grupo controle de 24,83 ( $\mathrm{DP}=2,67)$. No de Memória et al. (2013), a média para o grupo CCL foi 22,64 (DP=2,83) e para os controles foi 26,30 (DP=2,61). Em ambos os casos, os valores foram maiores que a média dos escores da nossa amostra (Tabela 5).

Na discriminação entre os idosos com TNM daqueles com TNL a área sob a curva foi de 0,876 , valor considerado bom (Figura 5). Com o ponto de corte 8, o MOCA apresentou sensibilidade de $83 \%$ e especificidade de $93 \%$. Aumentando para 12 o ponto de corte a sensibilidade aumenta para 92\%, com especificidade é de 67\% (Tabela 8). Isso evidencia que o MoCA boa capacidade discriminativa para TNM na população estudada, com boa sensibilidade e especificidade.

Isso pode ser útil ao profissional, como uma medida par se guiar frente a um paciente com queixas cognitivas e dificuldade de avaliação sobre a funcionalidade e há maiores chances de se tratar de um TNM e não apenas de um TNL, quando outras avaliações cognitivas mais aprofundadas não estiverem disponíveis e outros testes neurocognitivos não tem um bom desempenho. A validade discriminativa do MoCA em nossa amostra foi até 
melhor em diferenciar os casos de TNM de TNL do que TNL de indivíduos sem TNC, como evidenciado pela maior área sob a curva (Figuras 4 e 5).

No estudo de Rolf et al., (2013), o MoCA apresentou um poder discriminativo menor na avaliação "CCL vs DA" (área $=0,85$ ) do que na avaliação "CCL vs Controles" (área = $0,89)$, diferente do que aconteceu em nossa amostra. Uma possibilidade é que a comparação foi feita com portadores de DA, enquanto em nossa amostra foram incluídos TNM por diversas causas, em que o declínio pode se acentuar em outros domínios que não a memória, que é mais comum na DA. Diferenças no acometimento das funções cognitivas podem ocasionar desempenhos diferentes nas tarefas, dependendo se ela for avalia atenção, memória, função executiva, etc. (CUNNINGHAM et al., 2015).

Apesar de esta discriminação não estar na proposta inicial do MoCA, este tem sido analisado em diversos estudos quanto a sua capacidade de discriminar CCL e demência. Foram identificados sete estudos na revisão de O’Driscoll e Shaik, (2017), nos quais os pontos de corte variaram de 15 a 25 . Em todos os estudos a escolaridade foi acima de 5 anos. A sensibilidade variou de $81 \%$ (com especificidade de $80 \%$ ) a $100 \%$ (com especificidade de 96\%). A especificidade variou de 70\% (com sensibilidade de $89 \%$ ) a $98 \%$ (com sensibilidade de $96 \%)$.

Novamente, o ponto de corte em nossa amostra foi baixo quando tomamos em conta a pontuação máxima do instrumento e os valores de outros estudos. A pontuação no MoCA entre o grupo TNL e TNM foi estatisticamente diferente, com o pior desempenho no grupo TNM (Tabela 5)

Fizemos duas análises adicionais para avaliar a capacidade discriminativa do MoCA na diferenciação entre idosos sem TNC e idosos dos grupos clínicos (portadores de TNM ou TNL); e na diferenciação dos idosos com TNM e o restante da amostra (sem TNC ou com TNL). A área sob a curva ROC foi 0,800 , considerada boa, no primeiro caso, e 0,914, considerada excelente, no segundo caso (Figuras 6 e 7). O ponto de corte (melhor equilíbrio sensibilidade/especificidade) foi 16 no primeiro caso (sensibilidade 85\%/especificidade 67\%) e 8 no segundo caso (sensibilidade $83 \%$ especificidade 95\%) (Tabelas 9 e 10).

O MoCA mostrou boa validade quando aplicado tanto para discriminar um portador de qualquer TNC dos que não possuem nenhum comprometimento, quanto para um portador de um comprometimento mais intenso (TNM) do restante da amostra sem declínio ou com declínio leve, sendo melhor para esse segundo caso.

De forma geral, em nossa amostra, os valores de área sob a curva ROC para o MoCA em todas as análises foram de regular a excelente e os valores de sensibilidade e 
especificidades foram satisfatórios. $\mathrm{O}$ teste mostrou maior validade discriminativa sobretudo para diferenciar TNM de indivíduos sem TNC, e menor validade discriminativa para diferenciar TNL de indivíduos sem TNC.

Os pontos de corte variaram de 8 a 16. Abaixo de 8 há maior probabilidade de que o indivíduo seja diagnosticado como portador de TNM e acima de 16 de que ele não tenha nenhum TNC. Os pontos de corte recomendados são 9 para diferenciar TNM de indivíduos possivelmente sem TNC e 16 para diferenciar TNL de indivíduos sem TNC. Esses pontos de corte são menores que os recomendados na literatura para indivíduos com escolaridade maior que 4 anos.

A comparação entre os valores de ponto de corte disponíveis na literatura é difícil pela grande variação entre os países e mesmo entre regiões de um mesmo país. Podem-se citar alguns fatores para essas assimetrias: diferenças nas amostras selecionadas, nas pontuações adicionais atribuídas às diferentes escolaridades, problemas nas traduções, etc. É possível discutir sobre a influência da educação nessa variabilidade nas pontuações, mas os anos de educação e também a qualidade da educação podem não ser equivalentes entre os países e regiões, inviabilizando comparações. Até o momento, não há um padrão claro para o efeito da educação sobre o teste, especialmente para escolaridades abaixo de 8 anos. O que se sabe é que alguns itens do MoCA (desenho do relógio, fluência verbal fonêmica e abstração verbal) são influenciados pela educação (O’DRISCOLL; SHAIKH, 2017).

Apesar de no estudo de Memória et al. (2013), os autores não terem encontrado influência da escolaridade no desempenho no MoCA para o grupo sem TNC, a escolaridade afetou o desempenho em diferentes itens do MoCA para os grupos CCL e DA, especialmente os itens relacionados a funções executivas.

Essa influência da educação no desempenho dos diferentes grupos fala a favor da importância da escolaridade para a reserva cognitiva. Nos indivíduos que já tem algum comprometimento, ou seja, que já perderam sua reserva, a escolaridade passa a impactar o desempenho nas tarefas. Em nossa população, o desempenho geral nesse instrumento foi pior que os trazidos em outros estudos provavelmente pela baixa reserva cognitiva adquirida durante a vida, pela falta de escolaridade. Uma baixa reserva foi evidenciada no pior desempenho da amostra como um todo, já que mesmo no grupo sem TNC, quando comparado aos outros estudos, a média das pontuações foram menores (Tabela 5). Uma população com menor reserva cognitiva é mais vulnerável aos TNC (BRUCKI, 2010).

A figura 13 mostra a dispersão dos escores do MoCA em relação ao MEEM para toda a amostra. O coeficiente de correlação entre os dois instrumentos foi de 0,698 (coeficiente de 
Spearman), uma correlação moderada. De fato, a existência da correlação entre os escores sugere quem os testes possam estar aferindo aspectos cognitivos semelhantes.

Entretanto, apesar de aferirem aspectos semelhantes, estes testes podem fazer isso em níveis de dificuldade distintos. Isso é esperado, já que a natureza das tarefas e a forma de avaliações são também diferentes entre os instrumentos. Isso pode favorecer um ou outro instrumento a ser mais adequadas na discriminação dos TNC (MONTIEL et al., 2013).

Neste trabalho, também fizemos a avaliação das características psicométricas do instrumento de rastreio cognitivo MoCA basic. Este teste neurocognitivo foi proposto por Julayanont et al., (2015), como um instrumento para rastreio de CCL em idosos analfabetos e de baixa escolaridade, visto que o MoCA em sua versão original foi validado em uma amostra com alta escolaridade e inclui tarefas que dependem de educação formal.

$\mathrm{O}$ uso do MoCA pode acabar produzindo vieses na avaliação de analfabetos ou indivíduos com baixa escolaridade, pois estes podem ser equivocadamente classificados como portadores de declínio cognitivo ao apresentar desempenho ruim no teste. Uma metanálise realizada no Canadá, com o MoCA em sua versão original, detectou problemas com sensibilidade e especificidade e mostrou que o ponto de corte de 23 apresentava maior precisão de classificação (90\%) e melhor equilíbrio entre falso e verdadeiro positivo (CARSON; LEACH; MURPHY, 2018).

Uma vez que o nível educacional pode influenciar no desempenho do teste cognitivo, dissociar o comprometimento cognitivo do envelhecimento normal continua sendo um desafio ao rastrear TNL nesses grupos. Portanto, novos pontos de corte mais específicos para a realidade de cada população ou desenvolver um instrumento com tarefas que sofram menos influência e menor dependência de escolarização podem ser propostos para tentar contornar essa dificuldade.

Deste modo, os autores desenvolveram uma nova versão do MoCA, chamada de MoCA basic, substituindo os itens da versão anterior que mais dependiam da escolaridade por tarefas independentes de alfabetização e que mediam a mesma função cognitiva. Esta versão foi então validada em indivíduos de idade entre 55 e 80 anos, com menos de cinco anos de escolaridade, recrutados em um hospital de Bangkok, Tailândia. O grupo com considerado como CCL foram indivíduos que preenchiam diagnóstico para CCL por doença de Alzheimer, sem comprometimento da funcionalidade e que não preenchessem critério para demência. Após a análise inicial, para evitar influência da escolaridade, um ponto deveria ser adicionado se o indivíduo tivesse menos de 4 anos de escolaridade e se fosse considerado analfabeto (incapacidade de ler e escrever) (JULAYANONT et al., 2015c). 
Apesar de ter sido elaborado para detecção de indivíduos portadores de CCL, ou seja, TNL, o MoCA basic também tem foi aplicado em estudos com portadores de TNM por diversas causas (SALEH et al., 2019), e por DA leve (CHEN et al., 2016a; HUANG et al., 2018) e também para avaliar TNC por outras doenças não neurodegenerativas como infecção pelo HIV (HAKKERS et al., 2018) e declínio cognitivo em pacientes portadores de doença renal crônica (AMATNEEKS; HAMDAN, 2019).

Em nossa amostra, a capacidade discriminativa do MoCA basic foi avaliada para diferenciar os portadores de TNM dos indivíduos sem TNC. A área sob a curva ROC de 0,910, considerada excelente (Figura 8). O ponto de corte sugerido foi de 21, com sensibilidade de $100 \%$ e especificidade de $72 \%$ (Tabela 11). Estes resultados mostram que o MoCA basic é um instrumento com boa aplicabilidade para o rastreio de TNC na nossa amostra, com baixa escolaridade, já que teve alta sensibilidade (bom para um teste de rastreio) e boa especificidade, com uma validade discriminativa excelente.

Para identificar os indivíduos com TNL versus os indivíduos sem TNC, tarefa para o qual o MoCA basic foi proposto, a área sob a curva ROC foi de 0,834 , sendo considerada como boa. O ponto de corte com melhor equilíbrio entre sensibilidade (89\%) e especificidade (72\%) foi 21 . Com a pontuação de 22 , a sensibilidade passa a ser $100 \%$, mas a especificidade cai para $61 \%$. Como instrumento de rastreio, é indicado que tenha alta sensibilidade, mas que apresente também boa especificidade, assim, o ponto mais indicado é 21 .

O desempenho no MoCA basic do grupo TNL foi pior que o do grupo sem TNC, o que é evidenciado quando comparamos as médias dos escores para cada grupo. Essa diferença foi estatisticamente significativa, e pode apontar para que de fato a pior performance no teste esteja sendo decorrente do comprometimento cognitivo do grupo com TNL.

No estudo de Saleh et al. (2019), os autores também utilizaram o MoCA basic para discriminar TNM e TNL de indivíduos "controles". A área sob a curva ROC foi, respectivamente, de 0,992 , e de 0,988 . De forma semelhante ao que aconteceu no nosso estudo, a área sob a curva na identificação dos portadores de TNM foi maior que a dos TNL. Segundo estes autores os pontos de corte adotados deveriam ser diferentes dependendo da escolaridade. O ponto de corte "universal" recomendado para todos os indivíduos foi 21/22 com sensibilidade de 92,5\% e especificidade de 98,2\% para detecção de TNL e 16/17 com sensibilidade de 90,7\% e especificidade de 97,4\% para detecção de TNM. Em indivíduos com baixa escolaridade (menos de seis anos), o ponto de corte recomendado foi 18/19 para detecção de TNL com sensibilidade de $87 \%$ e especificidade de $100 \%$ e 13/14 para detecção de TNM com sensibilidade de 92,5 e especificidade de $100 \%$. 
No estudo de validação do MoCA basic, Julayanont et al. (2015) incluíram apenas indivíduos com CCL. A área sob a curva ROC foi de 0,900 para discriminar CCL vs. controles. O ponto de corte sugerido foi de 25 , com sensibilidade de $86 \%$ e especificidade de $86 \%$. Nesse trabalho os autores não relataram diferença significativa entre os escores de acordo com a escolaridade.

O ponto de corte em nossa amostra (21 tanto para TNL quanto para TNM) foi mais baixo que o proposto no estudo original de validação do MoCA basic. Em outros estudos que avaliaram o MoCA basic, os pontos de corte propostos variaram de 13 a 24 (CHEN et al., 2016a; HUANG et al., 2018; SALEH et al., 2019). Isso pode ocorrer por questões culturais de cada amostra e reforça a ideia de que não há um ponto de corte universal para todas as populações, pois muitas vezes esses dados têm que ser normatizados para cada país, segundo idade, escolaridade, entre outros fatores (APOLINARIO et al., 2018).

Para Saleh et al. (2019), a correlação positiva encontrada entre o nível de escolaridade e a pontuação total do MoCA basic neste estudo sugeriu que, apesar das modificações feitas no instrumento, ele ainda é afetado pela escolaridade.

Em nossa amostra, a escolaridade e a idade foram estatisticamente diferentes entre os três grupos de pacientes. Quanto maior o comprometimento clínico, maiores as médias de idade e menor a média de anos de escolaridade. No entanto, os escores totais do MoCA basic não diferiram entre os grupos TNM e TNL (Tabela 5), apenas comparados ao grupo sem TNC. Isto não ocorreu com as pontuações do MEEM e do MoCA, diferente entre todos os grupos (Tabela 5). No trabalho de Saleh et al. (2019), os grupos com pacientes com distúrbios neurocognitivos, tanto leve quanto maior, tenderam a ser mais velhos e com menor número de anos de escolaridade.

Sobre a ausência de diferença estatisticamente significativa do desempenho no MoCA basic entre o grupo TNM e TNL é possível supor duas explicações. Inicialmente, pode ser devido as próprias qualidades e tarefas do teste, que foram designadas para rastrear declínio cognitivo de intensidade leve (possíveis portadores de TNL) de indivíduos sem declínio cognitivo. É de se imaginar que se o teste detecta declínios leves, ele também o fará para declínios mais pronunciados. A dúvida é, no entanto, se ele consegue diferenciar quem tem este comprometimento em maior ou menor grau.

A segunda possibilidade é devido a dificuldades metodológicas na aplicação do instrumento em nossa amostra. Como não houve controle para o número de quantos indivíduos com TNL ou com TNM ficavam em cada grupo para realizar o MoCA basic ou o MoCA em sua versão original, o MoCA basic foi aplicado apenas em seis indivíduos com 
TNM (e 18 com TNL), o que pode ter comprometido a análise. O ponto de corte para identificação tanto do TNM quanto do TNL foi 21, resultado da menor capacidade do instrumento de discriminar esses dois transtornos pelos fatores descritos acima.

No estudo de validação da versão chinesa do MoCA basic, os autores decidiram dividir a amostra em três grupos, na tentativa de reduzir o viés educacional, de acordo com os anos de escolaridade: baixa ( $\leq 6$ anos), média (7 a 12 anos), alta ( $>12$ anos). Foram incluídos indivíduos de 50 a 80 anos. Os pontos de corte foram 19 no grupo de baixa escolaridade (sensibilidade $87,9 \%$, especificidade $81,0 \%$, área sob a curva: 0,896); 22 no grupo de ensino médio (7 a 12 anos) (sensibilidade 92,9\%, especificidade 91,2\%, área sob a curva: 0,949); e 24 no grupo de ensino superior (> 12 anos) (sensibilidade $89,9 \%$, especificidade $81,5 \%$, área sob a curva: 0,916). Dentro do mesmo grupo, os anos de escolaridade não afetaram os escores, mas cada grupo chegou a um ponto de corte diferente (CHEN et al., 2016).

Outro estudo analisou o MoCA basic para diferenciar diferentes quadros de comprometimento cognitivo, incluindo indivíduos sem comprometimento cognitivo, com CCL, e com DA, tanto leve quanto moderada, com idade de 50 - 90 anos. Os autores novamente decidiram dividir a amostra de acordo com o nível de escolaridade. Para identificar os indivíduos com CCL vs. sem comprometimento, o MoCA basic apresentou boa capacidade discriminativa, com área sob a curva maior que 0,800 nos três grupos educacionais, indicando que independente do nível de escolaridade o instrumento teve boa capacidade. Os pontos de corte com melhor sensibilidade e especificidade variaram (19 para o grupo com menor escolaridade, 22 para o grupo intermediário e 24 para o de maior escolaridade) (HUANG et al., 2018). Nesse mesmo estudo, para diferenciar entre CCL e DA (leve ou moderada), segundo os autores, a área sob a curva para o MoCA basic foi a mesma, “em torno de 0,800 " para os três grupos, e os pontos de corte em ordem crescente de escolaridade foram: 13, 15 e 16 (HUANG et al., 2018).

A constatação de que muitos estudos chegam a pontos de corte diferentes encontra reforço na explicação de que fatores culturais (ou seja, o acúmulo de conhecimento compartilhado, refletido em comportamentos, experiências, crenças, valores, atitudes), estilo de vida (fatores ligados aos recursos disponíveis no cotidiano, por exemplo, emprego, dieta), e educação (que pode ser considerada de uma forma mais ampla, como um aspecto da cultura e não apenas técnica e formal) variam entre e dentro dos grupos. Assim, pontos de corte ajustados para cada contexto de educação e cultura podem dar melhor suporte aos profissionais em decisões clínicas mais individualizadas (O’DRISCOLL; SHAIKH, 2017). 
Na nossa amostra, fizemos essa análise para avaliar área sob a curva ROC do MoCA basic, quando usado para discriminar idosos portadores de TNM dos portadores de TNL. Diferente do estudo de Huang et al. (2018), o valor da área foi de 0,671. Na nossa análise, o MoCA basic foi considerado, portanto, ruim (Figura 10). O teste neurocognitivo não mostrou boa capacidade para discriminar entre os idosos dos dois grupos clínicos. A sensibilidade foi de $83 \%$ e a especificidade de $56 \%$, com o ponto de corte 17 (Tabela 13), ponto de corte maior que os do estudo chinês.

Como mencionado anteriormente, é possível que o fato de apenas seis indivíduos com TNM terem sido submetidos ao MoCA basic dificulte as análises. A comparação com o estudo anterior é difícil por não fizemos classificação entre os idosos em subgrupos de escolaridade e tínhamos no grupo portadores de TNM por diversas causas, não apenas por DA.

Sobre o uso do MoCA basic para discriminação de pacientes com declínio cognitivo por outras causas ou associado a outras doenças (não neurodegenerativas) há alguns estudos. $\mathrm{Na}$ África do Sul, o MoCA basic foi considerado não válido como ferramenta de rastreio para TNC associados a infecção pelo vírus HIV. Segundo os autores, a curva ROC para triagem de TNC associado ao HIV para o MoCA basic foi de 0,590 (HAKKERS et al., 2018).

No Brasil, o único estudo disponível com o MoCA basic foi envolvendo pacientes portadores de doença renal crônica. Os autores utilizaram a versão brasileira do MoCA basic como instrumento de triagem de indivíduos com comprometimento cognitivo associado a doença renal. A amostra era composta por indivíduos de diversas idades (19-83 anos) e escolaridades, mas com predomínio de escolaridade acima de 5 anos (93,25\% do total). Para determinar o comprometimento cognitivo foi utilizado o MEEM. Os autores não mencionam sobre os critérios utilizados para definir esta condição (AMATNEEKS; HAMDAN, 2019).

A área sob a curva ROC para o MoCA nesse estudo foi de 0,777 . O ponto de corte sugerido foi de 21 , com sensibilidade de $77 \%$ e especificidade de $72 \%$. O ponto de corte encontrado para considerar comprometimento cognitivo associado a doença renal crônica numa população com maior escolaridade e de diversas idades foi a mesma encontrada em nosso estudo para idosos da comunidade de baixa escolaridade. Em nosso estudo, a proporção de idosos com mais de 5 anos de escolaridade foi de $18 \%$.

Fizemos também análises adicionais para avaliar a capacidade discriminativa do MoCA basic em diferenciar entre indivíduos sem TNC dos portadores de algum TNC (TNM ou TNL), bem como diferenciar os indivíduos com TNM do restante da amostra (tanto aqueles sem TNC, quanto os portadores de TNL). Nos dois casos o MoCA apresentou uma 
boa validade discriminativa (área sob a curva ROC de 0,853 e 0,848 , respectivamente), mas maior para discriminar indivíduos com algum TNC dos sem TNC (Figuras 11 e 12). O ponto de corte de 21 para o primeiro propósito apresentou sensibilidade de $92 \%$ e especificidade de $72 \%$. No segundo caso, o ponto de corte foi mais baixo, de 17 , e as taxas de sensibilidade e especificidade também foram mais baixas (83\% e 80\%) (Tabelas 14 e 15).

O MoCA basic apresentou uma melhor capacidade discriminativa para identificar indivíduos portadores de TNM frente indivíduos sem TNC. O teste apresentou boa capacidade para discriminar, em ordem decrescente de área sob a curva ROC, indivíduos portadores de qualquer TNC (TNL ou TNM) vs. indivíduo sem TNC; indivíduos portadores de TNM dos sem TNC ou portadores e TNL; e portadores de TNL vs. sem TNC. O teste não teve boa capacidade de discriminar portadores de TNM daqueles com TNL.

A correlação do MoCA basic com o MEEM foi moderada, com coeficiente de $\mathrm{r}=$ 0,647 ( $\mathrm{p}<0,01)$. A figura 14 mostra a dispersão dos escores do MoCA basic em relação ao MEEM para toda a amostra. Novamente, a existência da correlação entre os escores sugere que os testes possam estar aferindo aspectos cognitivos semelhantes.

A partir dos nossos resultados, reforçado com informações de outros estudos disponíveis na literatura, é possível concluir que o MoCA basic mostrou-se uma ferramenta válida, com valores de sensibilidade e especificidade adequados, para rastreio de casos de TNM e de TNL, mas não para discriminar entre TNM e TNL em uma amostra de idosos de baixa escolaridade da comunidade.

É importante ressaltar que o MoCA basic em nossa amostra apresentou validade discriminativa maior quando comparado ao MoCA em sua versão original. Isso pode falar a favor de que pela maior complexidade e influência da escolaridade do MoCA, sua capacidade de discriminar é prejudicada pelo baixo desempenho mesmo dos indivíduos sem TNC.

$\mathrm{O}$ fato de o MoCA basic ter sido pensado como uma ferramenta para a identificação de casos de TNL e de que na nossa amostra ele conseguiu identificar casos de TNM melhor que TNL mostra a dificuldade que esse diagnóstico representa na prática clínica. As formas de medir esse prejuízo cognitivo intermediário entre o declínio cognitivo do envelhecimento normal e o patológico seguem como um foco da pesquisa.

Há perspectivas futuras que buscam para estabelecer biomarcadores, exames de imagem e novas tecnologias como recursos diagnósticos para esta entidade clínica. Entretanto, testes de rastreio que detectam e quantificam esse prejuízo oferecem uma boa base para o clínico exercer seu julgamento e auxiliam o diagnóstico. O MoCA basic apresentou uma boa validade discriminativa na detecção tanto dessas formas precoces quanto das mais 
avançadas numa amostra populacional, da comunidade, sendo assim um instrumento promissor.

\section{Limitações do estudo}

Uma limitação do nosso estudo é que a amostra veio de uma área específica de baixa renda da cidade de São Carlos. A amostra é proveniente de uma unidade da saúde da família, assim estes resultados representam esta amostra específica. No entanto, as características socioeconômicas da nossa amostra são semelhantes ao perfil da população idosa brasileira, o que possibilita comparabilidade.

Trata-se de um estudo transversal, e por isso tem suas limitações, sobretudo na interpretação sobre associações e causalidade.

Além disso, não é possível assegurar que os fatores de confusão foram igualmente distribuídos entre os grupos de idosos. É preciso ainda mencionar possíveis erros advindos de viés de seleção e amostragem, recusas de participação ou em responder os questionamentos, e do viés de prevalência.

$\mathrm{Na}$ investigação sobre os instrumentos de rastreio cognitivo, a dependência de alguns subtestes do MoCA influenciados pela educação (por exemplo, funcionamento executivo) pode limitar a interpretação dos dados. Como não houve como controlar o tamanho dos grupos, estes acabaram não tendo o mesmo tamanho, o que pode influenciar a eficiência estatística.

Outra limitação é o fato de os grupos TNM e TNL serem heterogêneos, pois diferentes subtipos transtornos foram incluídos na amostra. No entanto, isso fornece melhores dados sobre a aplicação destes testes nos idosos portadores dessas condições de uma forma geral, o que é importante para uma ferramenta de rastreio. 


\section{CONCLUSÃO}

O presente estudo avaliou frequência de transtornos mentais em idosos residentes na área de abrangência de uma unidade do programa Saúde da Família. Além disso determinou e comparou as qualidades psicométricas de dois instrumentos de rastreio breve para declínio cognitivo.

A partir dos resultados, foi possível observar que os transtornos mentais estavam presentes em pelo menos $55 \%$ dos avaliados. Os transtornos mais comuns foram os transtornos neurocognitivos, seguidos dos transtornos ansiosos, transtornos depressivos, transtornos de sono e transtorno do uso de substâncias.

$\mathrm{O}$ instrumento de rastreio MoCA apresentou excelente validade discriminativa para identificar TNM e regular para identificar TNL. Os pontos de corte sugeridos para cada transtorno são $\quad 9 \quad$ (sensibilidade $\quad 83 \%$ /especificidade $95 \%$ ) $83 \% /$ especificidade 68\%), respectivamente. O MoCA basic apresentou excelente validade discriminativa para identificar TNM e boa para identificar TNL. O ponto de corte para ambas condições foi 21, com sensibilidade $100 \%$ (especificidade 72\%) para TNM e sensibilidade $89 \%$ (especificidade $72 \%$ ) para TNL.

Tanto o MoCA quanto o MoCA basic podem ser úteis para rastreio de TNC entre idosos de baixa escolaridade, da comunidade, podendo ser usados na atenção primária, uma vez que são de fácil entendimento e demandam apenas de alguns minutos para sua execução. Estes instrumentos podem apoiar os profissionais no julgamento clínico e melhor gestão sobre necessidade de investigações e recursos adicionais frente a idosos com queixas de declínio cognitivo. 


\section{REFERÊNCIAS}

ALEXANDRINO-SILVA, C. et al. Prevention of depression and anxiety in communitydwelling older adults: the role of physical activity. Archives of Clinical Psychiatry (São Paulo), v. 46, n. 1, p. 14-20, fev. 2019.

ALMEIDA-FILHO, N. et al. Brazilian multicentric study of psychiatric morbidity. British Journal of Psychiatry, v. 171, n. 6, p. 524-529, 2 dez. 1997.

AMATNEEKS, T. M.; HAMDAN, A. C. Sensitivity and specificity of the Brazilian version of the Montreal Cognitive Assessment - Basic (MoCA-B) in chronic kidney disease. Trends in Psychiatry and Psychotherapy, v. 41, n. 4, p. 327-333, out. 2019.

AMERICAN PSYCHIATRIC ASSOCIATION. Diagnostic and Statistical Manual of Mental Disorders, Fifth Edition (DSM-V). Fifith edi ed. Arlington, VA: American Psychiatric Association, 2013.

ANDERSON, M. I. P. et al. Saúde e qualidade de vida na terceira idade. Textos sobre Envelhecimento, v. 1, n. 1, p. 23-43, 1998.

ANDRADE, L. et al. Cross-national comparisons of the prevalences and correlates of mental disorders. Bulletin of the World Health Organization, v. 78, n. 4, p. 413-426, 2000.

ANDRADE, L. et al. Prevalence of ICD-10 mental disorders in a catchment area in the city of São Paulo, Brazil. Social Psychiatry and Psychiatric Epidemiology, v. 37, n. 7, p. 316-325, 2002a.

ANDRADE, L. H. et al. Mental Disorders in Megacities: Findings from the São Paulo Megacity Mental Health Survey, Brazil. PLOS ONE, v. 7, n. 2, p. e31879, 14 fev. 2012.

ANDREAS, S. et al. Prevalence of mental disorders in elderly people: The European MentDis-ICF65+ study. British Journal of Psychiatry, v. 210, n. 2, p. 125-131, 2017.

APOLINARIO, D. et al. Normative data for the Montreal Cognitive Assessment (MoCA) and the Memory Index Score (MoCA-MIS) in Brazil: Adjusting the nonlinear effects of education with fractional polynomials. International Journal of Geriatric Psychiatry, v. 33, n. 7, p. 893-899, jul. 2018.

ASHBY-MITCHELL, $\mathrm{K}$. et al. Life expectancy with and without cognitive impairment in seven latin American and Caribbean countries. PLOS ONE, v. 10, n. 3, p. 1-11, 2015.

AU, B.; DALE-MCGRATH, S.; TIERNEY, M. C. Sex differences in the prevalence and incidence of mild cognitive impairment: A meta-analysis. Ageing Research Reviews, v. 35, p. 176-199, 2017.

BALDAÇARA, L. et al. Psychiatric Emergencies in the Elderly. Epidemiological study. Arquivos Médicos dos Hospitais e da Faculdade de Ciências Médicas da Santa Casa de São Paulo, v. 57, n. 1, p. 11-18, 2012. 
BARTOLONI, L. et al. A population-based study of cognitive impairment in socially vulnerable adults in Argentina. The Matanza Riachuelo Study. Preliminary Results. Dementia \& Neuropsychologia, v. 8, n. 4, p. 339-344, dez. 2014.

BATISTA, M. P. P.; ALMEIDA, M. H. M. DE; LANCMAN, S. Politicas públicas para a população idosa: uma revisão com ênfase nas ações de saúde. Revista de Terapia Ocupacional da Universidade de São Paulo, v. 22, n. 3, p. 200-207, 1 dez. 2011.

BENEDETTI, T. R. B. et al. [Physical activity and mental health status among elderly people]. Revista de Saúde Pública, v. 42, n. 2, p. 302-7, 2008.

BICKEL, H.; KURZ, A. Education, occupation, and dementia: The bavarian school sisters study. Dementia and Geriatric Cognitive Disorders, v. 27, n. 6, p. 548-556, 2009.

BISCHKOPF, J.; BUSSE, A.; ANGERMEYER, M. C. Mild cognitive impairment - A review of prevalence, incidence and outcome according to current approaches. Acta Psychiatrica Scandinavica, v. 106, n. 6, p. 403-414, 2002.

BLAZER, D. G.; WU, L.-T. The Epidemiology of Alcohol Use Disorders and Subthreshold Dependence in a Middle-Aged and Elderly Community Sample. The American Journal of Geriatric Psychiatry, v. 19, n. 8, p. 685-694, ago. 2011.

BOFF, M. S.; SEKYIA, F. S.; BOTTINO, C. M. Prevalence of dementia among brazilian population: systematic review. Revista de Medicina (São Paulo), v. 94, n. 3, p. 154-161, 2015.

BORGES, G. L. G. et al. Prevalencia y factores asociados al consumo de tabaco, alcohol y drogas en una muestra poblacional de adultos mayores del distrito federal. Salud Mental, v. 37, n. 1, p. 15-25, 2014.

BORGES, G. M. Health transition in Brazil: regional variations and divergence/convergence in mortality. Cadernos de Saúde Pública, v. 33, n. 8, p. 1-15, 2017.

BOTTINO, C. M. C. et al. Prevalence ofdementia and MCI in Sao Paulo, Brazil (Symposium). International Psychogeriatrics, v. 17, n. s2, p. 20-127, 8 set. 2005.

BOTTINO, C. M. C. et al. Estimate of dementia prevalence in a community sample from São Paulo, Brazil. Dementia and Geriatric Cognitive Disorders, v. 26, n. 4, p. 291-299, 2008.

BRASIL. Política Nacional de Atenção Básica. Brasília: Ministério da Saúde. Secretaria de Atenção à Saúde. Departamento de Atenção Básica., 2012. v. 1

BROWN, D. S. et al. Use of the Montreal Cognitive Assessment and Alzheimer's Disease-8 as cognitive screening measures in Parkinson's disease. International Journal of Geriatric Psychiatry, v. 31, n. 3, p. 264-272, mar. 2016.

BRUCKI, S. M. D. Illiteracy and dementia. Dementia \& Neuropsychologia, v. 4, n. 3, p. 153-157, 2010. 
BRUCKI, S. M. D. Epidemiology of Mild Cognitive Impairment in Brazil. Dementia \& Neuropsychologia, v. 7, n. 4, p. 363-366, 2013.

BURLÁ, C. et al. Panorama prospectivo das demências no Brasil: um enfoque demográfico. Ciência \& Saúde Coletiva, v. 18, n. 10, p. 2949-2956, 2013.

BUSTAMANTE, S. E. Z. et al. Instrumentos combinados na avaliação de demência em idosos: resultados preliminares. Arquivos de Neuro-Psiquiatria, v. 61, n. 3A, p. 601-606, set. 2003.

CAMPOS, A. C. V.; GONÇALVES, L. H. T. Aging demographic profile in municipalities in the state of Pará, Brazil. Revista Brasileira de Enfermagem, v. 71, n. suppl 1, p. 591-598, 2018 .

CARSON, N.; LEACH, L.; MURPHY, K. J. A re-examination of Montreal Cognitive Assessment (MoCA) cutoff scores. International Journal of Geriatric Psychiatry, v. 33, n. 2, p. 379-388, 2018.

CARVALHO, V. A.; CARAMELLI, P. Brazilian adaptation of the Addenbrooke' $\mathrm{s}$ Cognitive. Dementia \& Neuropsychologia, v. 1, n. 2, p. 212-216, 2007.

CASTRO-COSTA, E. et al. Prevalence of depressive symptoms and syndromes in later life in ten European countries: The SHARE study. British Journal of Psychiatry, v. 191, n. NOV., p. 393-401, 2007.

CÉSAR, K. G. et al. Prevalence of Cognitive Impairment Without Dementia and Dementia in Tremembé, Brazil. Alzheimer Disease \& Associated Disorders, v. 30, n. 3, p. 264-271, $2016 \mathrm{a}$.

CHAGAS, M. H. N.; PESSOA, R. M. P.; ALMEIDA, O. P. Comparison of DSM-IV and DSM-5 dementia criteria among older people living in a community sample. International Journal of Geriatric Psychiatry, v. 33, n. 5, p. 801-802, maio 2018.

CHAIMOWICZ, F.; BURDORF, A. Reliability of Nationwide Prevalence Estimates of Dementia: A Critical Appraisal Based on Brazilian Surveys. PLOS ONE, v. 10, n. 7, p. e0131979, 1 jul. 2015.

CHAVES, M. L. et al. Incidence of mild cognitive impairment and Alzheimer disease in Southern Brazil. Journal of Geriatric Psychiatry and Neurology, v. 22, n. 3, p. 181-187, 2009.

CHEN, K.-L. et al. Validation of the Chinese Version of Montreal Cognitive Assessment Basic for Screening Mild Cognitive Impairment. Journal of the American Geriatrics Society, v. 64, n. 12, p. e285-e290, dez. 2016a.

CLEMENTE, R. S. G.; RIBEIRO-FILHO, S. T. Comprometimento cognitivo leve: aspectos conceituais, abordagem clínica e diagnóstica. Revista do Hospital Universitário Pedro Ernesto, v. 7, n. 1, p. 68-77, 2008.

COELI, C. M.; VERAS, R.; COUTINHO, E. Epidemiologia dos transtornos mentais em 
idosos: um estudo comunitario e hospitalar. In: BARRETO, M. (Ed.). Epidemiologia, serviços e tecnologias em saúde. 3 ed. Rio de Janeiro: Editora FIOCRUZ, 1998. p. 207-232.

CORREA-RIBEIRO, P. C. et al. Prevalence of dementia in elderly clients of a private health care plan: A study of the FIBRA-RJ. Dementia and geriatric cognitive disorders, v. 35, n. 1-2, p. 77-86, 2013.

COSTA, E. et al. Prevalence of International Classification of Diseases, 10th Revision Common Mental Disorders in the Elderly in a Brazilian Community: The Bambui Health Ageing Study. The American Journal of Geriatric Psychiatry, v. 15, n. 1, p. 17-27, jan. 2007.

CUNNINGHAM, E. L. et al. Dementia. The Ulster medical journal, v. 84, n. 2, p. 79-87, maio 2015.

DA SILVA, V. F. MIGRANTES NA PERIFERIA URBANA DO INTERIOR DE SÃO PAULO: TRAJETÓRIAS E IDENTIDADE. Cadernos CERU, n. 18, p. 91-105, 2005.

DE ARRUDA, L. M.; AVANSI, T. A. Analfabetismo na terceira idade: pesquisa do analfabetismo em Sinop - MT. Revista Eventos Pedagógicos, v. 5, n. 2, p. 397-402, 2014.

DECARLO, C. A. et al. BioAge: toward a multi-determined, mechanistic account of cognitive aging. Ageing research reviews, v. 18, n. 2, p. 95-105, nov. 2014.

DEPP, C. A.; JESTE, D. V. Bipolar disorder in older adults: a critical review. Bipolar Disorders, v. 6, n. 5, p. 343-367, out. 2004.

DI PIERRO, M. C. Educação de jovens e adultos na América Latina e Caribe: trajetória recente. Cadernos de Pesquisa, v. 38, n. 134, p. 367-391, ago. 2008.

DIAS, F. L. DA C. et al. Prevalence of late-life depression and its correlates in a communitydwelling low-educated population aged 75+ years: The Pietà study. Journal of Affective Disorders, v. 242, n. April 2018, p. 173-179, jan. 2019.

DINIZ, B. S. et al. Mild cognitive impairment: cognitive screening or neuropsychological assessment? Revista Brasileira de Psiquiatria, v. 30, n. 4, p. 316-321, dez. 2008.

DUBE, S. R. . et al. Cigarette smoking among adults and trends in smoking cessation - United States, 2008. Morbidity and mortality weekly report, v. 58, n. 44, p. 1227-1232, 2009.

DUFOUIL, C. et al. Older age at retirement is associated with decreased risk of dementia. European Journal of Epidemiology, v. 29, n. 5, p. 353-361, 4 maio 2014.

EAtON, W. W.; BIENVENU, O. J.; MILOYAN, B. Specific phobias. The Lancet Psychiatry, v. 5, n. 8, p. 678-686, 2018.

ENDESHAW, Y. W. et al. Sleep-disordered breathing and nocturia in older adults. Journal of the American Geriatrics Society, v. 52, n. 6, p. 957-960, 2004.

ENGROFF, P. et al. Doenças crônicas não transmissíveis e fatores sociodemográficos 
associados a sintomas de depressão em idosos. Jornal Brasileiro de Psiquiatria, v. 66, n. 1, p. $45-51,2017$.

ERVATTI, L. R.; BORGES, G. M.; JARDIM, A. DE P. Mudança Demográfica no Brasil no início do Século XXI: Subsídios para as Projeções da População. Estudos \& Análises. Informação Demográfica e socioeconômica. Rio de Janeiro: IBGE, 2015.

FAGUNDES, S. D. et al. Prevalence of dementia among elderly Brazilians: a systematic review. Sao Paulo Medical Journal, v. 129, n. 1, p. 46-50, 2011.

FERNANDES, A. C.; CORTÊS, M. R. Caracterização da base industrial do município de São Carlos-da capacidade de ajuste local à reestruturação da economia brasileira. Planejamento e Políticas Públicas, n. 21, p. 167-2010, 2000.

FICHMAN, H. C. et al. Predomínio de Comprometimento Cognitivo Leve Disexecutivo em idosos atendidos no ambulatório da geriatria de um hospital público terciário na cidade do Rio de Janeiro. Revista de Neuropsicologia Latinoamericana, v. 5, n. 2, p. 31-40, 2013.

FOLSTEIN, M. F.; FOLSTEIN, S. E.; MCHUGH, P. R. "Mini-mental state". A practical method for grading the cognitive state of patients for the clinician. Journal of Psychiatric Research, v. 12, n. 3, p. 189-198, nov. 1975.

FORLENZA, O. V. et al. Mild cognitive impairment (part 1): Clinical characteristics and predictors of dementia. Revista Brasileira de Psiquiatria, v. 35, n. 2, p. 178-185, 2013.

FRATIGLIONI, L.; WINBLAD, B.; VON STRAUSS, E. Prevention of Alzheimer's disease and dementia. Major findings from the Kungsholmen Project. Physiology \& Behavior, v. 92, n. 1-2, p. 98-104, set. 2007.

FUENTES, P.; ALBALA, C. Atualização em envelhecimento e demência no Chile. Dementia e Neuropsychologia, v. 8, n. 4, p. 317-322, 2014.

GAUTHIER, S. et al. Mild cognitive impairment. The Lancet, v. 367, n. 9518, p. 1262-70, 15 abr. 2006.

GIL, L. et al. Validation of the Montreal Cognitive Assessment (MoCA) in Spanish as a screening tool for mild cognitive impairment and mild dementia in patients over 65 years old in Bogotá, Colombia. International Journal of Geriatric Psychiatry, v. 30, n. 6, p. 655$662,2015$.

GILMARTIN-THOMAS, J. F. M.; LIEW, D.; HOPPER, I. Observational studies and their utility for practice. Australian Prescriber, v. 41, n. 3, p. 82-85, 1 jun. 2018.

GLUHM, S. et al. Usefulness of the Montreal Cognitive Assessment (MoCA) in Huntington's disease. Movement Disorders, v. 28, n. 12, p. 1744-1747, out. 2013.

GODINHO, C. et al. Estimation of the risk of conversion of mild cognitive impairment of Alzheimer type to Alzheimer's disease in a south Brazilian population-based elderly cohort: The PALA study. International Psychogeriatrics, v. 24, n. 4, p. 674-681, 2012. 
GOLDSTEIN, B. I.; HERRMANN, N.; SHULMAN, K. I. Comorbidity in bipolar disorder among the elderly: Results from an epidemiological community sample. American Journal of Psychiatry, v. 163, n. 2, p. 319-321, 2006.

GONÇALVES, D. M.; KAPCZINSKI, F. Prevalência de transtornos mentais em indivíduos de uma unidade de referência para Programa Saúde da Família em Santa Cruz do Sul , Rio Grande do Sul , Brasil. Cadernos de Saúde Pública, v. 24, n. 9, p. 2043-2053, 2008.

GRACIA-REBLED, A. C. et al. Influencia de la ocupación en el deterioro cognitivo libre de demencia en una muestra de sujetos mayores de 55 años de Zaragoza. Revista Española de Geriatría y Gerontología, v. 53, n. 3, p. 134-140, maio 2018.

GRAHAM, J. E. et al. Prevalence and severity of cognitive impairment with and without dementia in an elderly population. The Lancet, v. 349, n. 9068, p. 1793-1796, 21 jun. 1997.

GRENIER, S. et al. The Impact of DSM-IV Symptom and Clinical Significance Criteria on the Prevalence Estimates of Subthreshold and Threshold Anxiety in the Older Adult Population. The American Journal of Geriatric Psychiatry, v. 19, n. 4, p. 316-326, abr. 2011.

GUM, A. M.; KING-KALLIMANIS, B.; KOHN, R. Prevalence of mood, anxiety, and substance-abuse disorders for older Americans in the national comorbidity survey-replication. American Journal of Geriatric Psychiatry, v. 17, n. 9, p. 769-781, 2009.

HAKKERS, C. S. et al. The Montreal Cognitive Assessment-Basic (MoCA-B) is not a reliable screening tool for cognitive decline in HIV patients receiving combination antiretroviral therapy in rural South Africa. International Journal of Infectious Diseases, v. 67, p. 36-40, fev. 2018.

HERRERA, E. et al. Epidemiologic survey of dementia in a community-dwelling Brazilian population. Alzheimer disease and associated disorders, v. 16, n. 2, p. 103-8, 2002.

HUANG, L. et al. Chinese version of Montreal Cognitive Assessment Basic for discrimination among different severities of Alzheimer\&rsquo;s disease. Neuropsychiatric Disease and Treatment, v. Volume 14, p. 2133-2140, ago. 2018.

HYUN, J. et al. Effect of Mentally Challenging Occupations on Incident Dementia Differs Between African Americans and Non-Hispanic Whites. Journal of Alzheimer's Disease, p. 1-12, 12 maio 2020.

IBGE - INSTITUTO BRASILEIRO DE GEOGRAFIA E ESTATÍSTICA. Censo Demográfico 2010: Características da população e dos domicílios - Resultados do universo, p. 270, 2011.

IBGE - INSTITUTO BRASILEIRO DE GEOGRAFIA E ESTATÍSTICA. Pesquisa nacional por amostra de domicílios : síntese de indicadores: 2015. p. 108, 2015.

IBGE - INSTITUTO BRASILEIRO DE GEOGRAFIA E ESTATÍSTICA. Síntese de indicadores sociais: uma análise das condições de vida da população brasileira: 2016. $\mathrm{n}$. 36, p. 146, 2016. 
IBGE - INSTITUTO BRASILEIRO DE GEOGRAFIA E ESTATÍSTICA. Características gerais dos domicílios e dos moradores: 2017. Pesquisa Nacional por Amostra de Domicílios (PNAD) Contínua, p. 8, 2018.

JACOB, K. S. et al. The diagnosis of dementia in the community. International Psychogeriatrics, v. 19, n. 4, p. 669-678, 2007.

JUAREZ-CEDILLO, T. et al. Prevalence of mild cognitive impairment and its subtypes in the Mexican population. Dementia and Geriatric Cognitive Disorders, v. 34, n. 5-6, p. 271281, 2013.

JULAYANONT, P. et al. The Montreal Cognitive Assessment - Basic: A Screening Tool for Mild Cognitive Impairment in Illiterate and Low-Educated Elderly Adults. Journal of the American Geriatrics Society, v. 63, n. 12, p. 2550-2554, 2015.

KAMEL, N. S.; GAMMACK, J. K. Insomnia in the Elderly: Cause, Approach, and Treatment. American Journal of Medicine, v. 119, n. 6, p. 463-469, 2006.

KENSINGER, Elizabeth A.; CORKIN, Suzanne. Cognition in aging and age related disease. Handbook of the Neuroscience of Aging, p. 249-256, 2009.

KESSLER, R. C. et al. Lifetime prevalence and age-of-onset distributions of DSM-IV disorders in the national comorbidity survey replication. Archives of General Psychiatry, v. 62, n. 6, p. 593-602, 2005.

KESSLER, R. C. et al. Lifetime prevalence and age-of-onset distributions of mental disorders in the World Health Organization's World Mental Health Survey Initiative. World psychiatry, v. 6, n. 3, p. 168-76, 2007.

KESSLER, R. C. et al. The global burden of mental disorders: an update from the WHO World Mental Health (WMH) surveys. Epidemiologia e psichiatria sociale, v. 18, n. 1, p. 23-33, 2009.

KESSLER, R. C. et al. Age differences in major depression: results from the National Comorbidity Survey Replication (NCS-R). Psychological Medicine, v. 40, n. 2, p. 225-237, 17 fev. 2010.

KIM, W. J. et al. Utility of the Montreal Cognitive Assessment (MoCA) and its subset in HIV-associated neurocognitive disorder (HAND) screening. Journal of Psychosomatic Research, v. 80, p. 53-57, jan. 2016.

KNOPMAN, D. S. et al. Mild cognitive impairment and dementia prevalence: The Atherosclerosis Risk in Communities Neurocognitive Study. Alzheimer's and Dementia: Diagnosis, Assessment and Disease Monitoring, v. 2, p. 1-11, 2016.

KOSON, P. et al. P2-303: Different sensitivity of neuropsychological screening tests ACE-R and MMSE in patients with MCI and dementia. Alzheimer's \& Dementia, v. 8, n. 4S_Part_10,p. P369-P369, jul. 2012.

LEBRÃO, M. L.; LAURENTI, R. Saúde, bem-estar e envelhecimento: o estudo SABE no 
Município de São Paulo. Revista Brasileira de Epidemiologia, v. 8, n. 2, p. 127-141, jun. 2005.

LÉGER, D. et al. An international survey of sleeping problems in the general population. Current Medical Research and Opinion, v. 24, n. 1, p. 307-317, 2008.

LENZE, E. J. et al. Comorbidity of depression and anxiety disorders in later life. Depression and Anxiety, v. 14, n. 2, p. 86-93, 2001.

LIMA, A.; MONTENEGRO, P.; CATELLI, R. Indicador de Analfabetismo Funcional IINAF: Brasil 2018. São Paulo: Instituto Paulo Montenegro, 2018.

LOPES, B. et al. Biostatistics: fundamental concepts and practical applications. Revista Brasileira de Oftalmologia, v. 73, n. 1, p. 16-22, 2014.

LOPES, M. A. et al. Prevalence of cognitive and functional impairment in a community sample in Ribeirão Preto, Brazil. International Journal of Geriatric Psychiatry, v. 22, n. 8, p. 770-776, ago. 2007a.

LOPES, M. A. et al. Systematic review of dementia prevalence - 1994 to 2000. Dementia \& Neuropsychologia, v. 1, n. 3, p. 230-240, set. 2007b.

LOPES, M. A. et al. Prevalence of Alcohol-Related Problems in an Elderly Population and Their Association With Cognitive Impairment and Dementia. Alcoholism: Clinical and Experimental Research, v. 34, n. 4, p. 726-733, abr. 2010.

LOPES, M. A. et al. High prevalence of dementia in a community-based survey of older people from Brazil: Association with intellectual activity rather than education. Journal of Alzheimer's Disease, v. 32, n. 2, p. 307-316, 2012.

LOURENÇO, R. A.; SANCHEZ, M. A. DOS S. Accuracy of the Brazilian Version of the Informant Questionnaire on Cognitive Decline in the Elderly at Screening for Dementia in Community-Dwelling Elderly Participants. Journal of Geriatric Psychiatry and Neurology, v. 27, n. 3, p. 212-219, 10 set. 2014.

LUCK, T. et al. Incidence of Mild Cognitive Impairment: A Systematic Review. Dementia and Geriatric Cognitive Disorders, v. 29, n. 2, p. 164-175, 2010.

LUPPA, M. et al. Prevalence and risk factors of depressive symptoms in latest life-results of the Leipzig Longitudinal Study of the Aged (LEILA 75+). International Journal of Geriatric Psychiatry, v. 27, n. 3, p. 286-295, mar. 2012.

MACHADO, R. DA S. et al. Métodos de adaptação transcultural de instrumentos na área da enfermagem. Revista Gaúcha de Enfermagem, v. 39, p. e20170164, 2 jul. 2018.

MADRUGA, C. S. et al. Tobacco use among the elderly: The first Brazilian National Survey (BNAS). Aging and Mental Health, v. 14, n. 6, p. 720-724, 2010.

MAESTRE, G. E. et al. The Maracaibo Aging Study: Population and methodological issues. Neuroepidemiology, v. 21, n. 4, p. 194-201, 2002. 
MAGALHÃES, M. O. DE C. et al. Risk factors for dementia in a rural area of Northeastern Brazil. Arquivos de Neuro-Psiquiatria, v. 66, n. 2a, p. 157-162, 2008.

MANGONE, C. A.; ARIZAGA, R. L. Dementia in argentina and other Latin-American countries: An overview. Neuroepidemiology, v. 18, n. 5, p. 231-235, 1999.

MANLY, J. J. et al. Implementing Diagnostic Criteria and Estimating Frequency of Mild Cognitive Impairment in an Urban Community. Archives of Neurology, v. 62, n. 11, p. 1739, 1 nov. 2005.

MARINHO, V. et al. Tobacco use among the elderly: a systematic review and meta-analysis. Cadernos de Saúde Pública, v. 26, n. 12, p. 2213-2233, 2010.

MAZZOTTI, D. R. et al. Prevalence and correlates for sleep complaints in older adults in low and middle income countries: A 10/66 Dementia Research Group study. Sleep Medicine, v. 13, n. 6, p. 697-702, 2012.

MCDOWELL, R. D. et al. Mood and anxiety disorders across the adult lifespan: a European perspective. Psychological Medicine, v. 44, n. 4, p. 707-722, 31 mar. 2014.

MEJIA-ARANGO, S.; GUTIERREZ, L. M. Prevalence and incidence rates of dementia and cognitive impairment no dementia in the Mexican population: Data from the Mexican health and aging study. Journal of Aging and Health, v. 23, n. 7, p. 1050-1074, 2011.

MELO, N. C. V. DE; FERREIRA, M. A. M.; TEIXEIRA, K. M. D. Condições De Vida Dos Idosos No Brasil: Uma Análise a Partir Da Renda E Nível De Escolaridade. Revista Brasileira de Economia Doméstica, v. 25, n. 1, p. 4-19, 2014.

MEMÓRIA, C. M. et al. Brief screening for mild cognitive impairment: validation of the Brazilian version of the Montreal cognitive assessment. International Journal of Geriatric Psychiatry, v. 28, n. 1, p. 34-40, jan. 2013.

METZ, C. E. Basic principles of ROC analysis. Seminars in Nuclear Medicine, v. 8, n. 4, p. 283-298, out. 1978.

MÍAS, C. D. et al. Deterioro cognitivo leve: Estudio de prevalencia y factores sociodemográficos en la ciudad de Córdoba, Argentina. Revista de Neurologia, v. 44, n. 12, p. 733-738, 2007.

MOHAN, D. et al. A cross-sectional study to assess prevalence and factors associated with mild cognitive impairment among older adults in an urban area of Kerala, South India. BMJ Open, v. 9, n. 3, p. 1-8, 2019.

MOMEN, N. C. et al. Association between Mental Disorders and Subsequent Medical Conditions. New England Journal of Medicine, v. 382, n. 18, p. 1721-1731, 30 abr. 2020.

MONTIEL, J. M. et al. Evaluation of Montreal cognitive assessment for the differential diagnosis of mild cognitive impairment and Alzheimer's disease in elderly patients with more than 5 years of schooling: Data from a Brazilian sample. Advances in Aging Research, v. 
02, n. 04, p. 121-129, 2013.

MORAES, W. A. S. Insomnia in the elderly: The role of age-related changes in sleep homeostasis. Sleep Medicine, v. 16, n. 1, p. 3-4, 2015.

MUKAKA, M. M. Statistics corner: A guide to appropriate use of correlation coefficient in medical research. Malawi Medical Journal, v. 24, n. 3, p. 69-71, 2012.

MUÑOZ, M. et al. Alcohol use, abuse and dependence in an older European population: Results from the MentDis_ICF65+ study. PLOS ONE, v. 13, n. 4, p. e0196574, 30 abr. 2018.

NASREDDINE, Z. S. et al. The Montreal Cognitive Assessment, MoCA: a brief screening tool for mild cognitive impairment. Journal of the American Geriatrics Society, v. 53, n. 4, p. 695-699, 2005.

NAUGHTON, C.; BENNETT, K.; FEELY, J. Prevalence of chronic disease in the elderly based on a national pharmacy claims database. Age and Ageing, v. 35, n. 6, p. 633-636, 2 set. 2006.

NILSSON, J. et al. Changes in the expression of worries, anxiety, and generalized anxiety disorder with increasing age: A population study of 70 to 85 -year-olds. International Journal of Geriatric Psychiatry, v. 34, n. 2, p. 249-257, 19 fev. 2019.

NITRINI, R. et al. Prevalence of dementia in Latin America: A collaborative study of population-based cohorts. International Psychogeriatrics, v. 21, n. 4, p. 622-630, 2009.

NORONHA, B. P. et al. Padrões de consumo de álcool e fatores associados entre idosos brasileiros: Pesquisa Nacional de Saúde (2013). Ciência \& Saúde Coletiva, v. 24, n. 11, p. 4171-4180, nov. 2019.

NUSSBAUM, A. M. The Pocket Guide to the DSM-5 Diagnostic Exam. Arlington, VA: American Psychiatric Publishing: 2013

O'CONNOR, D. W. Do older Australians truly have low rates of anxiety and depression? A critique of the 1997 National Survey of Mental Health and Wellbeing. Australian and New Zealand Journal of Psychiatry, v. 40, n. 8, p. 623-631, 2006.

O'CONNOR, D. W.; PARSLOW, R. A. Different responses to K-10 and CIDI suggest that complex structured psychiatric interviews underestimate rates of mental disorder in old people. Psychological Medicine, v. 39, n. 9, p. 1527-1531, 2 set. 2009.

O'DRISCOLL, C.; SHAIKH, M. Cross-Cultural Applicability of the Montreal Cognitive Assessment (MoCA): A Systematic Review. Journal of Alzheimer's Disease, v. 58, n. 3, p. 789-801, 5 jun. 2017.

OMS. Global Tobacco Epidemic (2019) Report. In: WORLD HEALTH ORGANIZATION (Ed.). . World Health Organization Global Tobacco Epidemic Report. Washington, DC, US: WHO, 2019. p. 1.

OSÓRIO, F. L.; SOUZA JÚNIOR, C. R. B. FORMAÇÃO SÓCIOTERRITORIAL E 
POPULAÇÃO NO MUNÍCIPIO DE SÃO CARLOS-SP: CONTRADIÇÕES INERENTES AO "DESENVOLVIMENTO". Anais do I Simpósio Mineiro de Geografia. Universidade Federal de Alfenas: 2014. Disponível em: <https://www.unifalmg.edu.br/simgeo/system/files/anexos/Felipe Lehnenn Osório.pdf>

PANG, S. et al. Prevalence and predictors of tobacco use in the elderly. International Journal of Geriatric Psychiatry, v. 31, n. 7, p. 716-722, 2016.

PARAHYBA, M. I.; VERAS, R.; MELZER, D. Incapacidade funcional entre as mulheres idosas no Brasil. Revista de Saude Publica, v. 39, n. 3, p. 383-391, 2005.

PAZ FILHO, G. J. DA et al. Emprego do questionário CAGE para detecção de transtornos de uso de álcool em pronto-socorro. Revista da Associação Médica Brasileira, v. 47, n. 1, p. 65-69, 2001.

PEARCE, N. Classification of epidemiological study designs. International Journal of Epidemiology, v. 41, n. 2, p. 393-397, 1 abr. 2012.

PERES, M. A. DE C. Velhice e analfabetismo, uma relação paradoxal: a exclusão educacional em contextos rurais da região Nordeste. Sociedade e Estado, v. 26, n. 3, p. 631$662,2011$.

PESSOA, R. M. P. et al. Diagnostic criteria and prevalence of mild cognitive impairment in older adults living in the community: a systematic review and meta-analysis. Archives of Clinical Psychiatry (São Paulo), v. 46, n. 3, p. 72-79, 2019.

PETERSEN, R. C. et al. Mild Cognitive Impairment. Archives of Neurology, v. 56, n. 3, p. 303, 1 mar. 1999.

PETERSEN, R. C. Mild cognitive impairment as a diagnostic entity. Journal of Internal Medicine, v. 256, n. 3, p. 183-194, 2004.

PETERSEN, R. C. et al. Mild cognitive impairment: A concept in evolution. Journal of Internal Medicine, v. 275, n. 3, p. 214-228, 2014.

PILGER, C.; MENON, M. H.; MATHIAS, T. A. DE F. Socio-demographic and health characteristics of elderly individuals: support for health services. Revista Latino-Americana de Enfermagem, v. 19, n. 5, p. 1230-1238, 2011a.

PRINA, A. M. et al. Prevalence of anxiety and its correlates among older adults in Latin America, India and China: Cross-cultural study. British Journal of Psychiatry, v. 199, n. 6, p. 485-491, 2011.

PRINCE, M. et al. The global prevalence of dementia: a systematic review and metaanalysis. Alzheimer's \& Dementia, v. 9, n. 1, p. 63-75, 2013.

RAMOS-CERQUEIRA, A. T. A. et al. Identification of Dementia Cases in the Community: A Brazilian Experience. Journal of the American Geriatrics Society, v. 53, n. 10, p. 17381742, out. 2005. 
REHM, J.; TAYLOR, B.; ROOM, R. Global burden of disease from alcohol, illicit drugs and tobacco. Drug and Alcohol Review, v. 25, n. 6, p. 503-513, 1 nov. 2006.

REYNOLDS, K. et al. Prevalence of psychiatric disorders in U.S. older adults: findings from a nationally representative survey. World Psychiatry, v. 14, n. 1, p. 74-81, fev. 2015.

RIBEIRO, R. B.; MELZER-RIBEIRO, D. L.; CORDEIRO, Q. Morbidity and Mortality due to mental disorders in Brazil. Revista Brasileira de Psiquiatria, v. 34, n. 2, p. 217-220, jun. 2012.

RIEDEL-HELLER, S. G.; BUSSE, A.; ANGERMEYER, M. C. Are cognitively impaired individuals adequately represented in community surveys? Recruitment challenges and strategies to facilitate participation in community surveys of older adults. A review. European Journal of Epidemiology, v. 16, n. 9, p. 827-835, 2000.

RIEDEL-HELLER, S. G.; BUSSE, A.; ANGERMEYER, M. C. The state of mental health in old-age across the "old" European Union - a systematic review. Acta Psychiatrica Scandinavica, v. 113, n. 5, p. 388-401, maio 2006.

RITCHIE, K. et al. Prevalence of DSM - IV psychiatric disorder in the French elderly population service. The British Journal of Psychiatry, n. 184, p. 147-152, 2004.

ROALF, D. R. et al. Comparative accuracies of two common screening instruments for classification of Alzheimer's disease, mild cognitive impairment, and healthy aging. Alzheimer's \& dementia, v. 9, n. 5, p. 529-37, set. 2013.

RODRIGUEZ, J. J. L. et al. Prevalence of dementia in Latin America, India, and China: a population-based cross-sectional survey. The Lancet, v. 372, n. 9637, p. 464-474, ago. 2008.

SACHDEV, P. S. et al. The prevalence of mild cognitive impairment in diverse geographical and ethnocultural regions: The COSMIC Collaboration. PLoS ONE, v. 10, n. 11, p. 1-19, 2015.

SALEH, A. A. et al. Validation of Montreal Cognitive Assessment-Basic in a sample of elderly Egyptians with neurocognitive disorders. Aging \& Mental Health, v. 23, n. 5, p. 551-557, 4 maio 2019.

SANTOS-SILVA, R. et al. Increasing trends of sleep complaints in the city of Sao Paulo, Brazil. Sleep Medicine, v. 11, n. 6, p. 520-524, 2010.

SANTOS, É. G. DOS; SIQUEIRA, M. M. DE. Prevalência dos transtornos mentais na população adulta brasileira: uma revisão sistemática de 1997 a 2009. Jornal Brasileiro de Psiquiatria, v. 59, n. 3, p. 238-246, 2010.

SARMENTO, A. R. L.; Apresentação e aplicabilidade da versão brasileira da MoCA (Montreal Cognitive Assessment) para rastreio de comprometimento cognitivo leve: dissertação. São Paulo: Escola Paulista de Medicina da Universidade Federal de São Paulo. Programa de Pós-graduação; 2009

SCAZUFCA, M. et al. High prevalence of dementia among older adults from poor 
socioeconomic backgrounds in Sao Paulo, Brazil. International Psychogeriatrics, v. 20, n. 2, p. 394-405, 2008.

SCAZUFCA, M.; ALMEIDA, O. P.; MENEZES, P. R. The role of literacy, occupation and income in dementia prevention: the São Paulo Ageing and Health Study (SPAH). International Psychogeriatrics, v. 22, n. 8, p. 1209-1215, 3 dez. 2010.

SIEDLECKI, K. L. et al. Construct validity of cognitive reserve in a multiethnic cohort: The Northern Manhattan Study. Journal of the International Neuropsychological Society, v. 15, n. 4, p. 558-569, 1 jul. 2009.

SILVA, A.; DAL PRÁ, K. R. Envelhecimento populacional no Brasil: o lugar das famílias na proteção aos idosos. Argumentum, v. 6, n. 1, p. 99-115, 2014.

SILVA, P. A. DOS S. DA et al. Prevalência de transtornos mentais comuns e fatores associados entre idosos de um município do Brasil. Ciência \& Saúde Coletiva, v. 23, n. 2, p. 639-646, fev. 2018.

SOLHAUG, H. I. et al. Increased prevalence of depression in cohorts of the elderly: an 11year follow-up in the general population - the HUNT study. International Psychogeriatrics, v. 24, n. 1, p. 151-158, 18 jan. 2012.

SOUZA, M. M. C. DE. O analfabetismo no brasil sob enfoque demográfico. Cadernos de Pesquisa, n. 107, p. 169-186, jul. 1999.

STEINER, A. B. Q. et al. Mild cognitive impairment and progression to dementia of Alzheimer's disease. Revista da Associação Médica Brasileira, v. 63, n. 7, p. 651-655, jul. 2017.

TAMPUBOLON, G.; MAHARANI, A. When Did Old Age Stop Being Depressing? Depression Trajectories of Older Americans and Britons 2002-2012. The American Journal of Geriatric Psychiatry, v. 25, n. 11, p. 1187-1195, nov. 2017.

TEIXEIRA, A. L. et al. Prevalence of major psychiatric disorders in a cohort of oldest old in Brazil: The Pietà study. Alzheimer's \& Dementia, v. 5, n. 4, p. P392, jul. 2009.

THE WORLD BANK GROUP. Life expectancy at birth, total (years) - Brazil. Disponível em: <https://data.worldbank.org/indicator/SP.DYN.LE00.IN?locations=BR>. Acesso em: 2 mar. 2019.

TUFIK, S. et al. Obstructive Sleep Apnea Syndrome in the Sao Paulo Epidemiologic Sleep Study. Sleep Medicine, v. 11, n. 5, p. 441-446, 2010.

UNVERZAGT, F. W. et al. Prevalence of cognitive impairment: Data from the Indianapolis Study of Health and Aging. Neurology, v. 57, n. 9, p. 1655-1662, 13 nov. 2001.

VASCONCELOS-ROCHA, S. et al. Prevalência de transtornos mentais comuns entre idosos residentes em município do Nordeste do Brasil. Revista de Salud Publica (Bogota), v. 14, n. 4, p. 620-629, 2012. 
VERAS, R. Em busca de uma assistência adequada à saúde do idoso: revisão da literatura e aplicação de um instrumento de detecção precoce e de previsibilidade de agravos. Cadernos de Saúde Pública, v. 19, n. 3, p. 705-715, 2003.

VERAS, R. P.; COUTINHO, E. DA S. F. Estudo de prevalência de depressão e síndrome cerebral orgânica na população de idosos, Brasil. Revista de Saúde Pública, v. 25, n. 3, p. 209-217, jun. 1991.

VERAS, R. P.; MURPHY, E. The mental health of older people in rio de janeiro. International Journal of Geriatric Psychiatry, v. 9, n. 4, p. 285-295, abr. 1994.

VIANA, M. C.; ANDRADE, L. H. Lifetime Prevalence, Age and Gender Distribution and Age-of-Onset of Psychiatric Disorders in the São Paulo Metropolitan Area, Brazil: Results from the São Paulo Megacity Mental Health Survey. Revista Brasileira de Psiquiatria, v. 34, n. 3, p. 249-260, set. 2012.

VICTOR, J. F. et al. Perfil sociodemográfico e clínico de idosos atendidos em Unidade Básica de Saúde da Família. Acta Paulista de Enfermagem, v. 22, n. 1, p. 49-54, 2009.

VOLKERT, J. et al. The prevalence of mental disorders in older people in Western countries - a meta-analysis. Ageing Research Reviews, v. 12, n. 1, p. 339-353, jan. 2013.

WARD, A. et al. Mild cognitive impairment: Disparity of incidence and prevalence estimates. Alzheimer's and Dementia, v. 8, n. 1, p. 14-21, 2012.

WITTCHEN, H.-U. et al. Measuring symptoms and diagnosing mental disorders in the elderly community: the test-retest reliability of the CIDI65+. International Journal of Methods in Psychiatric Research, v. 24, n. 2, p. 116-129, jun. 2015.

WOLITZKY-TAYLOR, K. B. et al. Anxiety disorders in older adults: A comprehensive review. Depression and Anxiety, v. 27, n. 2, p. 190-211, 2010.

WORLD HEALTH ORGANIZATION. Dementia: a public health priority. Dementia. Geneva, Switzerland, 2012

WORLD HEALTH ORGANIZATION. Mental health and older adults. Disponível em: $<$ http://www.who.int/mediacentre/factsheets/fs381/en/>. Acesso em: 1 jan. 2016.

WU, L. T.; BLAZER, D. G. Illicit and nonmedical drug use among older adults: A review. Journal of Aging and Health, v. 23, n. 3, p. 481-504, 2011.

XAVIER, F. M. et al. Transtorno de ansiedade generalizada em idosos com oitenta anos ou mais. Revista de Saúde Pública, v. 35, n. 3, p. 294-302, 2001.

ZAITOUN, A. M. et al. Epidemiological Study of Dementia after Retirement. The Egyptian Journal of Neurology, Psychiatry and Neurosurgery, v. 45, n. 1, p. 65-74, 2008.

ZHANG, Y. S. et al. Prevalence and socio-demographic correlates of major depressive disorder in older adults in Hebei province, China. Journal of Affective Disorders, v. 265, n. November 2019, p. 590-594, 2020. 


\section{ANEXOS}

ANEXO A - Instrumento para avaliação clínica e diagnóstico psiquiátrico a partir do DSM-5. \#\# FOLHA DE RESPOSTA- ENTREVISTA PSIQUIÁTRICA \#\#

Escolaridade: Número de identificação do idoso:

Comorbidades:

Medicações em uso:

\begin{tabular}{|c|c|c|c|c|}
\hline Sistemas & \multicolumn{3}{|c|}{ Perguntas de triagem } & Diagnóstico \\
\hline \multirow{3}{*}{ Humor } & T. depressivos & Sim & Não & \\
\hline & Distimia & $\operatorname{Sim}$ & Não & \\
\hline & T. bipolar & Sim & Não & \\
\hline Psicoses & \multicolumn{3}{|l|}{ Sim } & \\
\hline \multirow{4}{*}{ Ansiedade } & TAG & Sim & Não & \\
\hline & T. de pânico & Sim & Não & \\
\hline & Fobia social & Sim & Não & \\
\hline & Fobia específica & Sim & Não & \\
\hline Obsessões e compulsões & \multicolumn{2}{|l|}{ Sim } & Não & \\
\hline Trauma & \multicolumn{3}{|l|}{ Sim } & \\
\hline \multirow[t]{2}{*}{ Dissociação } & $\begin{array}{l}\text { Amnésia } \\
\text { dissociativa }\end{array}$ & Sim & Não & \\
\hline & $\begin{array}{l}\text { despersonalização/ } \\
\text { desrealização }\end{array}$ & Sim & Não & \\
\hline Preocupações somáticas & \multicolumn{3}{|l|}{ Sim } & \\
\hline Alimentação & \multicolumn{3}{|l|}{ Sim } & \\
\hline \multirow{5}{*}{ Sono } & T. insônia & Sim & Não & \\
\hline & T. hipersonolência & Sim & Não & \\
\hline & Narcolepsia & Sim & Não & \\
\hline & Pernas inquietas & Sim & Não & \\
\hline & SAOS & Sim & Não & \\
\hline Substâncias e outras adições & \multicolumn{2}{|l|}{ Sim } & Não & \\
\hline \multirow{4}{*}{ Transtornos neurocognitivos } & Delirium & Sim & Não & \\
\hline & $\begin{array}{l}\text { T. neurocognitivo } \\
\text { leve }\end{array}$ & Sim & Não & \\
\hline & $\begin{array}{l}\text { T. neurocognitivo } \\
\text { maior (DSM-5) }\end{array}$ & Sim & Não & \\
\hline & $\begin{array}{ll}\text { Demência } & \text { (DSM- } \\
\text { IV) } & \end{array}$ & Sim & Não & \\
\hline
\end{tabular}

*Observações: 
ANEXO B - Montreal Cognitive Assessment - MoCA - Versão brasileira

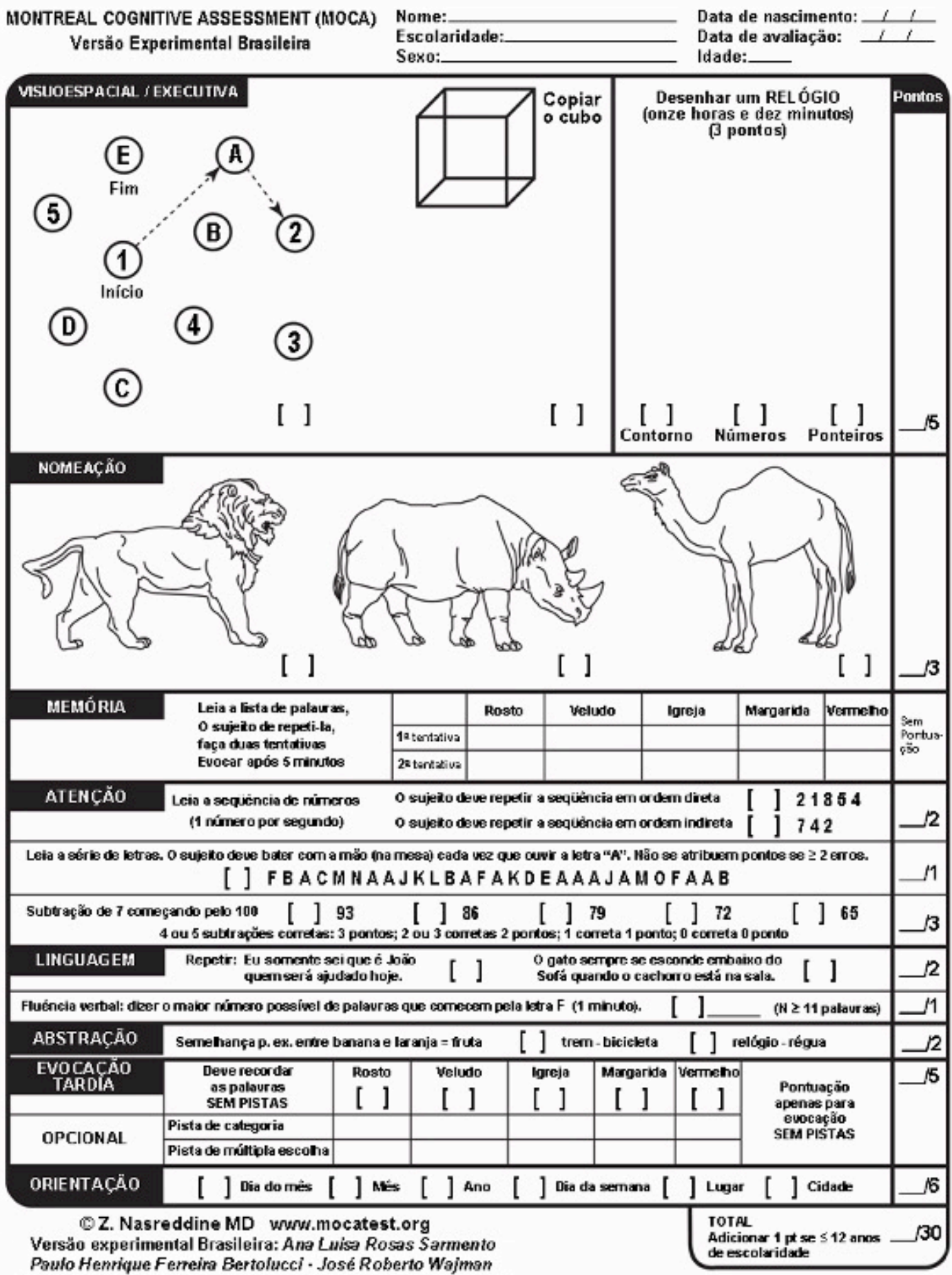
(UNIFESP.SP 2007) 
ANEXO C - Montreal Cognitive Assessment basic - Versão brasileira

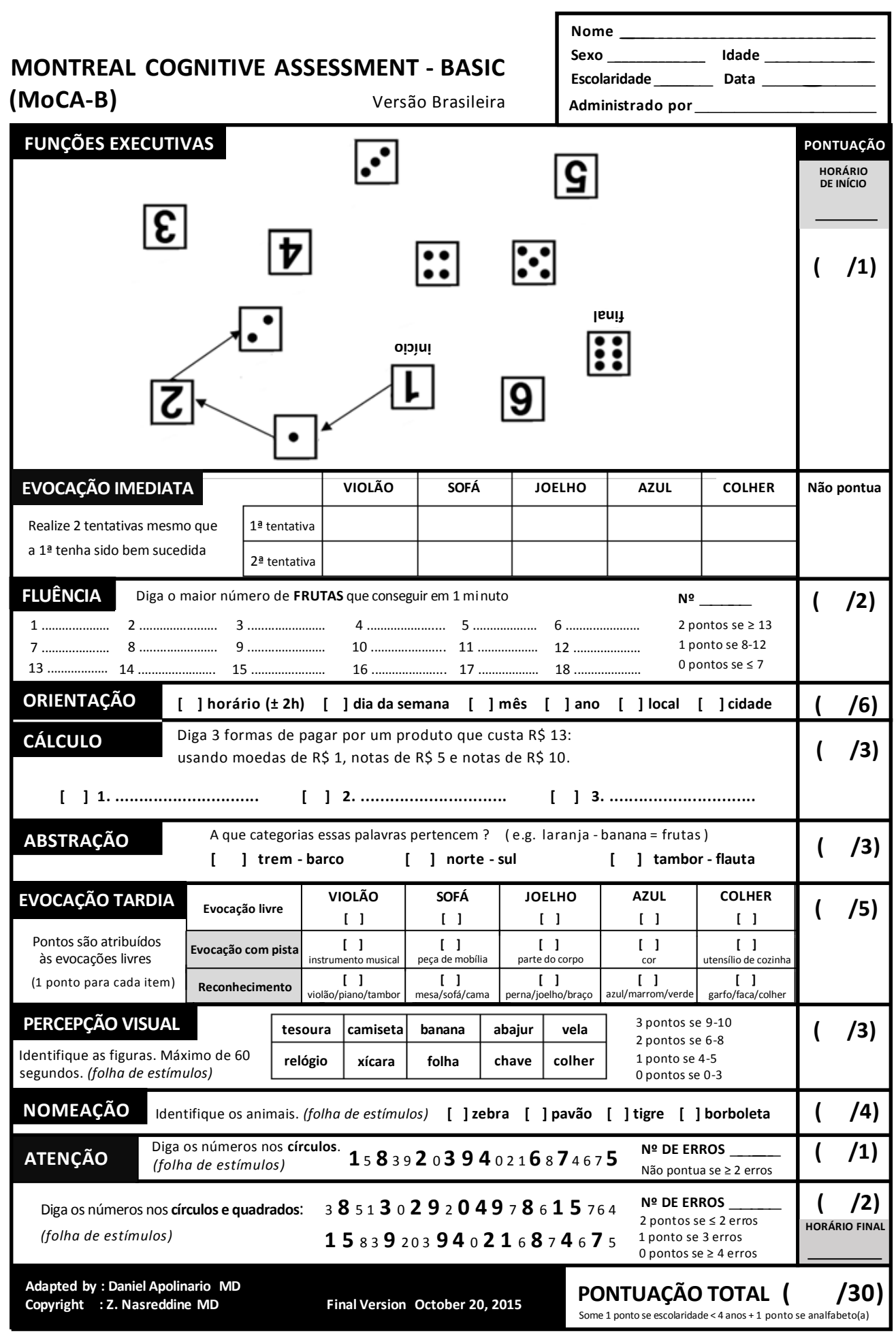




\section{ANEXO D - Termo de Consentimento Livre e Esclarecido}

\section{Termo de Consentimento Livre e Esclarecido}

NOME DA PESQUISA: Cognição social e comparação dos critérios de demência do DSM- IV e DSM-5 entre idosos atendidos na atenção básica

\section{PESQUISADOR REPONSÁVEL: Marcos Hortes N. Chagas (contato: 16 98145- 2367/setroh@hotmail.com)}

Você está sendo convidado a participar do estudo: "Cognição social e comparação dos critérios de demência do DSM-IV e DSM-5 entre idosos atendidos na atenção básica".

1. Objetivos e Justificativa: Essa pesquisa tem como objetivo estudar a frequência de pessoas com mais de 60 anos com demência que moram na sua região. Este quadro inclui pessoas que têm perda de memória, que se perdem com facilidade, que trocam as coisas de lugar e o nome das pessoas muitas vezes, que não conseguem mais fazer compras, entre outras atividades do dia-a-dia. Vamos também comparar duas maneiras que são usadas pelos profissionais de saúde para saber se você tem a demência. Além disso, queremos saber como está sua capacidade de reconhecer algumas emoções no rosto de outras pesssoas. A demência é um problema de saúde que acontece com certa frequência principalmente com as pessoas que possuem 60 anos ou mais. Ela pode prejudicar de maneira importante a realização das atividades do dia-a-dia, o relacionamento com as pessoas e tornar a pessoa dependente de cuidados. Por isso, há a necessidade de observar se isso pode estar acontecendo, para que medidas preventivas sejam tomadas.

2. Participação na Pesquisa: Sua participação na pesquisa será responder as perguntas feitas por um pesquisador sobre sua saúde e realizar alguns testes como tarefas para testar sua memória, sua capacidade de nomear objetos, fazer algumas contas e alguns desenhos, reconhecer faces de algumas emoções, entre outros.

3. Riscos e Benefícios: Como possíveis riscos do estudo, cita-se o possível desconforto e cansaço em realizar os testes e responder às perguntas propostas, que exigem engajamento do participante e podem demandar cerca de 50 minutos. Além disso, mesmo que pequena, há possibilidade de outras pessoas terem acesso às informações que você ofereceu. Deve-se considerar também que o diagnóstico de demência pode causar sofrimento psicológico, principalmente para participantes que não saibam do diagnóstico.

Você não terá necessidade de se deslocar para outro local para participar da pesquisa, pois a pesquisa será realizada em sua casa, no local que se sentir mais confortável.

Como benefícios de sua participação na pesquisa, poderemos obter informações sobre como identificar pessoas que possuem o quadro de demência. Também poderemos obter dados importantes sobre memória, atenção, prejuízo nas atividades do dia-a-dia e emoções sentidas da população estudada. De acordo com estas perguntas e testes, alguns participantes poderão ser identificados com o quadro de demência. Caso algumas perguntas e testes estejam alterados e exista a suspeita de demência, você será encaminhado para avaliação adequada na unidade de saúde do município.

Caso você aceite participar da pesquisa, você precisa saber que:

Somente você e os pesquisadores terão acesso às informações e aos testes e que é garantido o sigilo sobre todos os dados coletados e mantida a privacidade dos participantes na pesquisa. Estas informações serão utilizadas exclusivamente para este estudo e as análises serão realizadas de forma geral, sem a identificação individual dos participantes. $\mathrm{O}$ material coletado na pesquisa será arquivado no Departamento de Gerontologia da Universidade Federal de São Carlos.

Os resultados finais da pesquisa poderão ser divulgados em publicações ou eventos científicos, sendo que os dados pessoais dos participantes do estudo não serão revelados, o que garante o completo anonimato. 
A sua participação é voluntária e caso você se sinta desconfortável para responder às perguntas ou aos testes, a sua não participação ou a interrupção em qualquer momento do estudo não lhe causará qualquer problema ou dificuldade com relação a seu atendimento no serviço de saúde do município ou às visitas que a agente comunitária faz durante o ano.

Nesse estudo não haverá despesas financeiras para os participantes, e serão garantidos esclarecimentos, antes e durante o curso da pesquisa sobre a metodologia e resultados obtidos.

O pesquisador responsável pela pesquisa poderá ser contatado pelo telefone (16) 98145-2367.

Você ficará com uma das duas vias originais desse Termo de Consentimento e a outra via será arquivada pelo pesquisador.

$\mathrm{Eu}$,

RG

, tendo sido esclarecido sobre as condições do estudo, especialmente no que diz respeito ao objetivo da pesquisa, aos procedimentos a que serei submetido, aos riscos e benefícios do trabalho, declaro que tenho pleno conhecimento dos direitos e condições que me foram assegurados e manifesto livremente minha vontade de participar do referido estudo.

São Carlos, de de

Assinatura do Voluntário/Responsável

Assinatura do Pesquisador 
ANEXO E - Parecer do Comitê de Ética

\section{Aprovação pelo Comitê de Ética}

\section{UNIVERSIDADE FEDERAL DE Plotoformo SÃO CARLOS/UFSCAR}

\section{PARECER CONSUBSTANCIADO DO CEP}

\section{DADOS DO PROJETO DE PESQUISA}

Título da Pesquisa: Cognição social e comparação dos critérios de demência do DSM-IV e DSM-5 entre idosos atendidos na atenção básica

Pesquisador: Marcos Hortes Nisihara Chagas

Área Temática:

Versão: 2

CAAE: 48602515.5 .0000 .5504

Instituição Proponente: Universidade Federal de São Carlos/UFSCar

Patrocinador Principal: Financiamento Próprio

DADOS DO PARECER

Número do Parecer: 1.302 .505

Conclusốes ou Pendências e Lista de Inadequações:

Projeto aprovado. O pesquisador atendeu a todas as pendências do Parecer 1 .

Este parecer foi elaborado baseado nos documentos abaixo relacionados:

\begin{tabular}{|c|c|c|c|c|}
\hline Tipo Documento & Arquivo & Postagem & Autor & Situação \\
\hline $\begin{array}{l}\text { Informações Básicas } \\
\text { do Projeto }\end{array}$ & $\begin{array}{l}\text { PB_INFORMAÇOEESBASASICAS_DO_P } \\
\text { ROJETO 550432.pdf }\end{array}$ & $\begin{array}{l}08 / 09 / 2015 \\
21: 22: 02\end{array}$ & & Aceito \\
\hline $\begin{array}{l}\text { Recurso Anexado } \\
\text { pelo Pesquisador }\end{array}$ & carta_ao_cep.pdf & $\begin{array}{l}08 / 09 / 2015 \\
21: 20: 03\end{array}$ & $\begin{array}{l}\text { Marcos Hortes } \\
\text { Nisihara Chagas }\end{array}$ & Aceito \\
\hline $\begin{array}{l}\text { TCLE / Termos de } \\
\text { Assentimento / } \\
\text { Justificativa de } \\
\text { Ausência }\end{array}$ & TCLE_CEP_versao_2.pdf & $\begin{array}{l}08 / 09 / 2015 \\
21: 19: 40\end{array}$ & $\begin{array}{l}\text { Marcos Hortes } \\
\text { Nisihara Chagas }\end{array}$ & Aceito \\
\hline Outros & $\begin{array}{l}\text { Reconhecimento de Emoções } \\
\text { Faciais.pdf }\end{array}$ & $\begin{array}{c}20 / 07 / 2015 \\
11: 07: 12\end{array}$ & & Aceito \\
\hline Outros & RMET.pdf & $\begin{array}{c}20 / 07 / 2015 \\
11: 06: 58\end{array}$ & & Aceito \\
\hline Outros & Protocolo $i$ quest socio e escalas.pdf & $\begin{array}{c}20 / 07 / 2015 \\
11: 06: 28\end{array}$ & & Aceito \\
\hline Outros & Autorizacao prefeitura.pdf & $\begin{array}{c}20 / 07 / 2015 \\
11: 05: 59\end{array}$ & & Aceito \\
\hline
\end{tabular}

